\title{
Avaliação dos Parâmetros de Halitose e Sialometria em Pacientes submetidos à Radioterapia de Cabeça e Pescoço.
}

\section{Danielle Frota de Albuquerque}

Dissertação apresentada à Faculdade de Odontologia de Bauru, como parte dos requisitos para obtenção do título de Mestre em Odontologia, ărea de Estomatologia.

\section{Bauru}





\title{
Avaliação dos Parâmetros de Halitose e Sialometria em Pacientes submetidos à Radioterapia de Cabeça e Pescoço.
}

\section{Danielle Frota de Albuquerque}

\author{
Dissertação apresentada à \\ Faculdade de Odontologia de Bauru, \\ como parte dos requisitos para \\ obtenção do título de Mestre em \\ Odontologia, área de Estomatologia.
}

Prof. Dr. Luiz Eduardo Montenegro Chinellato

BAURU - SP 


\section{Avaliação dos parâmetros de halitose e sialometria em pacientes submetidos à radioterapia de cabeça e pescoço. / Danielle Frota de Albuquerque. - Bauru, 2007.}

131p. : il. ; $30 \mathrm{~cm}$.

Dissertação (Mestrado) - Faculdade de Odontologia de Bauru.

Universidade de São Paulo.

Autorizo, exclusivamente para fins acadêmicos e científicos, a reprodução total ou parcial desta dissertação, por processos fotocopiadores e outros meios eletrônicos.

Bauru, 29 de março de 2007.

Projeto de Pesquisa aprovado pelo Comitê de Ética em Pesquisa da Faculdade de Odontologia de Bauru, Universidade de São Paulo. Of.no $104 / 2005$. 


\section{Dados Curriculares}

\section{Danielle Frota de Albuquerque}

10 de janeiro de 1979

Fortaleza - Ce

1999-2004

2005-2007

Associações
Nascimento

Filha de Joaquim Cézar Dias de

Albuquerque e Maria Walhirtes Frota de Albuquerque.

Curso de Graduação em Odontologia pela Universidade de Fortaleza UNIFOR

Curso de Pós-Graduação em Estomatologia, ao nível de Mestrado, pela Faculdade de Odontologia de Bauru - Universidade de São Paulo USP.

Associação Brasileira de

Odontologia (ABO);

Associação Brasileira de Radiologia

Odontológica (ABRO);

Sociedade Brasileira de Pesquisa

Odontológica - SBPqO 

"O valor das coísas não está no tempo em que duram, mas na intensidade que acontecem. Por isso existem momentos inesquecíveis, coisas inexplicáveis e pessoas incomparáveís."

Fernando Sabino 



\section{Dedicatóría}

Dedico

À minha mãe Walhirtes,

meu exemplo de força, dedicação, carinho, competência e Amor, no maís digno sentido da palavra. Minha mãe é meu alicerce, meu apoio e meu equilibrio. Dedico essa vitóría a ela, deixando claro o quanto sua presença é fundamental em minha vída. Esta tese só foí concluída porque ela esteve do meu lado, com seus conselhos, paciência, sincerídade e mimos. Nunca conseguirei expressar meu real agradecimento e a imensidão do meu amor.

\section{Ao meu pai Cézar,}

homem digno, bondoso. Pai especial e presente, que me ensinou a humildade. Ele me apoíou mesmo quando não concordava com alguns caminhos que eu escolhia, transformando meus sonhos em seus. Agradeço os seus ensinamentos, os sacrificios, as preocupações, a dedicação a nossa família. Agradeço por ele confiar em mim e por me dizer sempre a verdade, mesmo sendo-The difícil. $\mathcal{E}$ u sou um pouquinho dele. Amoo incondicionalmente. 


\section{À minha írmã Laryssa,}

Tão parecida e tão diferente de mim! Sacrificou-se, adiou sonhos, sendo obrigada a amadurecer rapidamente para que eu concluisse o mestrado. Uma mulher linda, com brilho próprio e personalidade forte; tenho certeza de que alcançará seus objetivos rapidamente. Essa é maís uma etapa de nossas vidas que vencemos juntas. Minha irmã, minha amiga, minha luz.

$\mathcal{A}$ vocês três, dedico o resultado dos meus estudos, alegrias, tristezas e saudades que enfrentei nesta caminhada. Tudo o que eu sou hoje, devo a vocês. Obrigada pela convivêncía feliz e unida, pelos ensinamentos e conselhos. Não desistí frente os obstáculos que passamos por estarem do meu lado, por que juntos acreditamos na capacidade de superá-los.

Saibam que lembrei de vocês todos os dias e que a distância fortaleceu o nosso diálogo e nos aproximou ainda mais. Amo vocês. 
"Buscai primeíro o Reino de Deus e a sua justiça. $\mathcal{E}$ tudo aquílo vos será acrescentado."

$(\mathcal{M} t 6,33)$ 



\section{Agradecimento Especial}

\section{’̀ Deus,}

Pela a oportunidade de viver cercada de paz, amor e solidariedade. Por guiar os meus caminhos para sempre me tornar uma pessoa melhor.

Sem Ele não tería conseguido, poís os obstáculos teriam sido insuperáveis.

Obrigada por me fazer perceber o milagre da vida diariamente. 

"Tu te tornas eternamente responsável por aquilo que cativas". Antoine de Saint-Exupéry 



\section{Agradecimentos}

Agradecimentos

Ao meu orientador Prof. Dr. Luiz Eduardo Montenegro Chinellato, pelo incentivo e confiança. Pelo tempo dedicado a mim, pela sua sabedoría e experiêncía, pelo seu apoio, conversas e ensinamentos. O meu muito obrigada.

Aos professores do curso de mestrado, Profa. Ana Lúcía Alvarez Capelloza, Profa. Izabel Regina Fischer Rubira de Bullen, Prof. José Humberto Damante e aos professores de cirurgia, Prof. Eduardo Sant'Ana, e Prof. Osny Ferreira Júnior, por ensinar a transformar o árduo dever de transmitir conhecimento em um prazer diário, fruto de quem ama o que faz.

Aos meus professores Lúcío Mitsuo Kurita, pelos conhecimentos transmitidos de forma sábia e divertida, e ao $\mathcal{D} r$. José Osmar Vasconcelos Filho, pela paciência e serenidade. Obrigada por despertarem o meu interesse em radiologí. Também são responsáveis pelo meu sucesso. Muito Obrigada! 
Ao Professor Luiz Roberto $\mathcal{N}$ Loro, além da amizade, pela torcida e o incentivo ao meu mestrado. Ao professor Marlio Carlos e professora Sharmênia $\mathcal{N} u$ to, pelos conselhos e convivência agradável. Vocês foram importantíssimos não só na minha formação profíssional, mas também na inspiração de vír a ser professora.

Ao meu mestre e orientador $\mathcal{D} r$. Pedro Teixeira, que nunca mediu esforços para transmitir sua sabedoria, guiando-me os primeiros passos clínicos em Estomatologia; desde então, esteve presente em minhas conquistas. Meu muito obrigada.

Ao Prof. José Roberto Lauris, pelas orientações prestadas e pela colaboração na análise estatística desta pesquisa.

Aos funcionários do Departamento de Estomatología, Camila Medina, Elza Cassalate, Fernanda Cavalari, Hebe Pereira, Josieli Farinha, Luciana Zanon, Marília Gião, Patrícia Germimo, Reinaldo Vieira, Roberto Sales e Roque dos Santos, por estarem sempre dispostos a ajudar e contríbuir para um convívio agradável nesses anos.

Aos funcionários da biblioteca - FOB / USP Cybelle de Assumpção Fontes, Rita de Cássia Paglione, Valéria Cristina Trindade Ferraz, Vera Regina Casari Boccato, Ademir Padilha, Ana Paula Moço, César Augusto do 
Amaral Campos, Maria Caetano, Jane Pimentel Nogueira e Maria José dos Santos Formenti, sempre dispostos a ajudar da melhor forma, rompendo a seriedade da pesquisa e deixando a biblioteca cada vez mais acolhedora.

Aos funcionários do setor de xérox, em especial Ana Paula Bertonha e Salvador Cruz, dentre outros que participaram de todo o processo de pesquisa, sempre dispostos a ajudar

Ao $\mathcal{D}$ r. Edgard Melo Junior, pela paciência e sabedoria. Pelo exemplo de humanização e amor com o manejo dos pacientes. Com seus gestos, ensinou-me que com bondade se vence os obstáculos diários e, ainda, colhe-se frutos de amizades. Obrigada por toda a atenção e ensinamentos.

Aos funcionários do setor de cabeça e pescoço do Hospital Manuel de Abreu, pela dedicação ao trabalho exercido, mostrando a satisfação em ajudar a quem precisasse. Obrigada por atenderem aos meus pedidos, com atenção e carinho.

Aos médicos e funcionários de setor de radioterapia do Hospital Manuel de $\mathcal{A}$ breu pela ajuda sempre que necessária e, principalmente, ao $\mathcal{D} r$. Casuo Arakawa pelos esclarecimentos e disponibilidades. 
À Diretoría da Faculdade de Odontología de Bauru, da Universidade de São Paulo pelo trabalho desenvolvido para tornar a Universidade cada vez mais um campo de descobertas, aprendizagem e conhecimento.

À Comissão de Pós-Graduação da Faculdade de Odontología de Bauru, da Universidade de São Paulo pela competêncía, dedicação e ousadia na busca de avanços e condições importantes na qualificação dos profíssionais. 


\section{Agradeçimentos}

À minha avó Mirtes Frota, simplesmente sinônimo de amor, dedicação e fortaleza. Agradeço a chance que ela nos proporcionou do convívio diário e a participação na minha educação. Meu caráter tem traços dela. Eu sou ela. Agradeço por ela ser fã dos meus passos, por estar presente em minhas decísões, por todas as vezes que me disse "sim", mesmo quando a resposta certa era não. Pelo apoío de sempre mesmo sofrendo com a saudade, curtia meu crescimento profissional e intelectual. Ela partiu antes de chegar este momento, mas sei que continuará presente na minha vida. Meu amor é dela para sempre.

A minha avó María de Lourdes Albuquerque, que plantou em mim o prazer de passar conhecimento, de ensinar, de ser professora. Agradeço o apoío, a admiração de minhas vitórías. Pela pessoa maravilhosa que é, agradeço a forma simples, bondosa e sincera que tem de me amar. Eu a amo demais.

Ao meu avô Aguiar Albuquerque, que me ensinou o verdadeiro sentido da palavra "estudo", que me explicou que o conhecimento é um bem próprio, prazeroso e que não se perde. Dedicou-se inteiramente à família, amando e passando sua sabedoria. Certamente, ele ficaria orguhhosissimo de mais essa vitória minha. Obrigada por estar sempre do meu lado, iluminando meu caminho. 
À minhas tias queridas, Auxílíadora, Conceição, Paula, Walmirtes e Waldemirtes por acreditarem e apoiarem cada decísão minha, amando-me e rezando sempre por mim. Aos meus tios Antônio Albuquerque e $\mathcal{N}$ oeli, por ficarem felizes com minhas vitórias, como se eu fosse uma filha; e Francísco $e$ Luciene, por acompanharem meus passos com carinho.

Agradeço a minha tía Graça Linhares, que é exemplo de dedicação e afeto a minha família. Sempre presente nas menores necessidades, capaz de se sacrificar para nos fazer feliz, a mim e à minha famílía. 壬 a tía maís chorona, e eu a amo de coração. $\mathcal{E}$ ao meu tio Young $\mathcal{B l o o d , ~ p e l o ~ c a r i n h o ~ e ~ a m o r . ~}$

À minhas tías por opção do amor, Rita Marques, Fátima Gadelha e Marílía, que me curtem como se eu fosse fitha; que me deram segurança e força para continuar frente às difículdades. Agradeço a amizade à minha famílía e por estarem sempre dispostas a ajudar. O meu "Muito Obrigada."

Aos tíos Luciano e Luciene Marques, que já fazem parte da nossa família, por tantos anos de amizade, de carinho, conquísta e apoío. Passamos juntos momentos importantes na minha infância e adolescência que me ajudaram ao meu crescimento pessoal. Obrigada. 
Aos meus primos Arthur, Renata, Andréa e Rodrigo, pelo incentivo e amor. A Haaby, prima e irmã, sempre decidida, corajosa e amiga - obrígada pelo apoío. A Karine, pela presença em cada momento de minha vida, pelos conselhos como se fosse minha irmã mais velha; meu exemplo de honestidade e dedicação. Às minhas primas Waldira e Kátia, pela alegria, amor e simplicidade.

Aos meus primos Hélio Jr e Ana, pelos consethos, explicações, conversas, pela convivência agradável e mais próxíma, que o mestrado nos proporcionou.

Às minhas mais novas priminhas Aline, Livia e Helena pelos momentos prazerosos que passamos juntas e pela alegría que me proporcionaram.

丸̀ Inês Rodrigues, pela acolhida nas minhas idas a São Paulo, pelo carinho, apoío e solicitude. Obrigada!

Aos meus amigos do mestrado Gustavo Lautenschläger, Leticia Nery, Marta Cunha, Moacir Tadeu Rodrigues e Renata Teixeira, cuja amizade cultivada fez com que esses anos se passassem de forma leve e agradável. 
Aos amigos do Doutorado de Estomatologia, Carla, Etiene, Josiane, Melissa, Renato, Zanda, pela a disposição em ajudar sempre. A Cássia e Cláudio, pelo apoío de sempre. Ao Flávío Amado, pelas orientações, correções e conselhos importantíssimos para a realização deste trabalho.

Aos meus amigos Ricardo Virgolino pela lealdade e companheirísmo; Paulo Mauricio, pelo convívío divertido e de alto astral; Ronan Jacques, pelos momentos agradáveis; Ricardo Pianta, pelas conversas e conquistas compartilhadas, Renata Louro, pelo carisma; Flora Távora, pela acolhida e bom humor, Gabriela Vedolin, amiga prestativa; Ana Paula, pelo exemplo de competência e sinceridade. Todos vocês fizeram de Bauru um lugar maravithoso e cheio de boas lembranças.

Às minhas amigas, a Valéria Lobato, amiga presente, decidida e sincera; formamos fortes laços que com certeza serão eternos. Ao meu amigo Delano $\mathcal{E}$ loy, pelo carinho e presença sempre. A Melíssa Araújo, que misteriosamente nos tornamos grandes amigas - obrigada pelos conselhos, ensinamentos e carinho.

$\mathcal{A}$ minha eterna "roommate", Marta Cunha. Não tenho palavras para explicar tamanha afinidade. Pessoa humana, sincera, divertida e digna. Obrigada pela feliz convivência. 
丸̀ amiga Renata Cordeiro, cativante, prestativa e importantíssima na minha vida hoje e sempre. Temos afinidades não só profíssionais, mas também de sonhos. Obrigada por tudo.

$\mathcal{A}$ amiga Danielle De Bastiani, amiga que o destino a mim uniu, que facilmente, com o jeito meigo e alegre, transformou-se em uma amiga especial. Obrigada por escutar-me, entender-me; pelas lindas lembranças que temos juntas.

$\mathcal{A}$ amiga $\mathcal{A}$ line Dantas. A ela, tenho a agradecer o amor, a dedicação, a admiração. De convivência fácíl, ela torna a vida das pessoas ao seu redor suave, prazerosa. Amiga de muito tempo, sempre dividimos sonhos e sempre estaremos juntas nas realizações. Amo você, amíga.

$\mathcal{A}$ amiga Clarice $\mathcal{E}$ loy, cuja amizade foi um presente que o mestrado me deu. Obrigada pela amizade sincera desde o inicio, pelo companheirismo e por tornar as dificuldades leves. Amo.

丸̀ minha amiga Kadidja Machado. Mais que amiga, é irmã. Expressa sinceridade e alegría no olhar. Inteligente e culta, esteve do meu lado sempre que precisei; e assim continuará a ser, porque nossa amizade não tem fim. Obrigada por tudo. 
Às minhas amigas de Fortaleza, Alynne Vieira, Ana Flávia Bomfim, Beatriz Bezerra, Carol Sobral, Juliana Lemos, Lina Schlachter, Lyssa Arrais, Maria Elisa Machado, Milena Amaral, Mirela Marques, Rachel Bachá. Mesmo distantes, estão sempre presentes nas decísões de minha vida. Muito Obrigada.

$\mathcal{A}$ todos os colegas e alunos de pós-graduação que compartilharam aulas, apresentações, churrascos e que proporcionaram uma convivência sadia, além de aprendizado contínuo durante esses anos de amizade.

$\mathcal{A}$ todos os pacientes que participaram dessa pesquisa. Com a certeza de que aprendi muito mais que ensinei. Pela boa vontade, disposição e atenção.

$\mathcal{E}$, finalmente, a todos que participaram e colaboraram, direta ou indiretamente para o desenvolvimento e finalização desta dissertação. Sozinha não tería êxito nessa caminhada; e também a todos que tiveram papel importante para a transformação de um desejo em realidade. Muito obrígada. 


\section{SUMÁRIO}

LISTA DE FIGURAS

LISTA DE TABELAS

LISTA DE ABREVIATURAS E SÍMBOLOS

RESUMO

ABSTRACT

1-INTRODUÇÃO 43

2-REVISÃO DA LITERATURA 49

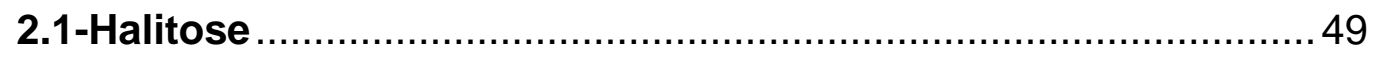

2.1.1-Microbiota bucal. ..................................................... 52

2.1.2-Saburra .................................................................... 53

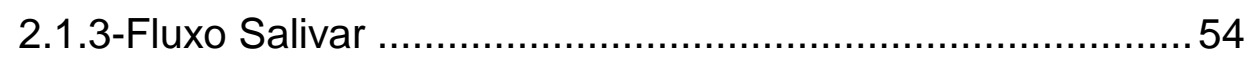

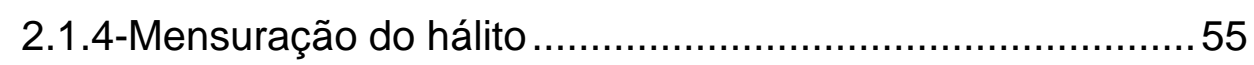

2.2-Radioterapia em cabeça e pescoço .........................................59

2.2.1-Efeitos adversos da radioterapia ..................................61

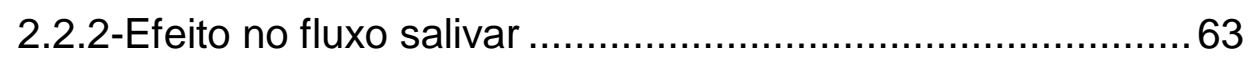

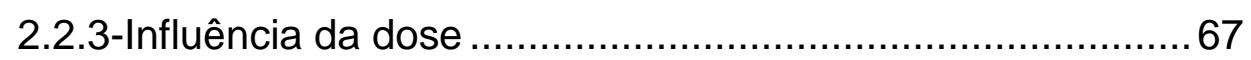

2.2.4-Qualidade de vida dos pacientes irradiados....................68

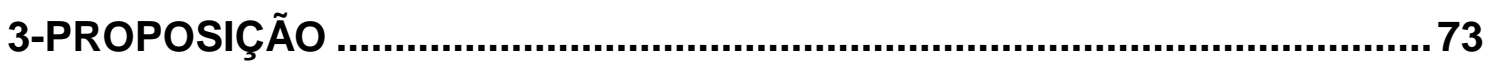

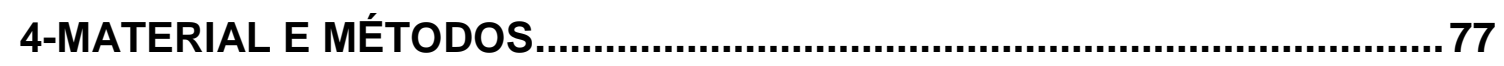

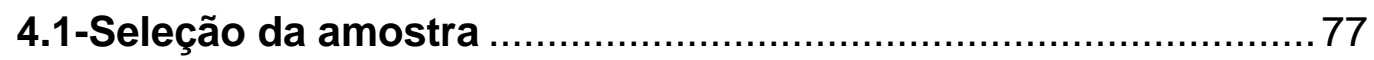

4.2-Critérios de inclusão ....................................................... 78

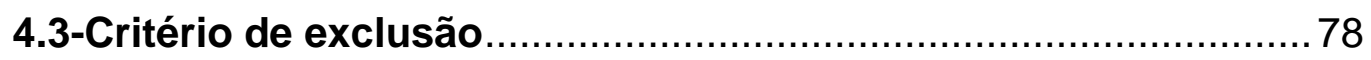

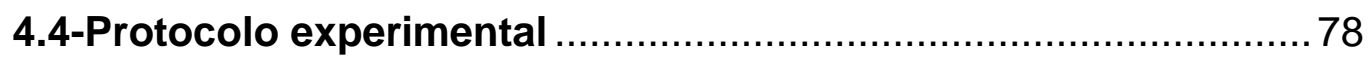

4.5-Questionário médico-odontológico ...................................... 79

4.6-Orientações prévias......................................................... 80

4.7-Coleta dos valores de halimetria ....................................... 80

4.8-Avaliação da saburra e novas medidas de halimetria ............... 82 
4.9-Teste BANA ${ }^{\mathrm{TM}}$ (benzoyl - DL - arginine - 2 napthylamide) ............84

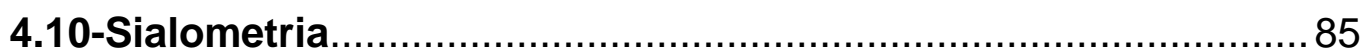

4.11-Protocolo do tratamento Radioterápico................................ 87

4.12-Análise estatística............................................................. 90

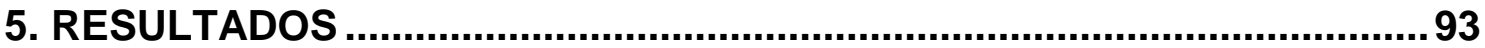

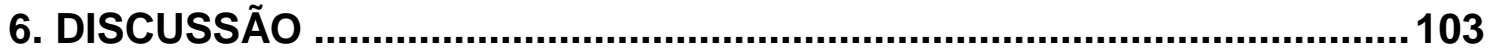

6.1 - Delineamento do estudo …............................................... 104

6.2 - Metodologia .................................................................. 106

6.3 - Discussão dos resultados..................................................... 109

6.3.1 - Halimetria oral ...................................................... 109

6.3.2 - Peso da saburra ...................................................... 109

6.3.3 - Fluxo salivar ........................................................ 111

6.3.4 - Teste BANA .......................................................... 112

6.4 - Considerações Finais ..................................................... 112

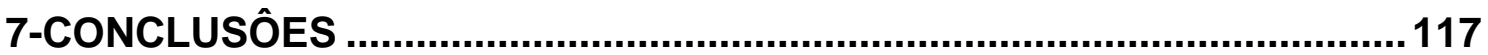

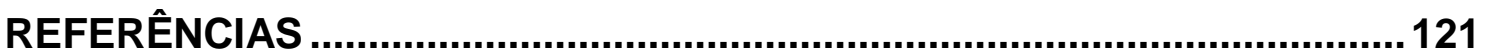

APÊNDICES

ANEXOS 


\section{LISTA DE FIGURAS}

FIGURA 1 Mesa de atendimento do paciente:

1)guardanapo; 2) gaze; 3) limpador de língua;

4) canudos; 5) papel filtro; 6) colher de dentina;

7) água destilada; 8) fita teste BANA;

9) hiperbolóide; 10) seringa para sialometria;

11) vidros para coleta de saliva. .............................................. 79

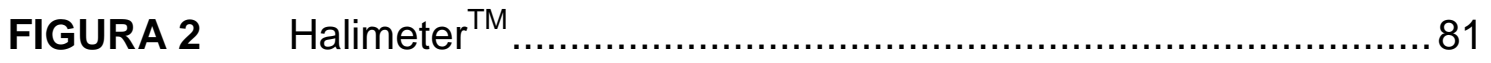

FIGURA 3 Canudo na boca do paciente para leitura da concentração dos CSVs

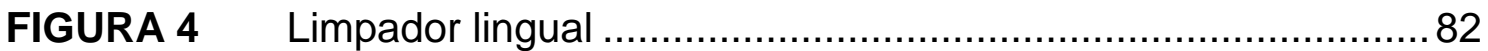

FIGURA 5 a) Remoção do excesso de umidade da língua;

b) Limpeza da língua; c) Remoção da saburra;

d) Saburra Lingual.

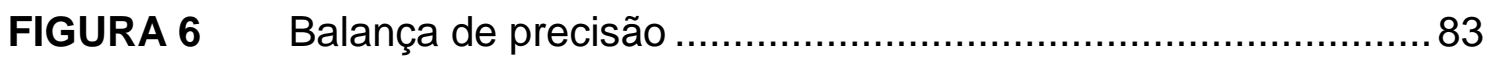

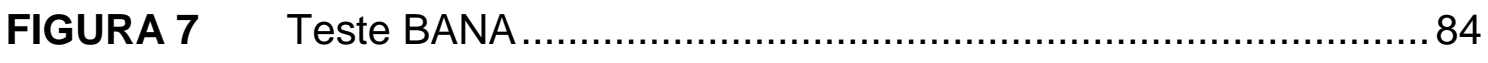

FIGURA 8 a) Colocação da saburra na fita teste com colher de dentina; b) Colocação de água destilada na fita teste; c) Dobragem da fita; d) Fita presa com clipe de papel

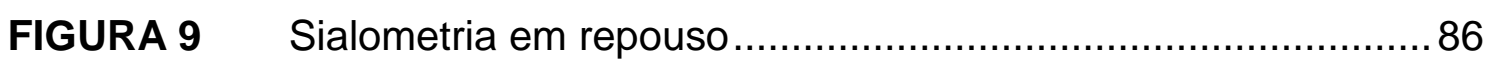

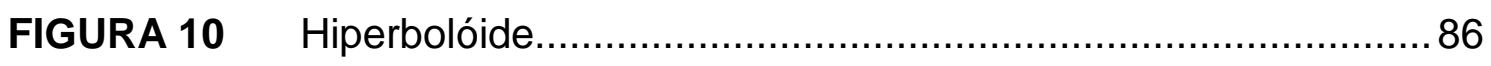

FIGURA 11 Recipiente de vidro com a saliva coletada.............................. 87

FIGURA 12 Máscara facial com a área de radiação delimitada

FIGURA 13 Paciente posicionado no aparelho de radioterapia.

FIGURA 14 Campo de irradiação (fossa supra-clavicular)

FIGURA 15 Campo de irradiação (paralelo oposto), abrangendo as glândulas salivares

FIGURA 16 Gráfico de dispersão entre HI e SAB da amostra total 
FIGURA 17 Gráfico de dispersão entre HI e HF da amostra total

FIGURA 18 Gráfico de dispersão entre SREP e SEST da amostra total.

FIGURA 19 Gráfico de dispersão entre HI e SAB da do grupo "radio".

FIGURA 20 Gráfico de dispersão entre HI e HF do grupo "radio".

FIGURA 21 Gráfico de dispersão entre SREP e SEST do grupo "radio".

FIGURA 22 Gráfico de dispersão entre HI e SAB do grupo "saúde".

FIGURA 23 Gráfico de dispersão entre HI e HF do grupo "saúde".

FIGURA 24 Gráfico de dispersão entre SREP e SEST do grupo "saúde".

FIGURA 25 Gráfico de dispersão entre HI e SAB do grupo "N.O.". 98

FIGURA 26 Gráfico de dispersão entre HI e HF do grupo "N.O." 


\section{LISTA DE TABELAS}

TABELA 1 Resultado da média e desvio padrão dos grupos "radio", "saúde" e "N.O." em relação às variáveis HI, HF, SAB, SREP, SEST 93

TABELA 2 Resultado da análise de variância a dois critérios. Comparação da halitose entre os grupos "radio", saúde e N. O. e fases HI e HF.

TABELA 3 Resultado do teste de Tukey para os grupo "radio", "saúde" e "N.O." em relação às fases HI e HF. 94

TABELA 4 Resultados do teste de análise de variância a um critério. Comparação da saburra entre os grupos "radio", "saúde", e "N. O.". 94

TABELA 5 Resultados do teste de análise de variância a um critério. Comparação da SREP entre os grupos "radio", "saúde" e "N.O.".

TABELA 6 Resultado do Teste de Tukey para os grupos "radio", "saúde" e "N.O.", em relação à SREP. 94

TABELA 7 Resultados do teste de análise de variância a um critério. Comparação da SEST entre os grupos "radio", "saúde" e "N.O.". 95

TABELA 8 Resultado do Teste de Tukey para os grupos "radio", "saúde" e "N.O.", em relação à SEST. 95 
TABELA 9 Resultados do teste de correlação de Pearson, entre as variáveis com possíveis relações causais com a halitose, na amostra 95

TABELA 10 Resultados do teste de correlações de Pearson entre as variáveis com possíveis relações causais com a halitose, no grupo "radio". 96

TABELA 11 Resultados do teste de correlações de Pearson entre as variáveis com possíveis relações causais com a halitose, no grupo "saúde".

TABELA 12 Resultado do teste de correlação de Pearson entre as variáveis com possíveis relações causais com a halitose, no grupo "N. O.". 98

TABELA 13 Resultado do teste de Student, aplicado para a comparação entre a halimetria e entre os grupos positivos e negativos para o teste BANA. 99 


\section{LISTA DE ABREVIATURAS E SÍMBOLOS}

$\%$

$\left(\mathrm{CH}_{3}\right)_{2} \mathrm{~S}$

(CH3SH)

ABO

BANA

cGy

$\mathrm{Cm}$

$\mathrm{CO}_{2}$

CG

CSVs

DNA

ELISA

FOB

Gy

HI

HF

$\mathrm{H}_{2} \mathrm{~S}$

Mg

ml

pH

ppb

QV

SAB

SEST

SREP

UNIFOR

USP porcentagem

dimetil sulfeto

metil mercaptana

Associação Brasileira de Odontologia

benzoyl - DL - arginine - 2 napthylamide

centrigray

centímetros

dióxido de carbono

cromatografia gasosa

compostos sulfurados voláteis

ácido desoxirribonucleico

enzyme-linked immunosorbent assay

Faculdade de Odontologia de Bauru

gray

halimetria bucal inicial

halimetria bucal após remoção da saburra

sulfeto de hidrogênio

miligrama

mililitro

potencial de hidrogênio

partes por bilhão

qualidade de vida

peso seco da saburra

fluxo salivar estimulado

fluxo salivar em repouso

Universidade de Fortaleza

Universidade de São Paulo 

"Feliz daquele que transfere o que sabe e aprende o que ensina."

Cora Coralina

\section{Resumo}





\section{RESUMO}

O objetivo deste estudo foi investigar as relações entre os parâmetros de halitose e sialometria em pacientes submetidos à radioterapia de cabeça e pescoço, avaliando a presença de saburra, classificada em termos de peso seco, fluxo salivar, teste BANA e halimetria oral e comparar os resultados entre os grupos. Foram examinados 48 pacientes divididos em três grupos. $O$ grupo 1 ("saúde") foi constituído de pacientes que haviam terminado o tratamento na Faculdade de Odontologia de Bauru (FOB), sem queixa de halitose e com íntegra saúde oral; o grupo 2 ("N. O.") por indivíduos com necessidades odontológicas e o grupo 3 ("radio") pacientes que haviam sido submetidos à radioterapia na região de cabeça e pescoço. Foram avaliadas as concentrações bucal de Compostos Sulfurados Voláteis (CSVs) através do monitor portátil de sulfetos Halimeter ${ }^{\mathrm{TM}}$, os valores relacionados à taxa de fluxo salivar em repouso e estimulado, teste BANA com material proveniente da saburra lingual e peso seco da mesma. Os resultados foram analisados utilizando o teste de análise de variância que quantificaram o hálito antes e após a remoção da saburra. As relações entre halimetria bucal, peso seco da saburra, fluxo salivar com e sem estímulo, e a relação entre fluxo salivar em repouso e estimulado foram feitas através do teste de correlação de Pearson. Para verificar correlações entre halimetria bucal inicial e teste $B A N A^{T M}$ foi utilizado o teste " $\mathrm{t}$ " de Student. Os resultados mostraram que houve diferença estatisticamente significante entre a halimetria oral nos grupo "saúde" e "radio" e, nos grupos "saúde" e "N.O." Pode-se observar também que houve relação entre a presença de saburra e os níveis de CSVs. Em relação ao fluxo salivar, foi observada uma redução estatisticamente significante entre o grupo "radio" e os outros dois. Nas condições dessa pesquisa, foi constatado que a halitose pode ser considerada um efeito adverso da radioterapia, vinculada à hipossalivação e saúde oral deficiente.

Palavras chaves: halitose, radioterapia, câncer de cabeça e pescoço. 

"Onde quer que você vá, vá com todo o coração." Confúcio

Abstract 



\section{ABSTRACT \\ Evaluation of oral halitosis parameters in patients submitted to the head and neck radiotherapy}

The aim of this study was to verify the halitosis parameters in patients who had received head and neck radiotherapy. The degree of halitosis was determined through the presence of tongue coating, classified according to its dry weight; the salivary flow rate, the BANA ${ }^{\mathrm{TM}}$ test and Halimeter ${ }^{\mathrm{TM}}$ oral measurements. $\mathrm{A}$ total of 48 subjects were examined, which were divided into three groups. Group 1 was consisted for patients with good oral health and no complains of bad breath; Group 2 consisted of patients with bad oral health condition and Group 3 comprised individuals who had received head and neck radiotherapy. The concentration of Volatile Sulfur Compounds (VSC) was assessed by means of a portable sulfide monitor (Halimeter ${ }^{\mathrm{TM}}$ ) and the values were correlated to the resting and stimulated salivary flow rate and to the BANA ${ }^{\mathrm{TM}}$ test with material collected from the tongue coating and its dry weight. Halitosis was quantified before and after the removal of the tongue coating and the data was analyzed by means of the ANOVA test. The correlation among salivary flow rate, weight of the tongue coating and Halimeter ${ }^{\mathrm{TM}}$ oral measurements was evaluated by the Pearson test. The results showed a statistically significant difference between group 1 and 3, and between groups 1 and 2. A relationship between the presence of tongue coating and the VSC levels was also demonstrated. In concerning to the salivary flow rate, there was a statistically significant reduction between group 1 and 3 , and group 2 and 3 . In the accordance of this study, halitosis can be considered a side effect of radiotherapy, tied with the hyposalivation and deficient oral health.

Key words: halitosis, bread odor, head and neck cancer, radiotherapy. 

"E nossa história não estará pelo avesso assim sem final feliz. Teremos coisas bonitas pra contar. E até lá vamos viver.

Temos muito ainda por fazer não olhe para traz, apenas

começamos"

Renato Russo 



\section{1 - INTRODUÇÃO}

No Brasil, as estimativas no ano de 2006 apontam que ocorreram cerca de 472.050 casos novos de câncer. Estima-se que o câncer de pele não melanoma (116 mil casos novos) será o mais incidente na população brasileira, seguido pelos tumores de mama feminina (49 mil), próstata (47 mil), pulmão (27 mil), cólon e reto (25 mil), estômago (23 mil), colo do útero (19 mil) e, em seguida, o câncer de boca (13 mil). Estes dados acompanham o mesmo perfil observado na população mundial. (INCA $\left.{ }^{42}, 2006\right)$

Segundo a Estimativa de Incidência de Câncer no Brasil para 2006, do Ministério da Saúde ${ }^{42}$, o câncer de boca apresentou cerca de 10.060 casos estimados entre homens e 3.410 entre as mulheres. O câncer de laringe é um dos mais comuns a atingir a região da cabeça e pescoço, representando cerca de $25 \%$ dos tumores malignos que acometem esta área e $2 \%$ de todas as doenças malignas.

O câncer de cabeça e pescoço é, atualmente, um dos grandes problemas de saúde mundial. Infelizmente, a maioria dos casos é diagnosticada em estágios avançados. Geralmente, são carcinomas espinocelulares, que normalmente requerem um tratamento intensivo e com altos custos. (HERCHENHORN $\left.{ }^{41}, 2004\right)$

As mais importantes terapias para tratamento de carcinomas espinocelulares de cabeça e pescoço são cirurgia e radioterapia, sendo a quimioterapia restrita a alguns carcinomas e, geralmente, usada para tumores avançados. (BORNAN ${ }^{10}$ et al., 2003).

A radioterapia, como um dos tratamentos para o câncer de cabeça e pescoço, constitui-se numa modalidade terapêutica que utiliza as radiações ionizantes no combate a neoplasias, com o objetivo de atingir células malignas, impedindo a sua multiplicação por mitose e/ou determinando a morte celular (INCA $\left.{ }^{42}, 2006\right)$. O tratamento radioterápico pode ser utilizado com a intenção curativa ou paliativa, e o esquema de aplicação dependerá da dose total calculada e da avaliação do radioterapeuta (SAWADA ${ }^{75}, 2006$ ). 
A radioterapia tem sido muito estudada, e tornou-se essencial no tratamento destas patologias. Entretanto, os efeitos colaterais da radioterapia em cabeça e pescoço, sejam eles agudos ou crônicos, têm impacto determinante na qualidade de vida do paciente. (ALMEIDA ${ }^{2}$ et al., 2004).

Apesar de a radioterapia ser efetiva no controle de carcinomas espinocelulares, seus efeitos adversos podem agravar o estado de saúde do paciente. Alterações encontradas devido à irradiação ocorrem principalmente em mucosas, ossos, glândulas salivares e dentes. Como conseqüência, diversas afecções são observadas nos referidos órgãos. (VISSINK ${ }^{96}, 2003$ )

Nas glândulas salivares, as degenerações atróficas e acinares causadas pela radioterapia resultam comumente no decréscimo da produção de saliva. (BONAN $^{10}$ et al., 2003; PONTES ${ }^{22}$ et al., 2004)

Tais efeitos colaterais são de grande importância para o cirurgiãodentista, que possui papel fundamental na redução dos mesmos, visto que os efeitos agudos e tardios da radioterapia causam desconfortos aos pacientes que dificultam ou limitam as suas atividades normais (SAWADA $\left.{ }^{75}, 2006\right)$. Numerosos estudos demonstram que a saúde bucal deficiente é um fator que diminui a qualidade de vida (GRITZ ${ }^{37}$ et al., 1999), e a preservação e/ou reabilitação da saúde bucal melhora e tem garantido uma vida mais confortável para o paciente tratado com radioterapia. (ALMEIDA ${ }^{2}$ et al., 2004).

Sendo as glândulas salivares radiossensíveis, a hipossalivação é uma seqüela comum em pacientes irradiados devido a tumores malignos na região das mesmas. A halitose está fortemente relacionada à quantidade de saliva, $\left(\mathrm{SOHN}^{82}\right.$ et al., 1999, MÖLLER ${ }^{59}$, 2004) podendo ser mais um efeito adverso que interfere na qualidade de vida e socialização desses pacientes.

Xerostomia é uma queixa subjetiva, que pode não estar relacionada aos achados físicos de boca seca e hipossalivação. Sua prevalência aumenta com a idade, devido à terapia com drogas, doenças sistêmicas, radioterapia, e pode estar relacionada à depressão, disfagia, problemas digestivos e desordens de fala $\left(\right.$ ASTOR $^{4}$ et al., 1999). A taxa de fluxo salivar pode ainda variar com o clima, idade, gênero, saúde geral e condição da dentição (BRETZ ${ }^{13}$ et al., 2000). 
Halitose é uma palavra proveniente do latim halitus, onde hálito significa "ar expirado" e osis se refere a uma alteração patológica. (CRISPIM, SAMPAIO ${ }^{19}$, 1999). Pode trazer prejuízos à saúde física e psicológica dos indivíduos, podendo limitar contatos sociais (BOHN $\left.{ }^{9}, 1997\right)$.

A halitose pode trazer prejuízos à saúde física e psicológica dos indivíduos, sendo uma restrição social importante. A presença de halitose, ou mesmo a preocupação em possuí-la, pode reduzir a confiança em si mesmo, em relação às outras pessoas e pode interferir no desempenho de atividades. (TARZIA $\left.{ }^{88}, 2003\right)$.

Como geralmente o hálito é emitido pela boca, é misturado e contaminado por compostos voláteis mal cheirosos que emanam da cavidade bucal. Então, o mau cheiro bucal se torna um componente contribuinte ou freqüentemente dominante do hálito ofensivo. (TONZETICH ${ }^{92}, 1977$ ).

A halitose é uma condição determinada por vários fatores interdependentes, como fluxo salivar, microbiota bucal gram-negativa, $\mathrm{pH}$ bucal alcalino, presença de detritos celulares e alimentares, dentre outros. (BOGDASARIAN ${ }^{8}, 1982$; TONZETICH ${ }^{92}, 1977$ ).

Por possuir etiologia tão variada, e incluir situações fisiológicas e patológicas, pode ser dividida nas seguintes categorias: (1) devida a fatores locais de origem patológica; (2) devida a fatores locais de origem não patológica; (3) devida a fatores sistêmicos de origem patológica; (4) devida a fatores sistêmicos de origem não-patológica; (5) devida à administração sistêmica de drogas; (6) devida à xerostomia (DOMINIC ${ }^{25}, 1982$ ).

A literatura demonstra grande relação da hipossalivação com a halitose (SOHN $^{82}$ et al., 1999, MÖLLER ${ }^{59}$, 2004) e com os efeitos adversos da radioterapia. (BONAN ${ }^{10}$ et al., 2003). No entanto, a relação entre a halitose e a radioterapia é pouco conhecida; portanto, o objetivo da presente pesquisa foi estabelecer uma correlação entre a presença ou não de halitose e suas causas, em pacientes submetidos à radioterapia em cabeça e pescoço. 



\section{"O que sabemos é uma gota, o que ignoramos é um oceano."}

Isaac Newton 



\section{2 - REVISÃO DE LITERATURA}

\section{1 - Halitose}

A halitose consiste de um termo amplo que caracteriza odores desagradáveis ou fétidos que emanam da boca e/ou do nariz, ou através desses órgãos. É também conhecida como mau hálito, fedor da boca, fetor oris, bafo ruim, entre outros.

O cheiro desagradável do hálito no ar expelido pelo pulmão é que constitui a halitose e, se deve ao aumento da quantidade de odorivetores ou à presença de odores normalmente ausentes no ar expirado. (TARZIA ${ }^{88}, 2003$ )

$\mathrm{Na}$ história antiga, há sempre referência para o fato de pessoas apresentarem hálito terrível e sendo sempre mencionado em comédias e tragédias. (TARZIA ${ }^{87}, 2004$; GREIN ${ }^{36}$, 2002). Titus Marcus Plautus (254-184 a.C.), dramaturgo romano, classificou o "fedor da boca" entre muitas razões de infidelidade conjugal, porque o "hálito de minha esposa tem um cheiro terrível, melhor seria beijar um sapo". Além desse, há Plutarco (6-120 d.C.), que fala sobre o hálito em sua obra. Shakespeare comenta sobre o odor desagradável em sua peça "Muito Barulho por Nada" e Millôr Fernandes, escritor atual diz "O maior anticoncepcional do mundo é o mau hálito". (TARZIA ${ }^{87}, 2004$; GREIN ${ }^{36}$, 2002).

A halitose acompanha a sociedade por muitos anos e há vários registros históricos sobre a sua presença; no entanto, somente em 1874 ela foi descrita como entidade patológica por Howe. (ELIAS ${ }^{27}$, 2006)

Os aspectos históricos e sociais da halitose foram bastante abordados por ELIAS ${ }^{27}$, em 2006. Segundo o autor, a halitose foi fator de preocupação para a sociedade, e ainda hoje se mostra presente, sendo um obstáculo para o convívio social. A falta de conhecimento de como se prevenir a halitose é o que ainda a torna um limitante da qualidade de vida.

O problema é essencialmente etiológico, e somente com observação cuidadosa e conhecimento científico aliado ao bom senso é que se evita que o paciente perambule de consultório para consultório, procurando alívio para seu mal, que o deprime e isola. (GREIN $\left.{ }^{36}, 2002\right)$ 
A etiologia da halitose é localizada na boca em torno de $90 \%$ dos casos e pode ser atribuía à saburra lingual, cárie dental, doença periodontal e infecções orais. (SALVADOR, FIGUEREDO ${ }^{72}$, 2001)

O odor fétido é resultante da putrefação dos restos alimentares realizada pelas bactérias orais, descamação celular, saliva e sangue. Em particular, por meio da proteólise das proteínas dos peptídeos e aminoácidos, dando origem a compostos voláteis como a metil mercaptana. A intensidade da halitose é associada ao aumento dos níveis intra-orais de compostos sulfurados voláteis (ROSEMBERG ${ }^{69}$ et al., 1999; SALVADOR, FIGUEREDO ${ }^{72}$, 2001).

DURHAM; MALLOY; HODGES ${ }^{26}$, em 1993, relataram as fontes mais comuns, bucais e não bucais, de halitose, para melhor compreensão diagnóstica. Observaram que a halitose pode refletir condições locais ou sistêmicas sérias como gengivite, doença periodontal, diabetes, falência hepática, infecção ou neoplasia no trato respiratório, e que é importante determinar principalmente se a fonte de odor é oral ou não, e que a qualidade do odor pode ajudar nesta determinação.

IWAKURA $^{43}$ et al., em 1994, descreveram a diversidade de características clínicas da halitose, demonstradas em dois grupos de pacientes com queixas primárias (onde halitose era a principal queixa do paciente) e secundárias (quando o paciente procurou tratamento devido a outros problemas bucais) de halitose. Sessenta e oito pacientes da Clínica de Halitose do Departamento de Odontologia Preventiva, da Tohoku University, Faculdade de Odontologia, Sendai, Japão, formaram o grupo de pacientes com halitose primária (grupo 1), e 19 pacientes encaminhados à Clínica Geral pelo Departamento de Diagnóstico Oral e Radiologia Oral, para vários tratamentos formaram o grupo com halitose secundária (grupo 2). Foi realizado questionário sobre queixa de halitose e exame organoléptico. Todos os pacientes foram tratados até que o mau hálito, se presente, se tornasse indetectável ao exame organoléptico. Vinte e cinco por cento dos pacientes do grupo 1 realmente possuíam halitose, contra $52,6 \%$ do grupo 2. A principal motivação dos pacientes do grupo 1 para a visita profissional foi a consciência do hálito baseada na atitude de outras pessoas (48,5\%). No grupo 2, foi a indicação da halitose por outros (52,6\%). Aproximadamente metade dos pacientes do grupo 1 (52,9\%) já havia visitado outras clínicas para tentar solucionar o problema, 
contra nenhum paciente do grupo 2. Os pacientes mais propensos a não se satisfazerem com o tratamento foram os do grupo 1, mas que não apresentavam halitose.

TORRES, VIANNA ${ }^{94}$, em 1999, avaliaram a halitose entre dois grupos com idades diferentes. O grupo 1 (G1) foi composto de pacientes com idades variando de 19 a 54 anos, e o grupo 2 (G2) foi composto de pacientes com idade igual ou superior a 55 anos. Foram aplicados 80 questionários com questões relativas à idade, o que entendem sobre halitose e sua origem, se a possuem, se a sentem quando acordam, se algum profissional da saúde foi procurado para resolver o problema, hábitos alimentares, rotina de higiene oral, como escovação e uso do fio dental, uso de enxaguatório e limpeza da língua, sensação de boca seca, problemas de saúde, fumo, uso de medicamentos e próteses. Não houve diferença significante entre os grupos, embora houvesse maior conhecimento sobre higiene oral em G1, e G2 mostrasse menor incidência do hábito de fumar.

AMADO, CHINELLATO, REZENDE ${ }^{60}, 2005$ estudaram os parâmetros da halitose em 21 pacientes com fissura de lábio e/ou palato (grupo 2) e um grupo controle de 21 pacientes sem queixas de halitose (grupo 1). Avaliaram o peso seco da saburra, fluxo salivar, halimetria oral e nasal, utilizando o Halimeter $^{T M}$. Os resultados mostraram que houve relação entre a presença de saburra e os níveis de CSVs, assim como entre fluxo salivar, tanto em repouso como estimulado, com os níveis de CSVs; no grupo 2, pôde-se ainda observar relação significante entre o peso da saburra e o fluxo salivar em repouso e estimulado, e a mesma relação entre fluxo salivar estimulado e peso da saburra após o agrupamento dos pacientes em um único grupo; não houve diferença significante entre os grupos em relação à halimetria bucal; o grupo 1 apresentou maiores valores de halimetria nasal do que o grupo 2; não houve relação entre os níveis de CSVs e a percepção do paciente sobre seu hálito. Os autores concluíram que os pacientes com fissura de lábio e/ou palato operados e com a saúde bucal controlada não mostraram diferenças significantes em relação aos parâmetros estudados, quando comparados com pacientes sem fissura. 


\subsection{1 - Microbiota oral}

A microbiota associada à halitose é predominantemente anaeróbica gram-negativa e utiliza, como fonte de nutrientes, células descamadas, saliva e fluidos gengivais oriundos do hospedeiro, assim como também provenientes da dieta. (SALVADOR, FIGUEREDO ${ }^{72}$, 2001; LOESCHE $^{51}$, 2003) Oitenta e duas espécies de bactérias orais podem ser implicadas na produção das componentes que causam o mau odor, alguns fatores contribuem para 0 aumento de determinada população, tais como: estagnação de saliva, redução do fluxo salivar, redução do carboidrato como substrato e elevação do $\mathrm{pH}$ salivar (LOESCHE $\left.{ }^{51}\right)$.

Alguns requisitos para que ocorra o mau hálito, são a presença de bactérias anaeróbias, de baixo nível de oxigênio, de $\mathrm{pH}$ alcalino salivar e de substratos que contenham enxofre. (BOGDASARIAN ${ }^{8}$, 1986; TONZETICH ${ }^{92}$, 1977)

Acreditando na possibilidade de que a cadaverina e putrescina estivessem associadas ao mau-hálito, GOLDBERG ${ }^{34}$ et al., em 1994, examinaram 52 indivíduos não-fumantes, sem doença sistêmica e não portadores de próteses totais. Foi realizada avaliação da concentração de CSVs através de monitor portátil de sulfetos (Halímeter ${ }^{\mathrm{TM}}$ ), avaliação com juízes de odor e análise do teste BANA ${ }^{\mathrm{TM}}$ com material proveniente de bolsa periodontal, dorso da língua e saliva. Os autores afirmaram haver evidência da participação de cadaverina como componente do mau-hálito. Houve relação entre o nível de cadaverina e medida de CSVs, mas não entre o nível de cadaverina e o teste BANA ${ }^{\mathrm{TM}}$.

GOLDBERG $^{33}$ et al., em 1997, mostraram relação entre a presença de Enterobacteriaceae e a produção de mau hálito. Os autores isolaram espécies de enterobactérias na saliva, bolsas periodontais e língua, e após crescimento in vitro, houve produção de mau cheiro. As bactérias estudadas demonstraram, ainda, grande capacidade de aderência ao polímero de dentaduras, demonstrando a produção de mau cheiro característico.

SCULLY \& PORTER ${ }^{78}$, em 1999, relataram que a inadequada higiene oral é a causa mais freqüente de halitose. Outras causas de halitose e gosto ruim incluem fumo e ingestão de diversos alimentos. Infecção sinusal ou de 
outras partes do sistema respiratório também podem ser responsáveis. Algumas doenças sistêmicas, como diabetes, podem dar cheiro ao hálito. A detecção da halitose geralmente é subjetiva, e a condução do problema se dá com: tratamento das causas, alimentação freqüente, evitar fumar ou comer determinados alimentos, melhoria da higiene oral, uso de bochechos com clorexidina e cloreto de cetilpiridíneo, utilização de goma de mascar e uso de formulas de manipulação.

AAS $^{1}$ et al. 2005 fizeram um estudo para definir a microbiota normal da boca. Mais de 700 bactérias foram detectadas. Tinham a finalidade de especificar tanto o local como tipo colonização bacteriana. Os nichos avaliados foram dorso e laterais de língua, epitélio da mucosa oral, palato duro e mole, placa dental supra e subgengival e tonsilas amigdaliana. A seqüência de DNA e RNA foi usada para determinar o tipo e a família das bactérias. Treze fitobactérias novas foram identificados e a espécie mais comum foi Genella, Granulicatella, Streptococos e Veilonela. Em cada local predominava de 20 a 30 espécies diferentes de bactérias e o número de bactérias predominantes em todos os locais por indivíduo variou de 34 a 72. As espécies associadas à cárie e periodontites não foram identificadas. A microbiota bacteriana saudável da boca é bem diversificada e possui características próprias de acordo com o substrato e o local. É importante definir inteiramente o microbiota humana saudável da boca antes que se possa compreender o papel das bactérias na doença oral.

\subsection{2 - Saburra}

A saburra é um material viscoso, esbranquiçado ou amarelado que adere ao dorso da língua, em maior porção na região do terço posterior. Pesquisas mostram que a língua representa um importante papel na produção do mau odor oral. (GALHARDO ${ }^{32}$, 2002).

A saburra se forma principalmente por um aumento da mucina salivar e por um aumento da descamação da mucosa oral que, quanto maior, maior será a quantidade de saburra. (TARZIA $\left.{ }^{87}, 2004\right)$

YAEGAKI; SANADA ${ }^{100}$, em 1992, realizaram estudo em que relacionaram o peso da saburra e a análise dos CSVs. Trinta e um indivíduos participaram do estudo, divididos em indivíduos com e sem doença periodontal, 
e a análise do CSVs foi feita através de cromatografia gasosa. A saburra de cada indivíduo foi removida, e seu peso úmido avaliado ( $\mathrm{mg}$ ), e novas análises de CSVs foram realizadas. O grupo com doença periodontal possuía muito mais saburra do que o grupo controle, e a produção de CSVs pela saburra do grupo com doença periodontal foi 4 vezes maior do que nos grupos controle, e, após a remoção da saburra, a produção de CSVs em ambos os grupos caiu praticamente pela metade.

SEEMANN ${ }^{80}$ et al., em 2001, compararam a efetividade de um limpador lingual, um raspador lingual e uma escova de dente na capacidade de redução dos níveis de CSVs. Foram incluídos no estudo 28 indivíduos, divididos em três grupos, avaliados em três consultas distintas, utilizando em cada uma delas um diferente dispositivo de limpeza, sendo que cada indivíduo serviu como seu próprio controle. Pôde-se constatar, ao final do estudo, que o limpador lingual mostrou uma maior percentagem de redução dos CSVs do que a escova dental até 25 minutos após a limpeza da língua, e maior redução do que observada com o uso de raspador lingual até 15 minutos após a limpeza. Não foi constatada redução nos níveis de CSVs por períodos maiores do que 30 minutos após a limpeza, em nenhum dos indivíduos, o que levou os autores a questionarem o efeito clínico da limpeza da língua de forma isolada objetivando a redução do mau-hálito.

\subsection{3 - Fluxo salivar}

A saliva desempenha inúmeras funções importantes para a manutenção da saúde bucal, entre elas, lubrificação, hidratação, capacidade tampão, mineralização, facilitação do paladar, proteção dos tecidos bucais, atividade antimicrobiana e outras. (SAMARAWICKRAMA ${ }^{73}$ et al., 2002.

Aproximadamente $0,3 \mathrm{ml}$ de saliva são produzidos por minuto em descanso e de 2 a $3 \mathrm{ml}$ durante estimulação. Uma taxa de saliva de menos de 0,1 a $0,2 \mathrm{ml}$ por minuto é anormal, assim como uma taxa estimulada menor do que 0,5 a $0,7 \mathrm{ml}$ por minuto (SREEBNY ${ }^{81}, 1989$ ).

SOHN ${ }^{22}$ et al. (1999) estudaram a relação entre halitose e função das glândulas salivares. Analisaram 100 pacientes com queixa de halitose, através de exame salivar e obtiveram seus valores de CSVs medidos pelo Halimeter $^{\mathrm{TM}}$. Os resultados mostraram 58 pacientes com salivação normal e 42 com 
salivação anormal. Os maiores valores de CSVs foram encontrados no grupo com salivação anormal $(p<0,01)$. Em 51 pacientes (36 com salivação normal e 15 com salivação anormal) obtiveram valores de CSVs abaixo de 100, e em 38 pacientes (21 com salivação normal e 17 com salivação anormal) obtiveram valores entre 100 e 200, e 11 pacientes ( 1 com salivação normal e $10 \mathrm{com}$ salivação anormal) tiveram valores de CSVs acima de 200. Os resultados, de acordo com os autores, mostraram relação entre halitose e função de glândula salivar.

BRETZ $^{13}$ et al., em 2000, realizaram um estudo para determinar o fluxo salivar de glândulas salivares menores (MSGO) de idosos com diferentes condições médicas e determinar a relação do MSGO com fatores demográficos, médicos, dentais, ingestão de medicamentos e reclamações subjetivas de boca seca. Dados foram obtidos de 653 indivíduos de várias clínicas, todos eles com mais de 60 anos. Os dados mostraram que indivíduos com alto MSGO tendem a usar mais medicamentos que os com baixo MSGO, sem diferença com relação à ingestão de medicamentos xerogênicos. Pessoas com baixo MSGO eram mais idosas, e na maioria mulheres. Condição dental não mostrou relação com MSGO. No contexto geral, apresentar idade mais avançada, gênero feminino, o vício do fumo e queixa de boca seca foram associados a um baixo MSGO.

\subsection{4 - Mensuração do hálito.}

A mensuração do hálito (halimetria) pode ser feita através da avaliação organoléptica, cromatografia gasosa, monitor de sulfidretos (Halimeter ${ }^{\mathrm{TM}}$ )

A inalação direta do mau odor é conhecida como avaliação organoléptica. É um método seguro para avaliar a presença de halitose, no entanto muito subjetivo, pois indivíduos possuem diferentes percepções de odor (ROSEMBERG ${ }^{69}$ et al. 1999), além de evidenciar ser um método desagradável para o pesquisador.

A partir de 1970 as pesquisas concentraram-se principalmente em identificar um método químico e instrumental de análises, objetivando os compostos primários da halitose. Nesse contexto, foi empregado um método 
específico com gás cromatográfico, que foi adaptado para a medição direta dos compostos sulfurados voláteis contidos no hálito. (TARZIA $\left.{ }^{88}, 2003\right)$

SCHIMIDT $^{76}$ et al. (1978) verificaram a correlação entre o método de mensuração organoléptica e a cromatografia gasosa (CG). Foram selecionados 120 voluntários e separados em dois estudos. Os CSVs presentes no hálito foram mensurados por $\mathrm{CG}$ e por 3 examinadores (organoléptica). Houve correlação significante entre os resultados organoléptica com os níveis de sulfeto de hidrogênio e de metil mercaptana.

O monitor para medir CSV é um aparelho portátil capaz de quantificar os odorivetores que compõem o hálito. $\mathrm{O}$ Halimeter $^{\mathrm{TM}}$ é um monitor para detectar gás sufidreto e outros compostos voláteis de enxofre (metil mercaptana e dimetilsufeto), é capaz de medir alterações do hálito tanto no diagnóstico quanto na proservação clínica. Tornou-se muito utilizado em pesquisas. $\left(\right.$ TARZIA $^{88}$, 2003)

De acordo com o fabricante do Halimeter $^{\mathrm{TM}}$, níveis normais de hálito estão em torno de 100 ppb, sendo aceitável como nível normal medições entre 50 e 100 ppb. O "zero" no aparelho deve ser ajustado em ambiente livre de substâncias voláteis, e o painel de leitura deve indicar "0"; caso contrário, deve ser ajustado manualmente. É aceito que o "zero" se encontre na faixa de -10 a +10. Lê-se também no manual que, mesmo com procedimento de coleta correto, podem existir grandes diferenças nas leituras de um mesmo indivíduo em um mesmo período, e também em momentos diferentes do dia. Devem ser tomadas 3 leituras e realizada a média, e que aproximadamente $90 \%$ das leituras são reproduzíveis com +/- 15 ppb, e aproximadamente $75 \%$ das leituras são reproduzíveis com $+/-10 \mathrm{ppb}$.

ROSENBERG ${ }^{70}$ et al., em 1991, compararam a reprodutibilidade e sensibilidade de métodos organolépticos para a avaliação do mau-hálito e avaliação com um monitor de sulfidretos pelo Halimeter $^{\mathrm{TM}}$. Foram avaliadas 42 pessoas com queixa de mau hálito, sem critérios de exclusão. Os indivíduos abstiveram-se de comer, beber, mastigar e bochechar por pelo menos duas horas antes da consulta. Para medir a sensibilidade do método quanto a mudanças no hálito, os pacientes foram instruídos a bochechar duas vezes por dia gluconato de clorexidina $0,12 \%$. Cada tratamento consistia de 2 bochechos consecutivos de 30 segundos, evitando beber ou comer por pelo menos 30 
minutos depois. A avaliação do hálito foi feita através de dois métodos distintos. No primeiro foi utilizado o Halimeter ${ }^{\mathrm{TM}}$, e no segundo foi utilizada a avaliação organoléptica feita por dois juizes, que deram valores de 0 a 5 . Foram feitas medidas do índice de placa e índice gengival em cada consulta, após a avaliação do hálito, e também foi feita a medida das bolsas. Houve confiabilidade de valores entre a primeira e segunda consultas, assim como sensibilidade do aparelho quanto aos valores reduzidos de CSVs resultantes do tratamento com clorexidina.

WILLIS $^{99}$ et al. em 1999, observaram a relação entre intensidade do mau-hálito, crescimento de bactérias redutoras de sulfetos e taxas de redução de sulfetos na boca humana. Avaliaram 30 voluntários adultos saudáveis com mau-hálito. Os voluntários se abstiveram de higiene oral por 24 horas, sem ingestão de água ou alimento antes da consulta. O mau-hálito foi determinado pela utilização do Halimeter ${ }^{\mathrm{TM}}$ e método organoléptico. Foi coletada saliva estimulada de cada indivíduo, assim como amostras de placa bacteriana das porções anterior e posterior da língua, mucosa do vestíbulo, mucosa alveolar vestibular, placa sub e supragengival, para determinação da contagem de microorganismos viáveis, número de bactérias redutoras de sulfeto e atividade sulfeto-redutora. A incidência de bactérias redutoras de sulfeto foi de $97 \%$ nos 30 voluntários, com base na contagem viável, e foram encontradas em todos os sete sítios examinados, sendo que o maior número médio encontrado destas bactérias foi na saliva e o menor número foi na mucosa alveolar vestibular. Em cada indivíduo e em cada sítio testado foi encontrada correlação altamente positiva $(p=0,0004)$ entre atividade sulfeto-redutora e proporção de bactérias redutoras de sulfeto. Encontrou-se fraca relação entre os valores organoléptico e do Halimeter ${ }^{\mathrm{TM}}$ para o mau-hálito, sem relação significante observada entre contagem viável total e intensidade do hálito. Tanto os números populacionais de bactérias redutoras de sulfeto, como a atividade sulfeto-redutora, foram negativamente relacionados com o mau-hálito pelo método organoléptico. Também foi negativa a relação entre crescimento e atividade de bactérias sulfeto-redutoras e valores halimétricos para cada indivíduo, porém, sem significância estatística. Concluiu-se que a fraca relação entre o método organoléptico e halimétrico indicou que sulfetos voláteis não foram os principais determinantes de mau-hálito na população estudada. 
Com o objetivo de examinar a associação entre o hálito oral total e níveis de sulfetos e fatores demográficos, e também de observar o mau-hálito oral total e níveis de sulfetos e parâmetros clínicos em toda a boca, MORITA; $W_{A N G}{ }^{63}$ em 2001, examinaram 81 pacientes, que foram avaliados quanto ao mau-hálito pelo método organoléptico e por um monitor de sulfetos (Halimeter $^{\mathrm{TM}}$ ). A saburra foi avaliada visualmente e classificada em graus de 0 a 3 (não visível até mais de dois terços da língua). Também foram avaliados os tecidos moles, cáries, profundidade de sondagem e sangramento à mesma. Um monitor de sulfetos sulculares foi utilizado e feito o escore do teste $B_{A N A}{ }^{T M}$. Foi observado que o volume de saburra e o índice de sangramento foram os fatores mais fortemente relacionados, tanto ao valor organoléptico quanto ao valor da halimetria. O gênero feminino e hábito de fumar foram negativamente associados com os valores organolépticos, e o escore do teste BANA $^{T M}$ da saburra foi significantemente relacionado com os valores da halimetria.

SPRINGFIELD ${ }^{83}$ et al., em 2001, demonstraram que a variabilidade na concentração de CSVs obtida de indivíduos em condições controladas se deve a mudanças biológicas na boca, e não a produto de artefato na coleta ou análise dos dados. Doze voluntários saudáveis tiveram o ar oral coletado de forma padronizada; as variações minuto a minuto nas concentrações de metil mercaptana, dimetil sulfeto e sulfeto de hidrogênio foram avaliadas e comparadas com as variações nas concentrações de dióxido de carbono $\left(\mathrm{CO}_{2}\right)$, visto que esta deveria ser constante por representar níveis sangüíneos da pressão parcial de $\mathrm{CO}_{2}$. Enquanto que as concentrações de CSVs variaram enormemente entre indivíduos e entre as coletas do mesmo indivíduo, as concentrações de $\mathrm{CO}_{2}$ mantiveram-se próximas mesmo entre diferentes indivíduos.

$\mathrm{OHO}^{65}$ et al., em 2001, determinaram o nível de mau-hálito em pacientes com queixa de halitose através do uso de diversos métodos, incluindo cromatografia gasosa, monitor portátil de sulfetos e método organoléptico. Foram examinados 155 pacientes, com idade média de 46 anos, que reclamavam de halitose que persistia por meses ou anos, sendo que alguns deles tinham seus problemas relatados por terceiros, e outros acreditavam possuir halitose devido à atitude de outras pessoas. O grau de halitose foi 
avaliado pelo método organoléptico. O nível de CSVs foi quantificado com cromatografia gasosa e monitor de sulfetos Halimeter ${ }^{\mathrm{TM}}$. O exame do hálito foi 2 a 3 horas após o café da manhã, conduzido por três juízes e avaliado de 0 a 3. A porcentagem de acerto entre os três juízes foi de $83 \%$. Foi utilizado o cromatógrafo por gás Shimadzu GC-14B (Shimadzu, Kyoto, Japão) com sistema de detector fotométrico. Foi também avaliada a área e espessura da saburra por inspeção, com escore de 0 a 3 para área e 0 a 2 para espessura. $O$ fluxo salivar não estimulado foi avaliado através da expectoração da saliva por 5 minutos, expresso em volume por minuto. Houve correlação significante entre os três métodos de avaliação utilizados. Uma correlação ainda maior foi verificada entre a cromatografia gasosa e o monitor de sulfetos. Concluíram os autores que houve significantemente mais saburra nos indivíduos com alto grau de halitose, enquanto que o fluxo salivar não demonstrou ser significativo para a determinação da halitose.

Atualmente foi lançado o Oral Chroma ${ }^{\mathrm{TM}}$, um cromatógrafo gasoso portátil, que mede as concentrações separadamente dos sufidritos, metil mercaptanas, dimetilsufetos, o que permite analisar as causas da halitose. (ODOMED $\left.{ }^{64}, 2007\right)$

\section{2 - Radioterapia em cabeça e pescoço}

O câncer deve ser tratado assim que diagnosticado, ainda que se manifeste por uma lesão aparentemente pequena. (MARTINS de CASTRO ${ }^{55}$, 2002) Os métodos de tratamento mais utilizados são a cirurgia, a radioterapia, a quimioterapia ou a associação desses. (MINICUCCI ${ }^{58}$ et al., 1994; ALMEIDA ${ }^{2}$ et al., 2004). Outros métodos vêm sendo aplicados, como o transplante de medula óssea, a imunoterapia e a hormonoterapia. INCA ${ }^{42}, 2007$

A radioterapia age por ionização dos tecidos que, somada a outros efeitos, como excitação e formação de radicais livres, causa mudanças químicas nos componentes celulares. $O$ dano tecidual está relacionado à dose de radiação absorvida e à fase da divisão celular no momento em que receberam a radiação, sendo que as estruturas intracelulares e os tecidos com maior capacidade de renovação celular são os mais afetados. (WHITMYER ${ }^{98}$ et al., 1997) 
As indicações para se empregar a radioterapia pós-operatória nos carcinomas de boca incluem um ou mais dos seguintes achados patológicos relacionados com o sítio primário: invasão óssea, margem que sejam positivas, invasão perineural, invasão do espaço vascular, extensão do tumor no interior dos tecidos moles do pescoço ou multicentricidade. (PARSONS, MENDENHALL, STINGER $\left.{ }^{66}, 1997\right)$

A radioterapia, quando aplicada na região de cabeça e pescoço, também atinge os tecidos normais, produzindo danos reversíveis e irreversíveis. Tais efeitos estão na dependência da dose de irradiação, tempo, volume do tratamento e uso de outras terapias. Outros fatores são inerentes ao próprio paciente, tais como seu estado de desenvolvimento ósseo e dentário, predisposição genética, sensibilidade própria do tecido e capacidade de reparação do tecido normal, mecanismo de compensação de doenças e anormalidades do paciente (CAIELLI, MARTHA, DIB ${ }^{16}, 1995$ )

O estágio atual do tratamento da doença, qualquer que seja a modalidade (cirúrgica, radioterápica ou quimioterápica), acarreta seqüelas, muitas vezes significativas, que comprometem sobremaneira a qualidade de vida do indivíduo. Especialmente em relação ao uso da radioterapia no protocolo terapêutico dos casos de neoplasias malignas da boca, uma das seqüelas que mais afeta a qualidade de vida dos enfermos é a xerostomia. Desde que a alteração do parênquima glandular seja permanente, as complicações secundárias à diminuição do fluxo salivar são crônicas e crescentes. (BAPTISTA NETO ${ }^{6}, 2003$ ).

CAIELLI, MARTHA, DIB ${ }^{16}$ em 1995 fizeram uma breve revisão mostrando a importância da participação multidisciplinar no tratamento do paciente oncológico no que diz respeito à prevenção e tratamento das seqüelas orais decorrentes da irradiação de cabeça e pescoço.

LIMA $^{48}$ et al. em 2001 fizeram uma revisão do uso da radioterapia para o tratamento das neoplasias malignas sediadas na região de cabeça e pescoço, com especial menção aos efeitos que estas causam aos tecidos da boca. Relataram os efeitos deletérios causados pela terapia por radiação de relevância para o cirurgião-dentista, tais como os que ocorrem nas glândulas salivares, ossos, dentes, mucosas da boca, músculos e articulações associados com a perda de células e o dano na vascularização local. 
LIU $^{50}$ et al. (2003) estudaram o tratamento de 83 pacientes com carcinoma espinocelular na nasofaringe tratados com radioterapia $\mathrm{e}$ quimioterapia. A resposta local foi completa em 81 pacientes (97.5\%) e em 2 pacientes não houve êxito. Dois pacientes tiveram comprometimento nos linfonodos e 14 tiveram comprometimento sistêmico posterior. As metástases distantes são ainda o principal impacto na sobrevivência. A associação da quimioterapia e de outros agentes sistêmicos com a radioterapia são mais eficazes, e necessários para diminuir a taxa da metástase a distância nesse tipo de tumor.

MANFRO $^{53}$ et al., em 2006, avaliaram a sobrevida de 93 pacientes portadores de CEC de laringe sem possibilidades de tratamento oncológico curativo, e relacionaram com fatores demográficos (idade, sexo), clínicos e terapêuticos (tratamento realizado) de pacientes. A sobrevida média dos pacientes, após ser determinado o fim do tratamento curativo, foi de 3,51 meses. A idade, tratamento realizado e o estágio da doença não estiveram relacionados com o tempo de sobrevida após o início dos cuidados paliativos. $O$ sexo dos pacientes apresentou importância significativa na sobrevida ( $p=$ 0,02 ), sendo o masculino de 2,9 meses contra feminino de 8,2 meses. A maior causa de falência de tratamento foi a presença de doença loco-regional avançada. O sítio de metástase à distância mais freqüente foi o pulmão. Os autores concluíram que a sobrevida desses pacientes é bastante curta, não chegando a 4 meses, não importando qual o tipo de tratamento ao qual o doente foi submetido.

\subsection{1 - Efeitos adversos da radioterapia}

Os efeitos da radioterapia na região de cabeça e pescoço, que podem ser agudos ou crônicos, têm um impacto significativo na qualidade de vida do paciente oncológico.

ALMEIDA $^{2}$ et al. 2004, enumerou os efeito agudos em: mucosite, disgeusia, disfagia, infecção oportunista, xerostomia; e os tardios em: cárie de radiação, osteorradionecrose, trismo. Além desses, GOMES ${ }^{35}$ et al., 2003 citam como efeito da radioterapia: eritema, necroses severas, depilação, necrose pulpar, dor, hipersensibilidade dental e deficiência nutricional. 
Em crianças, a radioterapia ainda tem mais efeitos. Além de todos os citados, segundo MINICCUCCI ${ }^{58}$ et al. (1994) há a anormalidades de desenvolvimento crânio-facial, como hipodesenvolvimento maxilar e/ou mandibular, formação de estruturas mineralizadas anômalas.

BRUINS ${ }^{14}$ et al. (1998) propuseram um modelo da escolha da préterapia dental de pacientes com câncer de boca. Construiu um anagrama com as possibilidades de tratamento e encontrou que o método proposto teve $95 \%$ de confiabilidade e que auxiliam no planejamento do tratamento dental préradioterápico.

A mucosite ocorre devido à alteração de vários fatores, tendo sempre como base uma inflamação provocada diretamente pela ação da irradiação sobre a mucosa. Pode provocar alterações locais e sistêmicas, o que pode comprometer o tratamento para o tumor, debilitando sensivelmente o paciente. (BORAKS ${ }^{11}$, et al. 2000)

HANDSCHEL $^{40}$ et al. (2001) fizeram biópsias na mucosa de 45 indivíduos antes da radiação, durante a radioterapia, após atingir a dose de 60 Gy, e com 2 e 12 meses pós-radiação para analisar as alterações histomorfológicas, a população de células do tecido subepitelial da mucosa oral irradiada. Foi encontrado que, após a radiação, houve um decréscimo da quantidade de vasos sangüíneos e uma diferença significativa da quantidade dos macrófagos e das moléculas de adesão endotelial nas mucosas antes da radiação, durante a radiação e imediatamente após.

A disgeusia ocorre por haver uma atrofia gradual das papilas gustativas, decorrente da ação da radioterapia e viscosidade da saliva. (EPSTEIN ${ }^{30}$ et al., 2000) Com o término do tratamento, o paladar pode se restabelecer em aproximadamente 4 meses; entretanto, alguns pacientes relataram não apresentar remissão do quadro. Não existem formas terapêuticas deste quadro, e o profissional deve diminuir a ansiedade do paciente. (ALMEIDA ${ }^{2}$, 2004)

Segundo VISSINK ${ }^{96}$ et al. (2003), a alteração do paladar tem uma forte influência no estado nutricional do paciente, pois está associado com diminuição do apetite, alteração da quantidade de alimento que o pacientes conseguem ingerir e, consequentemente, perda de peso. 
VISSINK ${ }^{96}$ et al. (2003) fizeram uma revisão das seqüelas orais da radioterapia de cabeça e pescoço, caracterizando-as. Deram enfoque às complicações que ocorrem na mucosa oral, paladar, glândula salivar, dentição, periodonto, osso, músculos e articulações, epiglote e disfunções nutricionais.

VISSINK $^{95}$ et al. (2003) revisaram a prevenção e o tratamento das conseqüências da radioterapia de cabeça e pescoço, caracterizando a mucosite, alteração no paladar, hipossalivação, cáries, osteorradionecrose.

A osteorradionecrose é uma das mais sérias complicações da radioterapia na região maxilofacial. (STORE, SMITH, LARHEIM ${ }^{84}, 2000$ ). O quadro clínico é caracterizado por dor intensa, formação de fístula, seqüestros ósseos, ulceração da pele com exposição da cortical e fraturas patológicas. $O$ tratamento exige ações conjuntas de diversas especialidades, o que eleva sua complexidade. (STURDART-SOARES ${ }^{85}$, 2002).

A cárie de radiação não é um efeito direto da radiação, e, sim, uma conseqüência da hipossalivação. Trata-se de cáries rampantes, que destroem a coroa. É o resultado da diminuição do fluxo salivar, com manutenção da oferta de carboidratos cariogênicos e deficiência de higienização oral e, ainda, alterações de viscosidade e $\mathrm{pH}$ salivar. (ALMEIDA ${ }^{2}$, 2004)

O trismo ou limitação de abertura pode acontecer quando a patologia envolveu os músculos ou a articulação temporomandibular, e pode ser também resultado da ação da radioterapia nos músculos da mastigação, quando a região de ATM está envolvida na área de radiação ou associação desses fatores. A limitação de abertura dificulta a higiene oral, fala, alimentação adequada, tratamento dental, exame da orofaringe e pode causar desconforto para o paciente. $O$ risco de desenvolver trismo é freqüente e pode-se tentar prevenir com um planejamento associado à fisioterapia com exercícios de abertura máxima e mobilidades da ATM, que o paciente pratica antes da radioterapia. (VISSINK ${ }^{95}, 2003$; VISSINK ${ }^{96}, 2003$ )

\subsection{2 - Efeito da radioterapia no fluxo salivar.}

É importante diferenciar a condição física da redução do fluxo salivar (dado objetivo) em relação à sensação de boca seca relatada pelo paciente (dado subjetivo). (COELHO ${ }^{18}$ et al. 2002; DAWES ${ }^{20}$, 2004) A xerostomia é uma sensação subjetiva de boca seca e a hipoassalivação é um achado objetivo e 
redução do fluxo salivar. A xerostomia (sensação de boca seca) ocorre quando o nível de fluxo salivar estiver diminuído devido à evaporação ou à absorção da água pela mucosa. (DAWES $\left.{ }^{20}, 2004\right)$

A saliva desempenha inúmeras funções para a manutenção da saúde oral; entre elas, lubrificação, hidratação, capacidade tampão, mineralização, facilitação do paladar, proteção dos tecidos intrabucais, atividade antimicrobiana, entre outras. (SAMARAWICKRAMA ${ }^{73}$, 2002)

A influência da radioterapia sobre as glândulas salivares atua tanto na quantidade de saliva quanto na qualidade, tornando a saliva mais espessa e pegajosa.

BUCHER $^{15}$ et al. (1988) analisaram amostras salivares de 11 pacientes portadores de linfoma de HODGKIN, tratados por meio da irradiação do campo manto. Seus achados revelaram que a velocidade do fluxo salivar estimulado sofreu uma redução em torno de $50,8 \%$, enquanto que a não estimulada teve uma redução menor, em torno de $39 \%$.

LIMA $^{49}$ (1999), numa avaliação sialométrica e sialoquímica da saliva de indivíduos submetidos à radioterapia de cabeça e pescoço, observou uma redução de 50\% da salivação estimulada com a dose de 15Gy. Ao término do tratamento radioterápico em que todos os pacientes foram submetidos a doses acima de 6.300cGy e radiação bilateral "alta" (tumores de orofaringe e base de língua), o fluxo estimulado teve uma redução de $64 \%$ dos valores iniciais. 0 fluxo continuou a diminuir gradativamente e aos 2,4 e 6 meses após o término do tratamento radioterápico, diminui até $79 \%$.

TAYLOR e MILLER ${ }^{89}$ (1999) afirmaram que a xerostomia é a mais severa e irreversível forma de disfunção salivar, em geral provocada pela irradiação, danificando as células acinares. Isto ocorre durante a radioterapia dos tumores de cabeça e pescoço, resultando na pior forma de destruição iatrogênica das glândulas salivares. Relatos de sintomas de boca seca não estão necessariamente associados com a diminuição do fluxo salivar, entretanto, uma perda significativa do fluxo salivar torna difícil o processo de formação do bolo alimentar e sua conseqüente deglutição, podendo ocorrer deficiência nutricional. A saliva também facilita a dicção; se diminui a quantidade e sua qualidade é alterada, o paciente é prejudicado social e 
emocionalmente. Os autores sugerem maior cuidado com as glândulas salivares em pacientes que vão receber radiação na área.

BORAKS ${ }^{11}$ et al., (2000) afirmaram que a xerostomia decorrente da radiação ocorre sempre que as glândulas salivares maiores ou menores forem contidas no campo da irradiação de tumores malignos da boca e pescoço, pois a secreção da saliva declina drasticamente nessas situações.

BONAN $^{10}$ et al., em 2003, avaliaram o fluxo salivar de pacientes durante a radioterapia de cabeça e pescoço. Foi avaliado um total de 47 indivíduos divididos em pacientes sob radioterapia e indivíduos saudáveis (grupo controle). Foi observado que, apesar do fluxo salivar ser semelhante em ambos os grupos no início da pesquisa, a redução do fluxo salivar dos pacientes após o início do tratamento radioterápico foi evidente $(p=0,0008)$, e o fluxo mantevese inalterado, sem aumento, após o término do tratamento. Os autores concluíram que a radioterapia leva a uma redução importante no fluxo salivar durante e depois do tratamento.

MÖLLER ${ }^{59}$ et al., em 2004, fizeram um estudo prospectivo da função da glândula salivar em pacientes submetidos à radioterapia devido a carcinomas de células escamosas de orofaringe. A amostra constituiu de 54 pacientes que estavam em tratamento radioterápico na região de cabeça e pescoço. Foram avaliados o fluxo, $\mathrm{pH}$ e a capacidade tampão, determinada antes, durante e depois de 12 meses da radiação completa. Os autores observaram que a radioterapia na região de glândulas salivares maiores induz severamente a hipossalivação com alteração do pH e da capacidade tampão. As cirurgias de cabeça e pescoço têm um impacto negativo nos níveis de fluxo salivar, especialmente quando a glândula submandibular é removida. Entretanto, cirurgia depois da radiação não é um fator agravante quando a radioterapia atuou incluindo todas as glândulas salivares maiores.

DAWES; ODLUM ${ }^{21}$, em 2004, compararam o fluxo salivar estimulado e volume residual de saliva em 23 indivíduos do grupo controle e 25 pacientes que receberam radioterapia ou removeram a glândula salivar (ou ambos) devido a câncer de cabeça e pescoço. O fluxo salivar do grupo de pacientes foi significativamente menor em comparação com o controle. Entretanto, em relação ao volume residual de saliva, não houve diferença significativa. O grupo de pacientes foi redividido, de acordo com autopercepção de boca seca, e o 
grupo que relatava muita sensação de boca seca (10) tinha $71 \%$ menos saliva que o grupo controle. Os resultados sugerem que os indivíduos que relatam boca seca nem sempre têm falta completa da saliva, podendo apresentar secura em algumas áreas da boca, principalmente no palato duro, onde a película salivar é particularmente fina e o há maior absorção e evaporação da saliva.

PONTES, POLIZELLO, SPADARO ${ }^{22}$, em 2004, fizeram uma avaliação clínica e bioquímica da saliva em paciente com xerostomia induzida por radiação, de 21 pacientes, antes e após o tratamento de pacientes radioterápicos para cabeça e pescoço (grupo experimental) e de 21 pacientes sem câncer (grupo controle). Foi medido o fluxo salivar, a capacidade tamponante, concentração de proteína total salivar, atividade da amilase, e o perfil eletroforético. Foi observada uma redução estatisticamente significativa para o fluxo salivar $(p<0.01)$ e para a capacidade tamponante. Não foi observada alteração significativa na concentração de proteína total. A atividade efetiva da amilase foi significativamente diminuída $(p<0.01)$. Os autores concluíram que no presente estudo houve uma redução significativa nos níveis de fluxo salivar, na capacidade tamponante e no perfil eletroforético, em relação aos pacientes saudáveis.

DIRIX ${ }^{24}$ et al., em 2004 avaliaram a eficácia clínica do BioXtra para cuidado com a boca seca. Foi aplicado um questionário de xerostomia, divido em 3 partes (escores para os sintomas de xerostomia, qualidade de vida, escala analógica visual) em um grupo de 34 pacientes com xerostomia radioinduzida. Foi avaliado antes e depois de 4 semanas, com uso de gel, dentifrício e colutório oral da BioXtra. Encontraram que os produtos da BioXtra diminuíram significativamente os sintomas de xerostomia. $\mathrm{Na}$ escala analógica, houve um decréscimo da média de 59,8 antes para 36,4 depois do tratamento. A qualidade de vida melhorou significativamente de 59,4 para 70,5 . nenhum paciente teve efeito adverso e somente 1 não achou o produto fácil de usar.

GUEBUR $^{38}$ et al., em 2006, avaliaram a perda do fluxo salivar total não estimulado de 17 pacientes durante a radioterapia na região e cabeça e pescoço. Foram realizadas duas coletas de saliva pelo método de "spiting"; a primeira, prévia, ao início da radioterapia, e, a segunda, ao final do tratamento. A xerostomia foi encontrada em $70,58 \%$ dos pacientes após a radioterapia e 
houve uma redução de 53,33\% da saliva total não estimulada. Concluíram que a radioterapia convencional na região de cabeça e pescoço ocasiona quadros gravíssimos de xerostomia, que permanecem durante o todo o tratamento radioterápico.

\subsection{3 - Influência da dose de radiação}

A unidade do sistema internacional de dose absorvida é o Gy (gray), que corresponde a $100 \mathrm{rad}$, o qual é definido como $0,01 \mathrm{j} / \mathrm{kg}$ (joule por quilograma) para qualquer tecido e, usualmente, como unidade de tratamento, o cGy (centrigray), que corresponde a $1 \mathrm{rad}$, representando a absorção de 1 $\mathrm{j} / \mathrm{kg}$.(MARTINS DE CASTRO ${ }^{55}$, 2002; LANGLAND, LANGLAIS ${ }^{46}$, 2002)

Segundo WHITMYER ${ }^{98}$ et al. 1997, os pacientes com carcinomas de cabeça e pescoço recebem uma dose entre 50 a 70 Gy como uma dose curativa. Essa dose geralmente é aplicada de forma fracionada, ou seja, por um período de 5 a 7 semanas, uma vez ao dia, 5 dias por semana e com a dose diária de 2 Gy. A vantagem de aplicar a dose fracionada da radiação é permitir que o tempo favoreça a reparação dos tecidos saudáveis e que o tumor diminua seu volume lentamente.

$\mathrm{Na}$ radioterapia, os primeiros sintomas de mucosite se apresentam com dose de radiação recebida equivalente a 1000 cGy, o que, geralmente, ocorre na primeira semana de tratamento. A sensação de boca seca ocorre por volta da segunda ou terceira semana de radiação, com doses aproximadas de 2000 a 2500 cGy. (CAIELLI ${ }^{16}$ et al., 1995)

$\mathrm{JEN}^{44}$ et al., em 2006, mediram o fluxo saliva em repouso e estimulado de 50 pacientes com carcinoma na nasofaringe submetidos à radioterapia, antes, durante, 1, 3 e 6 meses e 1 e 2 anos após radioterapia. Objetivaram avaliar mudanças na quantidade de saliva antes, durante e após radiação, especialmente na primeira semana de tratamento; a capacidade de recuperação e o prognóstico dos fatores que afetam as glândulas salivares na terapia por radiação. Encontraram que as glândulas foram muito radiosensíveis e respondiam à radiação muito precocemente. Após 720 cGy no quarto dia de um tratamento de 8 semanas, a taxa do fluxo salivar em repouso e estimulado tinham diminuído em $40 \%$ a $50 \%$. O pico inferior de salivação foi encontrado em 3600 cGy (4 semana). Uma segunda fase de diminuição da secreção 
salivar foi observada após a conclusão da radioterapia. O estudo não mostrou nenhuma recuperação da função das glândulas salivares, e o melhor tratamento para a hipossalivação radioinduzida é a redução da dose de radiação nas glândulas.

\subsection{4 - Qualidade de vida dos pacientes irradiados}

A terminologia "qualidade de vida" (QV) tem sido muito usada para avaliar o estado de saúde e o impacto das aplicações terapêuticas em pacientes com diferentes doenças. A Organização Européia para Pesquisa e Tratamento de Câncer (European Organization for Research and Treatment of Câncer -EORTC) coordena os estudos em várias áreas da Oncologia, inclusive sobre QV, nos países da Europa, América e Oceania, e relata a complexidade e dificuldade que envolve o conceito desse termo (HAMMERLID; BJORDAL; AHLNER-ELMQVIS $^{39}$, 1997). Segundo TERRELL ${ }^{90}$ (1999), a expressão QV inclui a percepção do paciente em encontrar a satisfação no trabalho, no lar, religião, família e educação, ou seja, o conceito de QV está diretamente ligado a auto-avaliação do sujeito.

Para pacientes com câncer de cabeça e pescoço, a auto-avaliação sobre QV é muito útil como auxílio das medidas de avaliação de efetividade de tratamento (TESTA, SIMONSON, $\left.{ }^{91} 1996\right)$. Apesar dos recentes avanços no diagnóstico e tratamento, os tumores de cabeça e pescoço estão associados à desconfiguração e disfunções que afetam domínio de importância vital. Além disso, o tratamento dessas patologias leva às inúmeras complicações agudas e crônicas, que acompanham muito tempo da vida dos pacientes. (EPSTEIN ${ }^{29}$ et al., 1999)

EPSTEIN ${ }^{29}$ et al. (1999) avaliaram a qualidade de vida de 65 pacientes que tinham terminado a radioterapia na região de cabeça e pescoço de 6 a 8 meses. Aplicaram um questionário que avalia fatores que influenciavam na QV. Relataram que havia disfagia em $63,1 \%$, mudanças de paladar em $75,4 \%$, alteração na fala em $50,8 \%$, dificuldade no uso das próteses em $48,5 \%$, que a dor foi freqüente em $58,4 \%$ dos pacientes, e que esta interfere nas atividades diárias em $30,8 \%$. Concluíram que as complicações orais da radioterapia na região de cabeça e pescoço são extremamente comuns e afetam significativamente na QV. 
MATIAS $^{56}$, em 2005, entrevistou 143 pacientes com carcinoma epidermóide na boca e orofaringe, para avaliar os padrões da QV no contexto brasileiro. Os pacientes com tumores maiores na orofaringe ou região posterior da boca, os que apresentaram metástases e os que foram submetidos à radioterapia apresentaram indicações significativamente $(p<0,05)$ piores de $Q V$. Mastigar, ansiedade, engolir e saliva foram os itens de pior pontuação; e dor, engolir, mastigar e saliva foram as queixas mais freqüentes na semana anterior à semana que antecedeu a entrevista.

SAWADA, DIAS, ZAGO ${ }^{75}$ (2006) avaliaram os efeitos colaterais da radioterapia nos pacientes com câncer na região de cabeça e pescoço e sua influência na qualidade de vida de 32 pacientes, através de questionário e avaliação de maneira quantitativa. A xerostomia $(84,5 \%)$ foi o sintoma mais presente nos resultados, seguidos por saliva pegajosa $(75,1 \%)$, pele ressecada (65,7\%), irritação e depressão (56,3\%), dificuldade no paladar (72\%), dores de garganta $(34,4 \%)$. Ao correlacionarem efeitos colaterais com a qualidade de vida dos pacientes, houve diferença estatisticamente significante $(p<0,05)$, concluindo que esses efeitos influenciam na qualidade de vida dos pacientes.

MCMILLAN $^{57}$ et al. (2006) pesquisaram a radioterapia de intensidade modulada (IMRT) e seu efeito na qualidade de vida de pacientes com tumor de cabeça e pescoço. Os pesquisadores observaram que o fluxo salivar recuperase em pelos menos $25 \%$ ao período anterior à radioterapia após 1 ano. 

"O mais importante da vida não é saberes onde estás, mas sim para onde vais." Goethe 



\section{3 - PROPOSIÇÂO}

- Avaliar o hálito bucal em pacientes submetidos à radioterapia cabeça e pescoço (grupo radio), pacientes com necessidades odontológicas (grupo N.O.), e pacientes com saúde oral íntegra (grupo saúde), comparando os resultados entre os grupos;

- Investigar as relações entre os parâmetros estudados (peso seco da saburra lingual, fluxo salivar com e sem estímulo, teste BANA) e a halitose bucal;

- Medir o fluxo salivar do grupo "radio" e compará-lo com o fluxo dos pacientes não submetidos à radioterapia (grupo N.O. e grupo saúde). 

"Comece por fazer o que é necessário, depois o que é possível

e de repente estará a fazer o impossivel."

São Francisco de Assis 



\section{4 - MATERIAL E MÉTODOS}

Todos os pacientes assinaram o Termo de Consentimento Livre e Esclarecido (apêndice B), receberam informações referentes a todas as etapas da pesquisa, e poderiam remover seu consentimento a qualquer momento do estudo.

O projeto de pesquisa foi aprovado pelo Comitê de Ética em Pesquisa da Faculdade de Odontologia de Bauru, da Universidade de São Paulo, em 26 de outubro de 2005, no processo $n^{\circ} 104 / 2005$. (anexo 1)

\section{1 - Amostra}

A amostra foi constituída de 48 indivíduos, divididos em três grupos distintos:

- O grupo I (saúde) foi constituído de 10 pacientes que finalizaram tratamento odontológico na Faculdade de Odontologia de Bauru, sendo 4 mulheres e 6 homens, com a média de idade de 41,30 anos.

- O grupo II (N.O.) foi constituído de 13 pacientes, sendo 5 mulheres e 8 homens, com média de idade de 44,69 anos que procuraram a Faculdade de Odontologia de Bauru e ainda não haviam sido submetido a qualquer tratamento odontológico.

- O grupo III ("radio") constituído de 25 pacientes selecionados entre pacientes do Hospital Manoel de Abreu, referenciado pelo SUS para tratamento de câncer, localizado na cidade de Bauru. Para esse grupo, foram analisados 62 prontuários. Desses, foram selecionados 45 pacientes, sendo que somente 25 compareceram nas duas consultas.

O grupo "radio" e o grupo "N.O." apresentavam a saúde oral deficiente, com presença de doença periodontal e cárie. 


\section{2 - Critérios de inclusão}

Todos os pacientes do grupo "radio" (grupo III) eram maiores de 18 anos e foram submetidos à radioterapia em região de cabeça e pescoço para tratamento ou complementação de tratamento de tumores de cabeça e pescoço. A área da radiação deveria abranger pelo menos uma das glândulas salivares maiores ou parte dela.

O tratamento radioterápico de todos os pacientes já havia sido concluído, e os mesmos estavam em acompanhamento de 1 a 6 meses após a última sessão de radioterapia.

\section{3 - Critérios de exclusão}

Possuir doenças sistêmicas, no que concernem os grupos I e II, afora câncer tratado para o grupo III.

\section{4 - Protocolo experimental}

Todos os atendimentos foram realizados em duas consultas. $\mathrm{Na}$ primeira, os pacientes responderam a um questionário relativo a dados pessoais, saúde geral e oral (apêndice C), o qual incluía história pregressa da doença e tratamento radioterápico; hábitos de vida e alimentares. Ainda nesta consulta, o paciente recebia orientações prévias para os procedimentos a serem realizados no segundo momento.

Na segunda consulta, era realizada a halimetria, coleta da saburra, teste BANA e sialometria em repouso e estimulada. Na figura 01 . Observam-se os materiais usados para os procedimentos.

Todas as fases serão explicadas detalhadamente a seguir.

Todos os pacientes relacionados à pesquisa foram encaminhados à Faculdade de Odontologia de Bauru para tratamento de suas necessidades odontológicas, relativas ou não ao hálito. Para os pacientes que demonstraram baixos índices de salivação e/ou halitose, foi prescrita hidratação bucal com Salivan (laboratório: Apsen), indicado para hipossalivação/ xerostomia, 
bochechos com o colutório sem álcool Saúde Bucal (Odomed) e creme dental com flúor, prescritos conforme a necessidade de cada caso.

\section{5 - Questionário médico-odontológico}

Primeiramente foi preenchido um questionário sobre as condições de saúde bucal e geral do paciente, para a identificação de patologias e/ou quaisquer fatores que influenciassem o hálito.

No referido questionário foram anotados os dados relativos aos parâmetros de halitose, preenchido pela cirurgiã-dentista encarregada do exame clínico do paciente. Em seguida, os pacientes foram submetidos a um exame para avaliação de sua saúde bucal, sendo avaliado qualquer fator que interferisse diretamente no hálito dos mesmos. Todos os dados eram anotados nos prontuários dos pacientes.

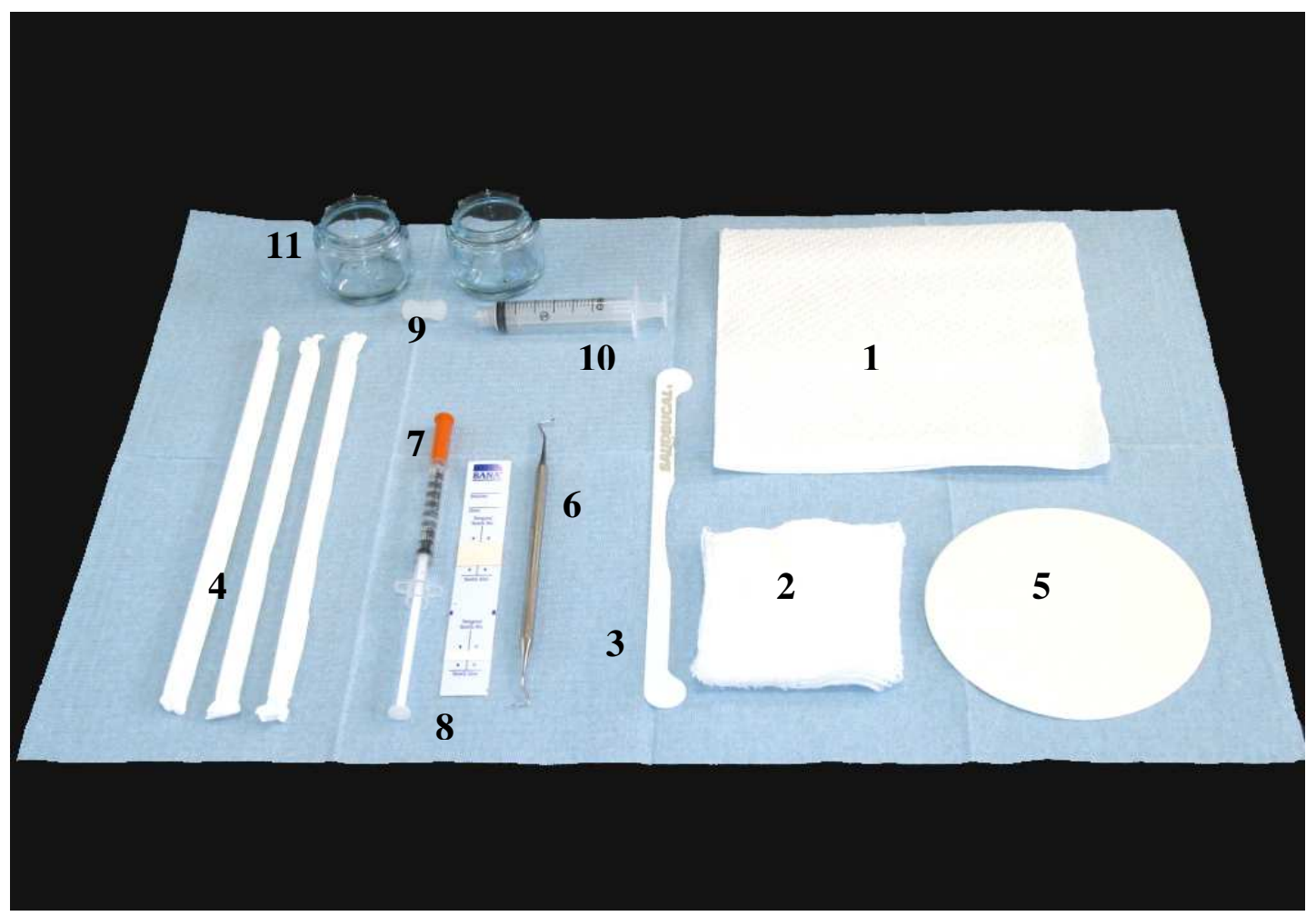

Figura 01: Mesa de atendimento do paciente: 1) guardanapo; 2) gaze; 3) limpador de língua; 4) canudos; 5) papel filtro; 6) colher de dentina; 7) água destilada; 8) fita teste BANA; 9) hiperbolóide; 10) seringa para sialometria; 11) vidros para coleta de saliva. Fonte: AMADO ${ }^{3}$, 2003 


\section{6 - Orientações prévias.}

Previamente aos exames, os pacientes receberam as seguintes orientações (apêndice D), objetivando uma maior padronização em relação à coleta dos dados para halimetria.

1. Evitar, 24 horas antes da consulta, comida muito condimentada e/ou aromatizada.

2. Evitar, 3 horas antes da consulta:

2.1. Escovar os dentes;

2.2. Usar fio dental;

2.3. Usar enxaguatório bucal;

2.4. Usar pastilhas ou goma de mascar;

2.5. Bebidas alcoólicas;

2.6. Fumar.

3. No momento da consulta não estar usando perfumes ou outras substâncias aromatizantes.

\section{7 - Coleta dos valores de halimetria.}

Com o intuito de quantificar os valores do hálito e diferenciar as fontes de odor, foram realizadas as halimetrias bucais de todos os indivíduos, com a utilização do aparelho Halimeter ${ }^{\mathrm{TM}}$ (Interscan corporation, Chatsworth, USA).(figura 02) Cada paciente ficou sentado sem falar por 1 minuto, com a boca fechada. Um canudo plástico descartável conectado ao monitor de sulfetos foi introduzido $4 \mathrm{~cm}$ dentro da boca do paciente (figura 03). Este foi instruído para trazer a boca levemente aberta sobre o canudo, e não inspirar ou expirar durante as leituras. 


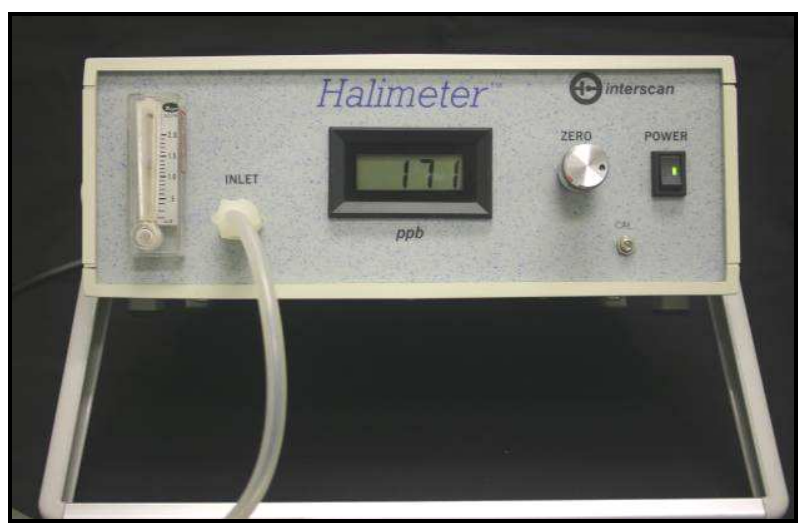

Figura 02 - Halimeter ${ }^{\mathrm{TM}}$

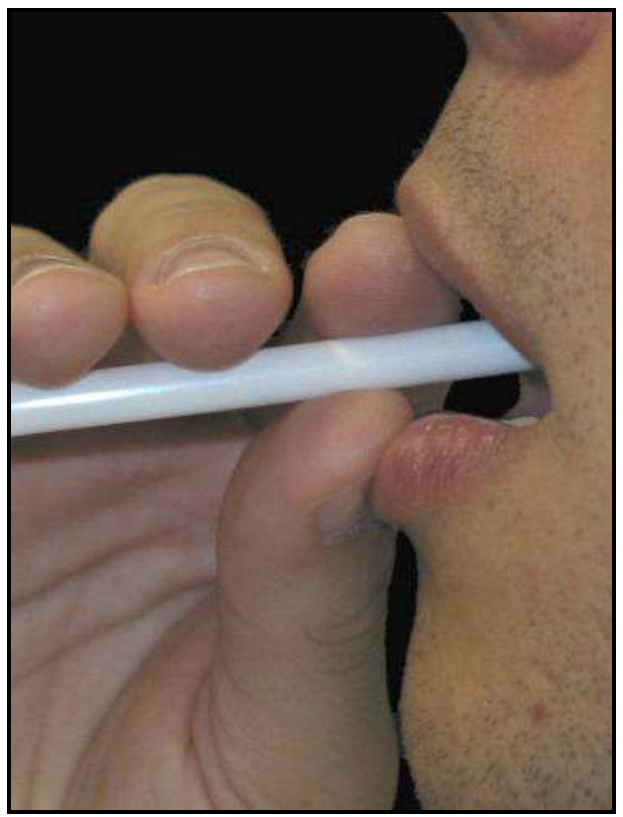

Figura 03 - Canudo na boca para fazer a leitura da concentração de CSVs. Fonte: $\mathrm{AMADO}^{3}, 2003$

O monitor de sulfetos possui uma bomba que puxa o ar pelo canudo, e assim que o ar passa pelo sensor eletrolítico, a concentração dos CSV é detectada. Quando o aparelho registrasse o valor máximo no monitor, em partes por bilhão, este dado era registrado.

As medidas de CSVs bucais foram realizadas em triplicata, sendo obtida uma média, e entre cada medida do hálito os pacientes permaneceram de boca fechada durante 1 minuto. O procedimento foi realizado uma quarta vez, simultaneamente à expiração lenta do paciente, procurando identificar, desta 
forma, um aumento ou redução dos valores de halimetria conforme o ar bucal se misturava com o ar proveniente dos pulmões, demonstrando, assim, causa sistêmica de hálito.

\section{8 - Avaliação da saburra e novas medidas de halimetria}

O excesso de umidade da língua foi removido com uma gaze e a saburra removida com um limpador lingual da empresa Saúde Bucal ${ }^{\circledR}$ (figura 04 e 05), e colocada em um papel filtro previamente pesado. Uma pequena parte do material colhido foi utilizada para a realização do teste BANA ${ }^{\mathrm{TM}}$, e o restante armazenado durante 24 horas para secagem e posterior pesagem, obtendo-se desta forma o peso da saburra, por meio de balança de precisão (A\&D Company, limited, Tokyo) (figura 06).

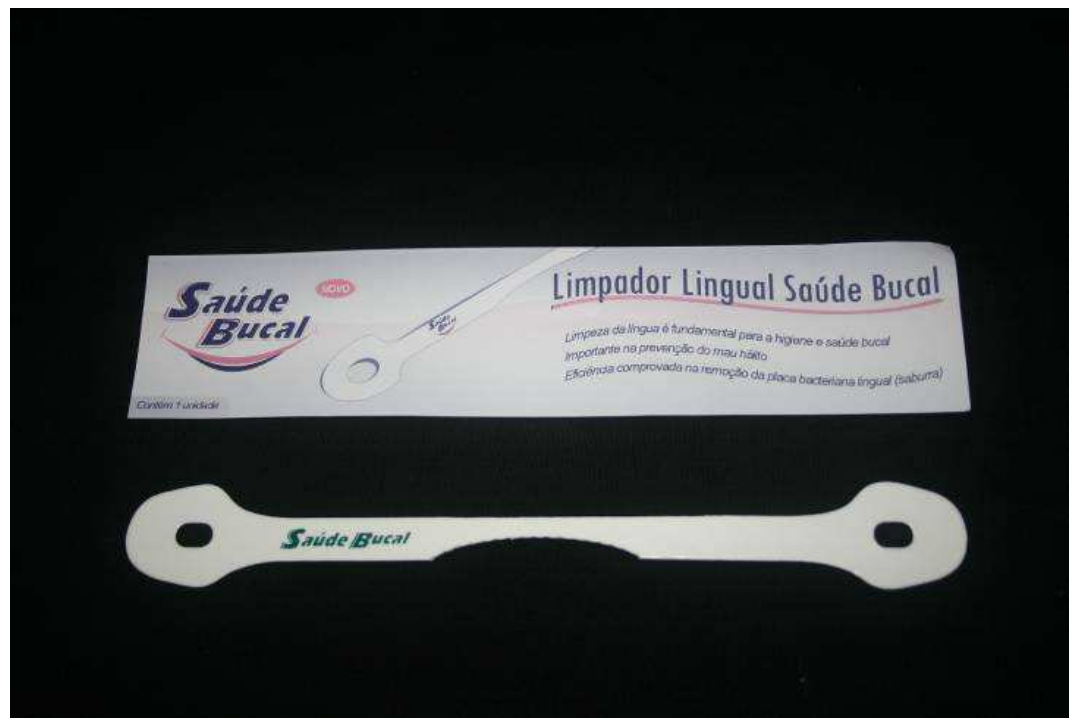

Figura 04 - Limpador lingual 


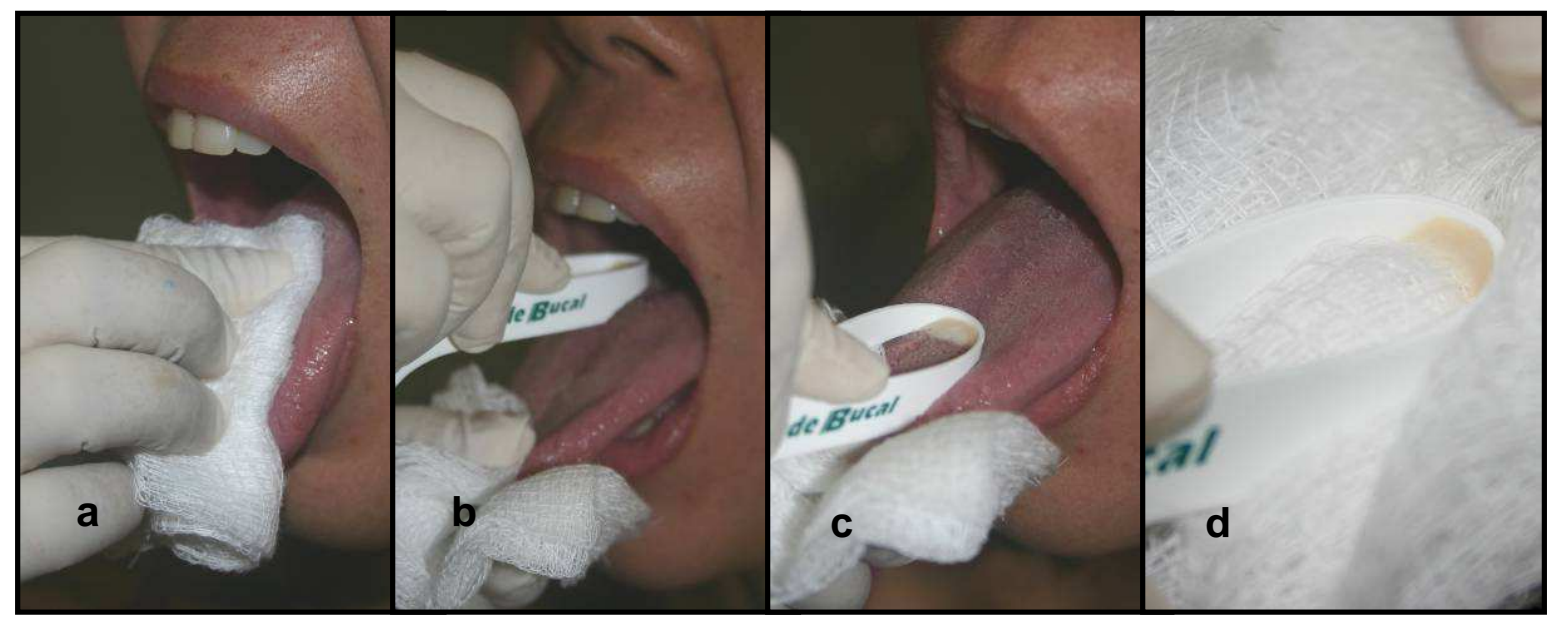

Figura 05 - a) Remoção do excesso de umidade da língua; b) Limpeza da língua; c) Presença da saburra após a limpeza; d) Saburra lingual.

Após a remoção da saburra, as medidas de hálito bucal foram tomadas novamente, para identificar alterações nas concentrações dos CSVs (compostos sulfurados voláteis).

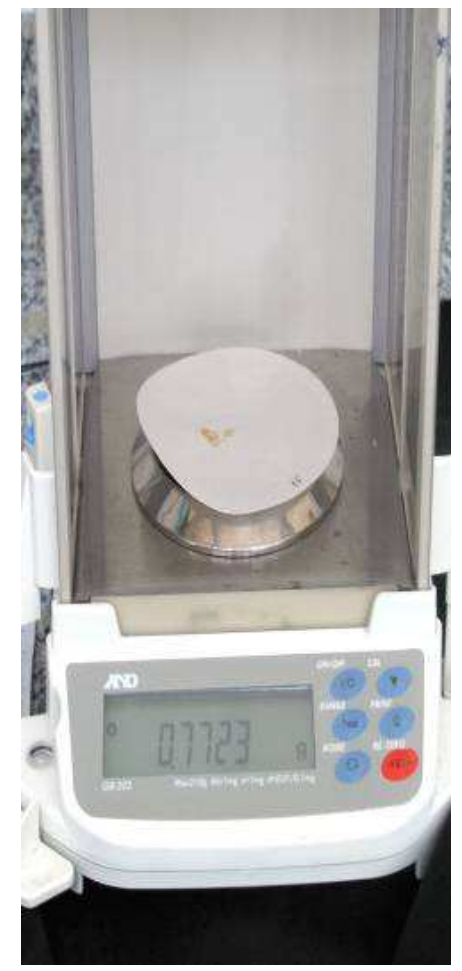

Figura 06 - Balança com a saburra seca no papel filtro para a pesagem. 


\section{9 - Teste BANA ${ }^{\mathrm{TM}}$ (benzoyl - DL - arginine - 2 napthylamide)}

Foi realizado com o objetivo de identificar uma possível relação entre a presença de microorganismos BANA positivos e os valores de halimetria. Para isso foi utilizado o teste BANA (figura 07). Uma pequena parte do material a ser colhido com o raspador lingual foi transferida para a fita de teste BANA ${ }^{\mathrm{TM}}$ com o auxílio de um escavador (Escovador ICE 17, Industria Brasileira) de dentina. Uma gota de água destilada foi derramada sobre o local do reagente, a fita dobrada e mantida desta forma com um clipe de papel, para que o reagente entrasse em contato com o material orgânico, permanecendo assim por 1 dia inteiro, conforme indicado pelo distribuidor (figura 08). Após esse período era observada a reação e obtido o resultado, classificado em negativo e positivo, de acordo com a coloração obtida.

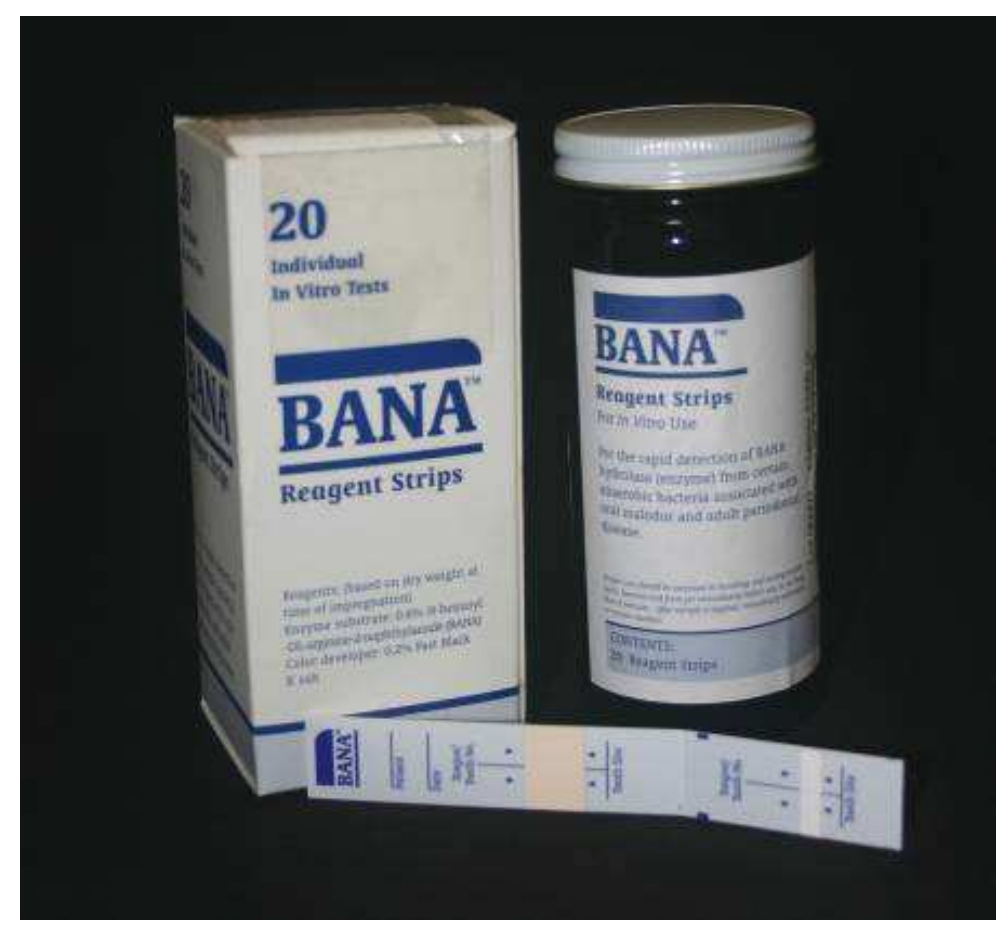

Figura 07 - Teste BANA 


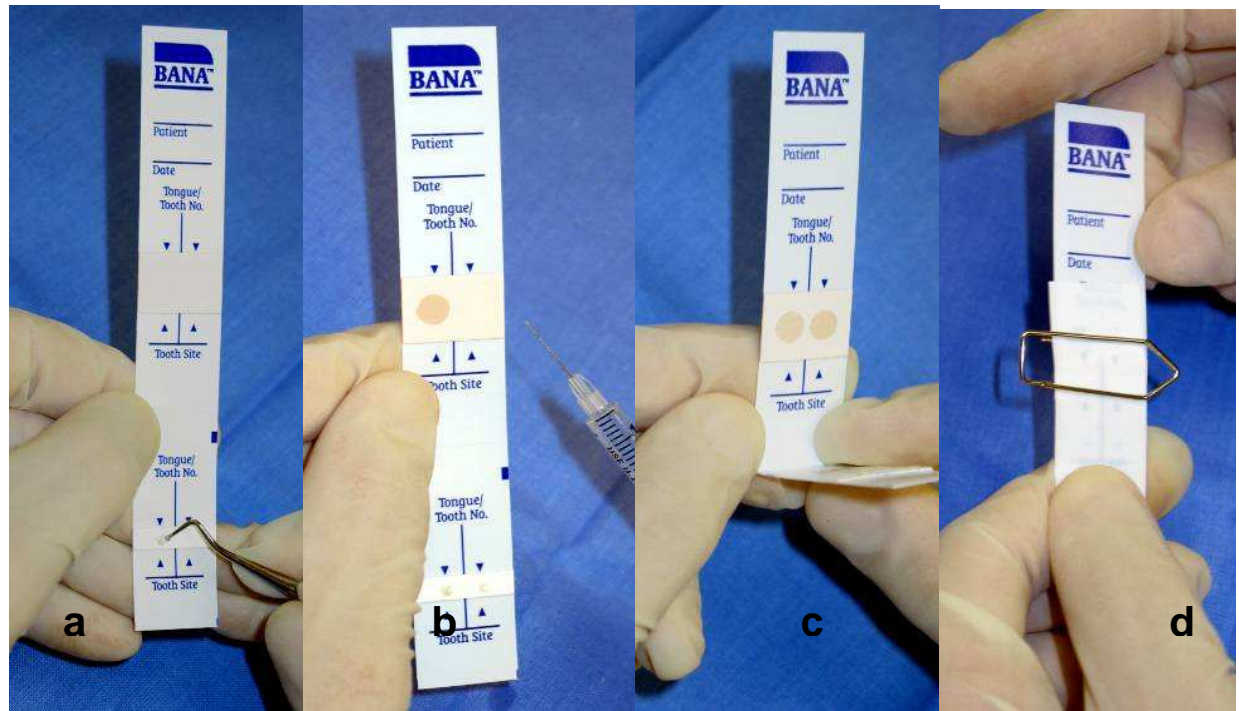

Figura 08 - a) colocação da saburra na fita teste com colher de dentina; b) colocação de água destilada na fita teste; c) dobragem da fita; d) fita presa com clipe de papel. Fonte: $\mathrm{AMADO}^{3}, 2003$.

\subsection{0 - Sialometria}

Cada paciente permaneceu por 5 minutos em repouso, com os olhos abertos, sem estimular a salivação, e verteu toda a saliva obtida em um recipiente de vidro (figura 09). Após isso cada paciente recebeu um pequeno pedaço de borracha de silicone hiperbolóide estéril. e descartável da marca Saúde bucal ${ }^{\circledR}$ (figura 10), o qual foi usado para estimular a salivação através da mastigação (fluxo salivar com estímulo) durante 5 minutos, vertendo toda a saliva obtida também em um recipiente de vidro (Saúde bucal ${ }^{\circledR}$ ) (figura 11). A quantidade de saliva, em ambos os testes, foi obtida com seringa plástica descartável de 5 mililitros. 


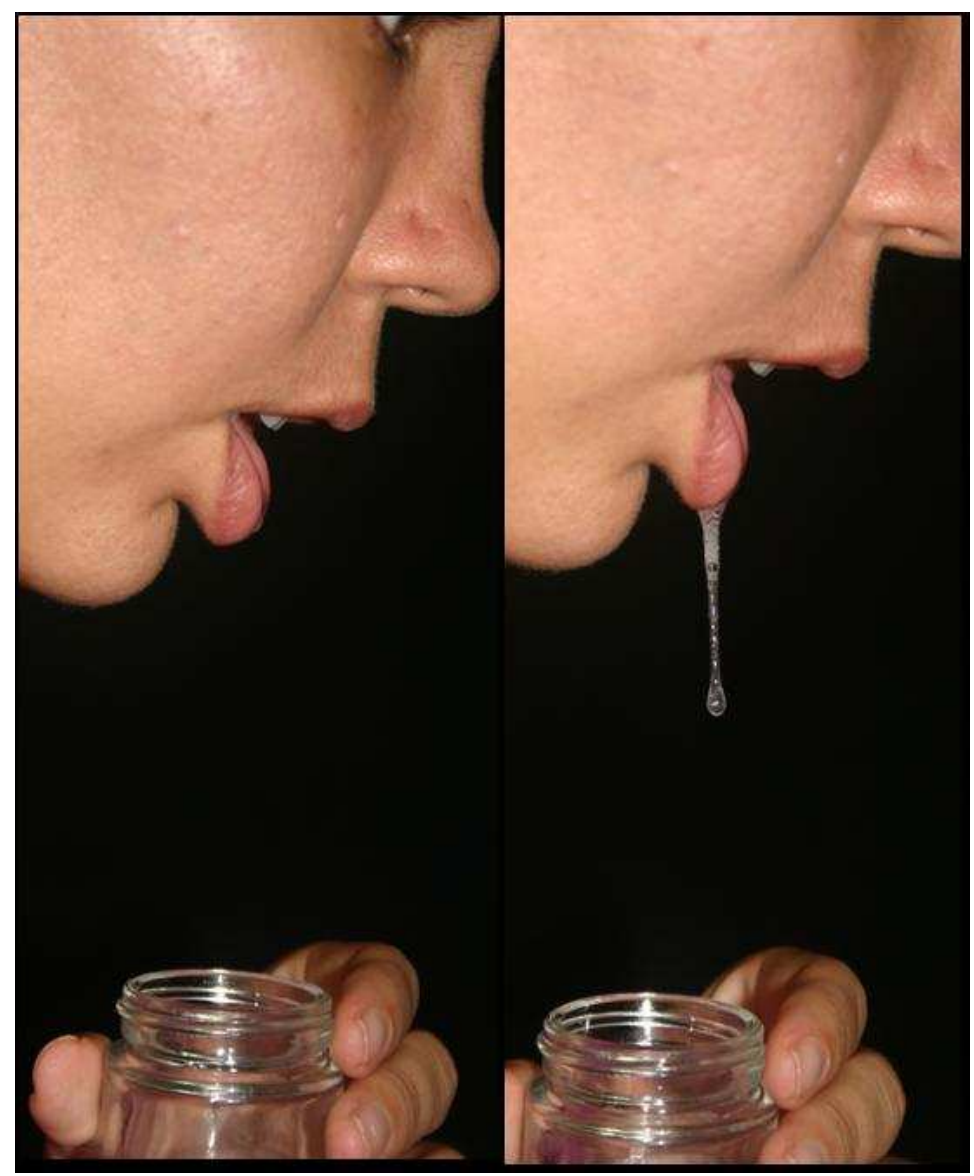

Figura 09 - Sialomeria em repouso

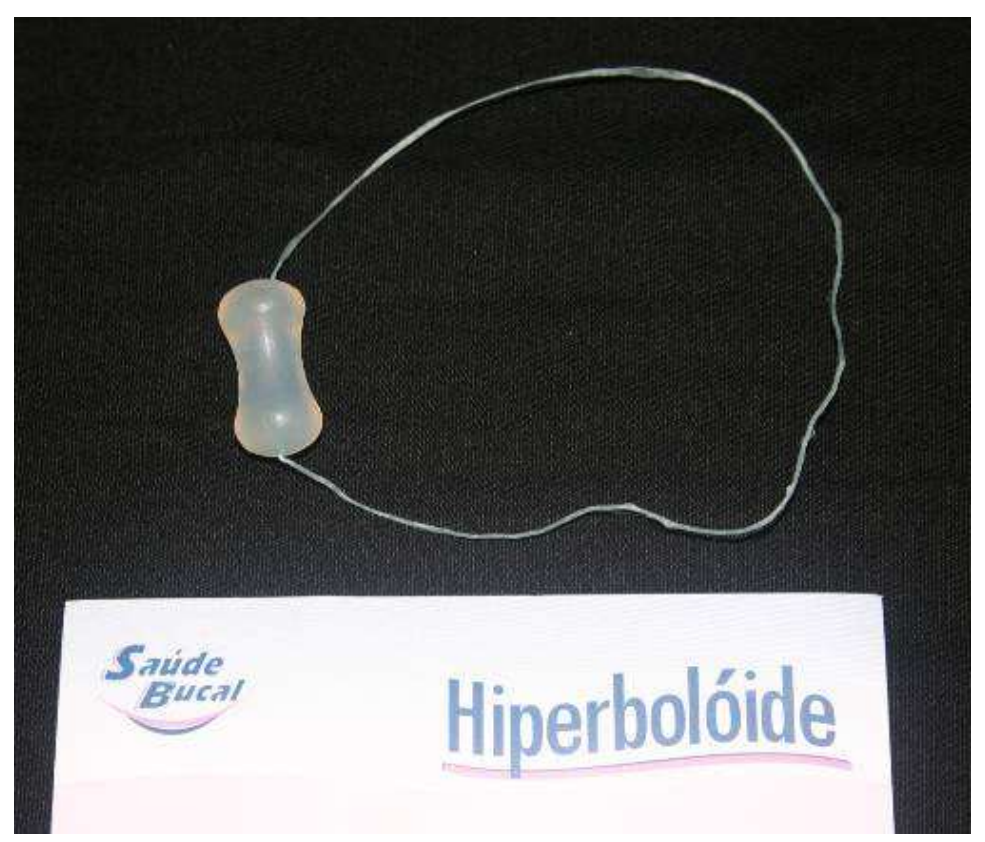

Figura 10 - Hiperbolóide. 


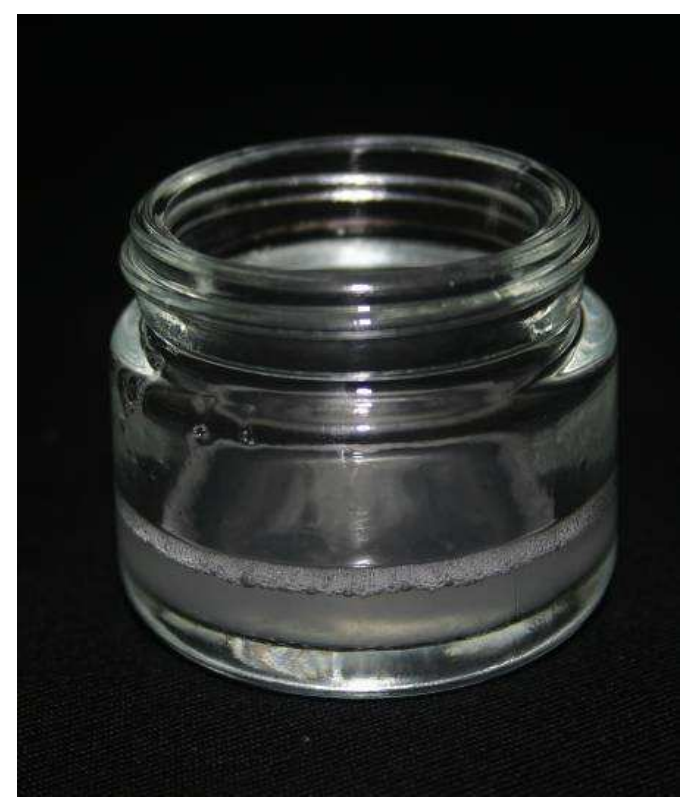

Figura 11 - Recipiente de vidro com a saliva coletada.

\subsection{1 - Protocolo do tratamento Radioterápico}

O protocolo de tratamento radioterápico foi o mesmo para todos os pacientes do grupo "radio". O paciente usava uma máscara facial para colimação do feixe de radiação, individualmente moldada, para reduzir a radiação desnecessária (figura 12).

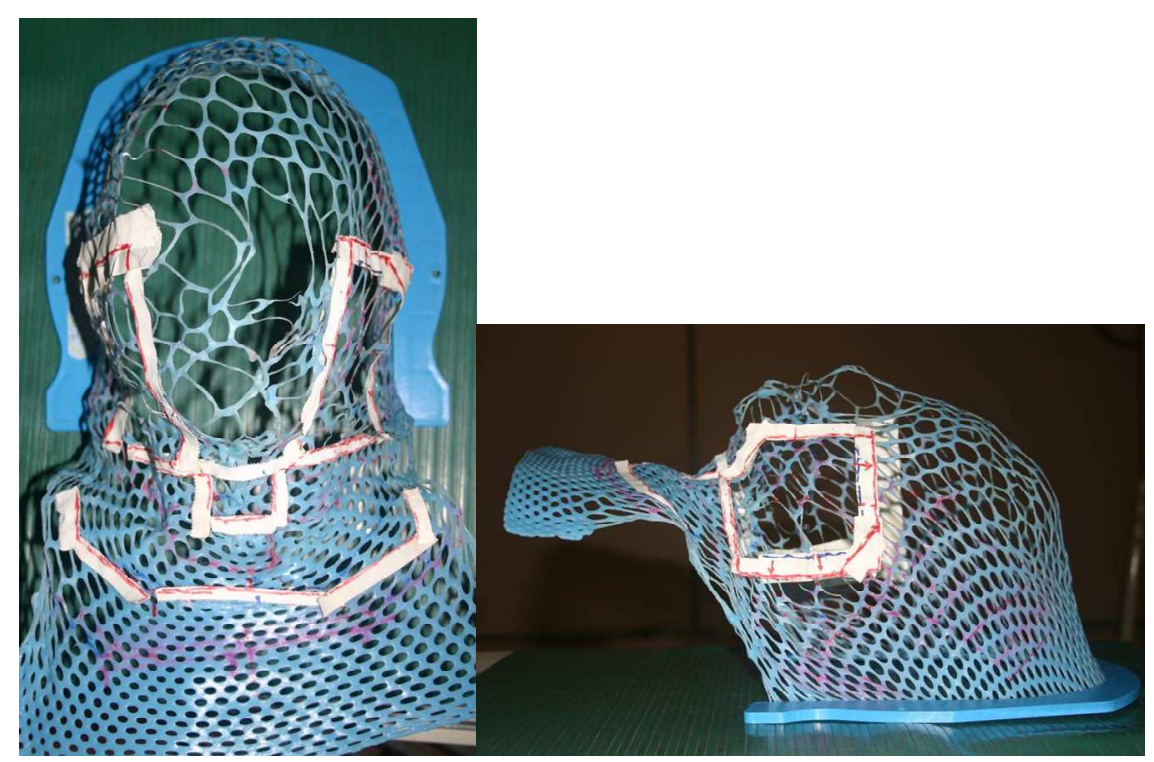

Figura 12 - Máscara facial com a área de radiação delimitada. 
O tratamento da radiação foi realizado no aparelho Theratron 80 (Atomic Energy of Canadá Limited) (figura 13). A dose total de radiação variou de 6480 cGy do máximo a, no mínimo, de 5040 cGy, com a média de 5463,2 cGy, fracionado em dose diária de 180 cGy, com números de dias variados individualmente para cada paciente.

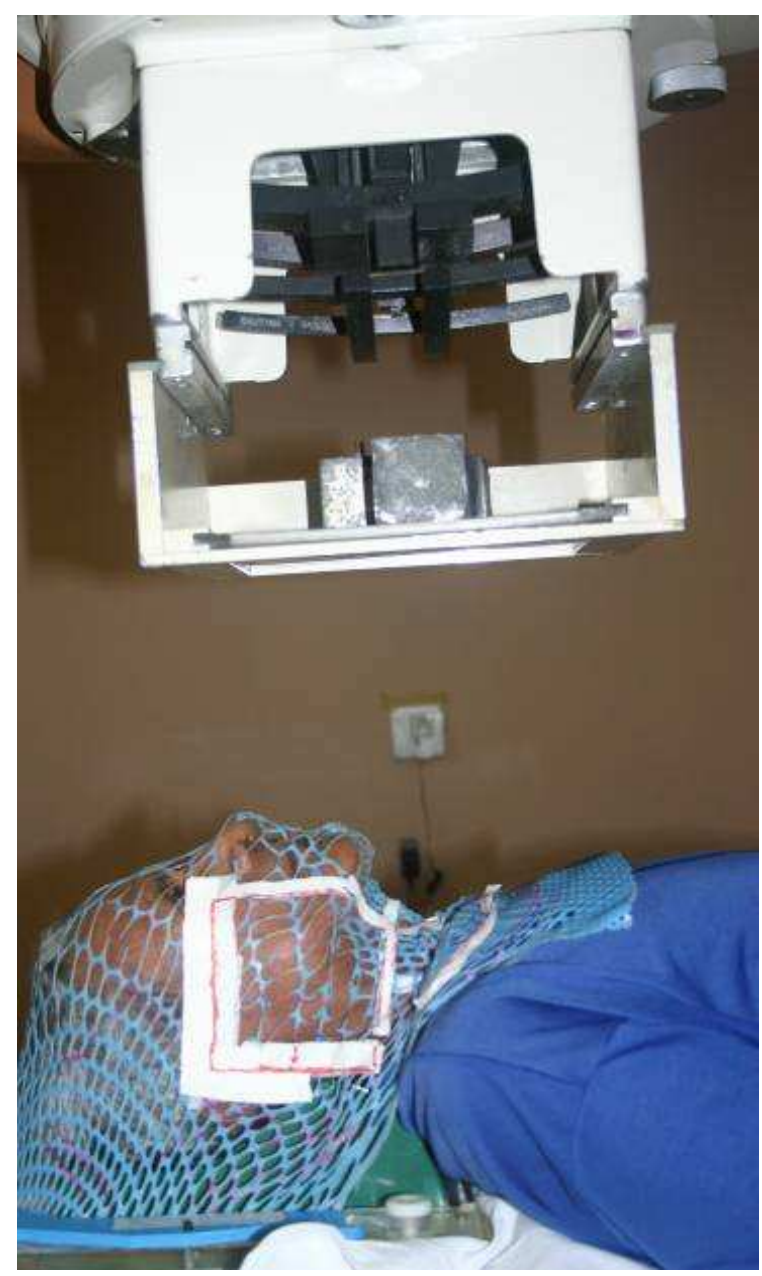

Figura 13 - Paciente posicionado no aparelho de radioterapia.

Todos os pacientes receberam a radiação diariamente em duas áreas, a fossa supraclavicular e o paralelo oposto. A primeira consiste de uma área com formato de um trapézio que se estende do terço inferior do pescoço até a região supraclavicular (figura 14). O paralelo oposto é constituído de duas áreas trapezionais iguais de lados opostos, que corresponde a uma área que vai da região infra-auricular até a asa do nariz, tangenciando o plano de Frankfurt no limite superior e no anterior da comissura labial até a ponta do mento, se estendendo para a região do pescoço com o limite inferior na altura 
do osso hióide (figura 15). O tamanho e a profundidade da área de incidência do feixe de radiação sofreram uma pequena variação para cada caso, dependendo das características do tumor. A dose e o fracionamento do tratamento eram individuais para cada caso e decidido pela equipe médica.

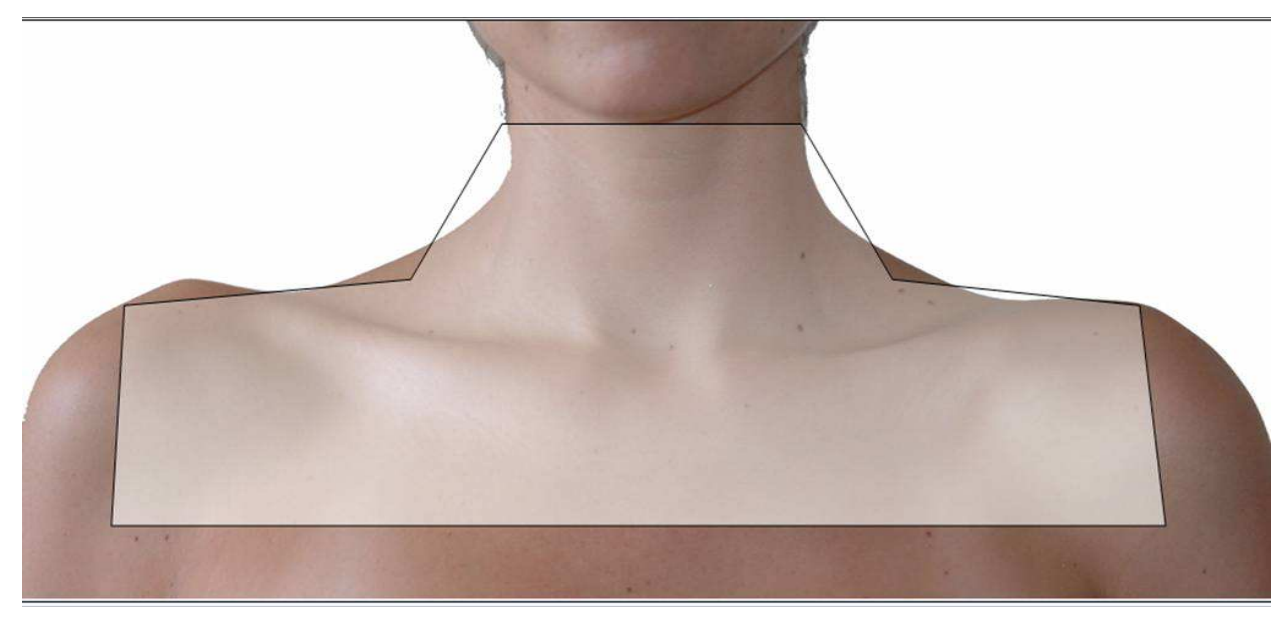

Figura 14 - Campo de irradiação (região supraclavicular).

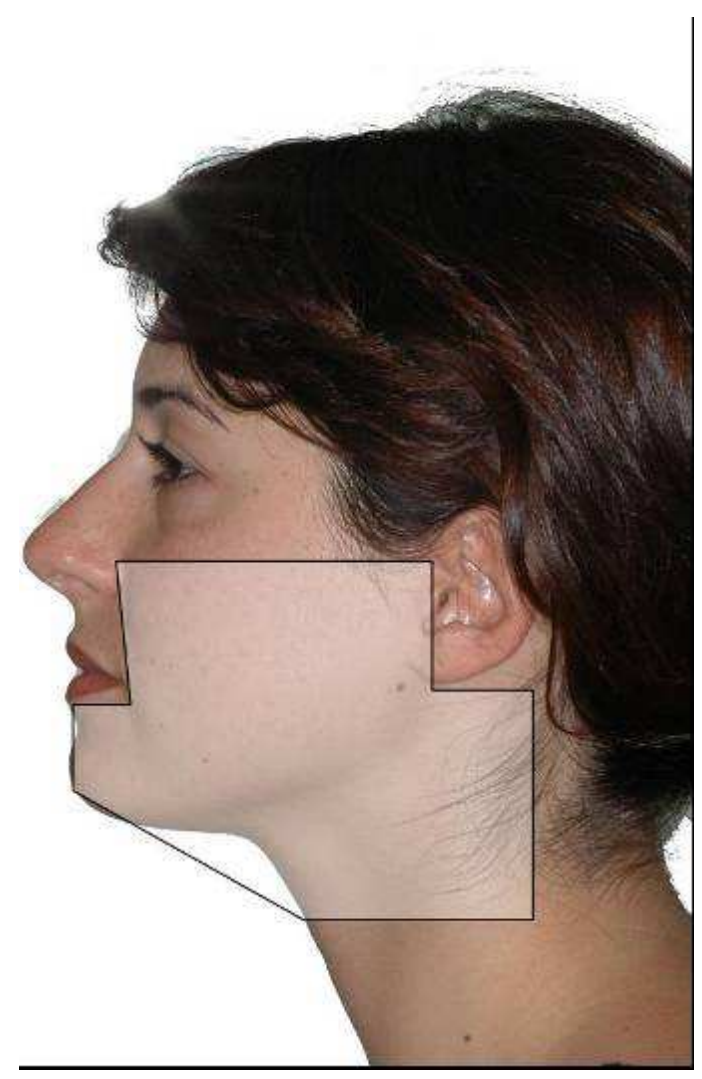

Figura 15 Campo de irradiação (paralelo oposto) que abrange as glândulas salivares. 
Esse é o protocolo utilizado para os pacientes do setor de radioterapia do Hospital Manuel de Abreu. Todos os pacientes selecionados tiveram pelo menos uma das glândulas salivares envolvidas na área de radiação.

\subsection{2 - Análise estatística}

Os resultados foram analisados utilizando o teste de análise de variância de um ou dois critérios, dependendo da situação, nas variáveis que quantificaram o hálito antes e após a remoção da saburra. Quando houve diferença significativa, foi realizado o teste de Tukey.

As relações entre halimetria bucal, peso seco da saburra, fluxo salivar com e sem estímulo, e a relação entre fluxo salivar em repouso e estimulado foram feitas através do teste de correlação de Pearson.

Para verificar correlações entre halimetria bucal inicial e teste BANA ${ }^{\mathrm{TM}}$ foi utilizado o teste "t" de Student. Em todos os casos foi adotado nível de significância de $5 \%$. 
"Só sabemos com exatidão quando sabemos pouco; à medida que vamos adquirindo conhecimentos, instala-se a dūvida." Goethe 



\section{5 - RESULTADOS}

A amostra constituiu de 48 pacientes divididos em três grupos: grupo I de pacientes normossistêmico com saúde oral, grupo II pacientes normossistêmico e com necessidades odontológicas, e grupo III pacientes que tinham sido submetidos à radioterapia na região de cabeça e pescoço.

Todos esses pacientes do grupo "radio" haviam tido câncer na região de cabeça e pescoço, foram submetidos à radioterapia e já haviam concluído o tratamento. Os tumores que acometeram o grupo foi carcinoma espinocelular (22) ou adenocarcinoma (3) em diferentes localizações: laringe (6), faringe (4), glândula parótida (3), fossa amigdaliana (2), prega vocal (1), língua (1), mucosa jugal (1), assoalho de boca (1)

Para avaliar os resultados serão utilizadas as seguintes abreviaturas a seguir:

HI- halimetria inicial (ppb)

HF- $\quad$ halimetria após a remoção da saburra (ppb)

SAB- $\quad$ peso seco da saburra $(\mathrm{mg})$

SREP- fluxo salivar em repouso $(\mathrm{ml})$

SEST- fluxo salivar com estímulo (ml)

Tabela 01 Resultado da média e desvio padrão dos grupos I, II, III em relação as variáveis $\mathrm{HI}, \mathrm{HF}, \mathrm{SAB}$, SREP, SEST.

\begin{tabular}{c|l|l|l|l|l|l}
\hline \multirow{2}{*}{ Variáveis } & \multicolumn{2}{|c|}{ Saúde } & \multicolumn{2}{c|}{ N.O. } & \multicolumn{2}{c}{ Radio } \\
\cline { 2 - 7 } & Média & D. P. & Media & DP & Média & DP \\
\hline HI & 65,133 & 28,03 & 148,102 & 60,324 & 143,747 & 62,092 \\
\hline HF & 50,4 & 24,95 & 137,846 & 57,887 & 123,453 & 49,670 \\
\hline SAB & 0,0179 & 0,007 & 0,02455 & 0,009 & 0,016 & 0,017 \\
\hline SREP & 3,33 & 1,365 & 4,269 & 1,386 & 1,448 & 1,015 \\
\hline SEST & 8,46 & 2,307 & 9,085 & 1,664 & 2,548 & 1,660 \\
\hline
\end{tabular}


Foi utilizada análise de variância (ANOVA) de acordo com o critério avaliado para cada situação e quando houve diferença estatisticamente significante $(p<0,05)$, foi aplicado o Teste de Tukey.

Valores em negrito foram estatisticamente significantes para $p<0,05$.

Tabela 2. Resultado da análise de variância a dois critérios. Comparação da halitose entre os grupos "radio", saúde, N.O. e fases HI e HF.

\begin{tabular}{l|c|c|c|c|c|c}
\cline { 2 - 7 } & $\begin{array}{c}\text { GL } \\
\text { Efeito }\end{array}$ & $\begin{array}{c}\text { QM } \\
\text { Efeito }\end{array}$ & $\begin{array}{c}\text { GL } \\
\text { Erro }\end{array}$ & $\begin{array}{c}\text { QM } \\
\text { Erro }\end{array}$ & $\mathbf{F}$ & $\mathbf{p}$ \\
\hline Grupos & 2 & 50209,9 & 45 & 5201,7 & 9,652 & $\mathbf{0 , 0 0 0}$ \\
\hline Fase & 1 & 4726,4 & 45 & 316,0 & 14,956 & $\mathbf{0 , 0 0 0}$ \\
\hline Interação & 2 & 224,3 & 45 & 316,0 & 0,709 & 0,497 \\
\hline
\end{tabular}

Tabela 3. Resultado do Teste de Tukey para do os grupos "radio", Saúde e N.O. em relação às fases HI e HF.

\begin{tabular}{l|c|c|}
\cline { 2 - 3 } \multicolumn{1}{c|}{} & Saúde & N.O. \\
\hline Radio & $\mathbf{0 , 0 0 0}$ & 0,853 \\
\hline Saúde & & $\mathbf{0 , 0 0 0}$ \\
\hline
\end{tabular}

Tabela 4. Resultado do teste de análise de variância a um critério. Comparação da saburra entre os grupos "radio", saúde, N.O.

\begin{tabular}{c|c|c|c|c|c|c}
\cline { 2 - 7 } & $\begin{array}{c}\text { GL } \\
\text { Efeito }\end{array}$ & $\begin{array}{c}\text { QM } \\
\text { Efeito }\end{array}$ & $\begin{array}{c}\text { GL } \\
\text { Erro }\end{array}$ & $\begin{array}{c}\text { QM } \\
\text { Erro }\end{array}$ & F & p \\
\hline Grupos & 2 & 0,0003 & 45 & 0,0001 & 1,804 & 0,176 \\
\hline
\end{tabular}

Tabela 5. Resultado do teste de análise de variância a um critério. Comparação da SREP entre os grupos "radio", saúde, N.O.

\begin{tabular}{c|c|c|c|c|c|c}
\cline { 2 - 7 } & $\begin{array}{c}\text { GL } \\
\text { Efeito }\end{array}$ & $\begin{array}{c}\text { QM } \\
\text { Efeito }\end{array}$ & $\begin{array}{c}\text { GL } \\
\text { Erro }\end{array}$ & $\begin{array}{c}\text { QM } \\
\text { Erro }\end{array}$ & $\mathbf{F}$ & $\mathbf{p}$ \\
\hline Grupos & 2 & 37,364 & 45 & 1,434 & 26,047 & $\mathbf{0 , 0 0 0}$ \\
\hline
\end{tabular}

Tabela 6. Resultado do Teste de Tukey para do os grupos "radio", Saúde e N.O., em relação à SREP.

\begin{tabular}{l|c|c|}
\cline { 2 - 3 } \multicolumn{1}{c|}{} & Saúde & N.O. \\
\hline Radio & $\mathbf{0 , 0 0 2}$ & $\mathbf{0 , 0 0 0}$ \\
\hline Saúde & & 0,197 \\
\hline
\end{tabular}


Tabela 7. Resultado da análise de variância a um critério. Comparação entre a amostra (grupos "radio", saúde, N.O.) e SEST.

\begin{tabular}{c|c|c|c|c|c|c}
\cline { 2 - 7 } & $\begin{array}{c}\text { GL } \\
\text { Efeito }\end{array}$ & $\begin{array}{c}\text { QM } \\
\text { Efeito }\end{array}$ & $\begin{array}{c}\text { GL } \\
\text { Erro }\end{array}$ & $\begin{array}{c}\text { QM } \\
\text { Erro }\end{array}$ & $\mathbf{F}$ & $\mathbf{p}$ \\
\hline Grupos & 2 & 236,198 & 45 & 3,275 & 72,117 & $\mathbf{0 , 0 0 0}$ \\
\hline
\end{tabular}

Tabela 8. Resultado do Teste de Tukey para do os grupos "radio", Saúde e N.O., em relação à SREP.

\begin{tabular}{l|c|c|}
\cline { 2 - 3 } \multicolumn{1}{c|}{} & Saúde & N.O. \\
\hline Radio & $\mathbf{0 , 0 0 0}$ & $\mathbf{0 , 0 0 0}$ \\
\hline Saúde & & 0,722 \\
\hline
\end{tabular}

As avaliações dos parâmetros avaliados neste estudo estão apresentadas nas tabelas seguintes. Sempre que houver resultado estatisticamente significante quanto ao teste de correlação de Pearson, um gráfico será apresentado, para uma melhor compreensão.

Tabela 9. Resultados do teste de correlação de Pearson entre as variáveis com possíveis relações causais com a halitose, na amostra.

\begin{tabular}{c|c|c}
\hline VARIÁVEIS & r & P \\
\hline HI X SAB & 0,401 & $\mathbf{0 , 0 0 5}$ \\
\hline HI X SREP & 0,082 & 0,578 \\
\hline HI X SEST & 0,025 & 0,079 \\
\hline HI X HF & 0,922 & $\mathbf{0 , 0 0 0}$ \\
\hline SAB X SREP & 0,175 & 0,234 \\
\hline SAB X SEST & 0,171 & 0,245 \\
\hline SREP X SEST & 0,831 & $\mathbf{0 , 0 0 0}$ \\
\hline
\end{tabular}

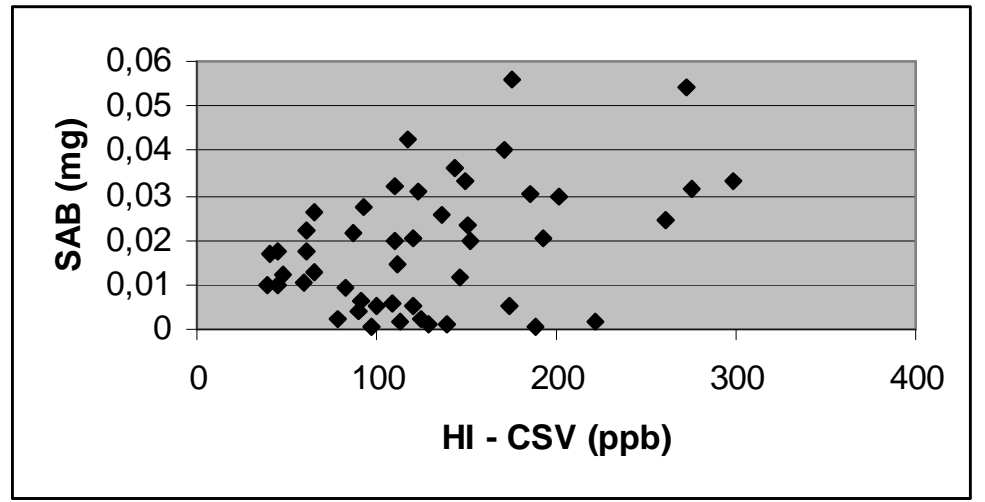

FIGURA 16 - Gráfico da dispersão entre $\mathrm{H} 1$ e SAB da amostra total. 


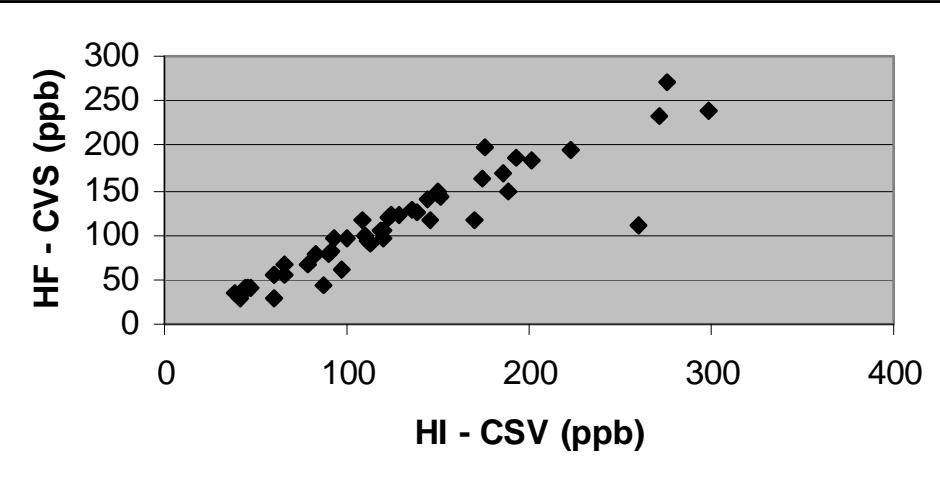

FIGURA 17 - Gráfico da dispersão entre $\mathrm{HI}$ e HF da amostra total.

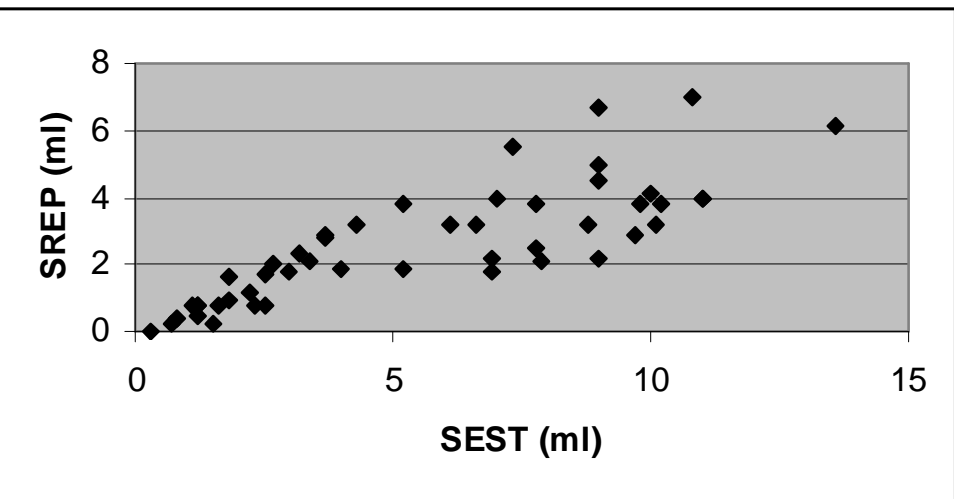

FIGURA 18 - Gráfico de dispersão entre SREP e SEST da amostra total.

Tabela 10. Resultados do teste de correlação de Pearson entre as variáveis com possíveis relações causais com a halitose, no grupo "radio".

\begin{tabular}{c|c|c}
\hline VARIÁVEIS & $\mathbf{r}$ & $\mathbf{P}$ \\
\hline HI $\times$ SAB & 0,407 & $\mathbf{0 , 0 4 3}$ \\
\hline HI $\times$ SREP & 0,021 & 0,918 \\
\hline HI $\times$ SEST & 0,197 & 0,344 \\
\hline HI $\times$ HF & 0,861 & $\mathbf{0 , 0 0 0}$ \\
\hline SAB X SREP & 0,069 & 0,740 \\
\hline SAB x SEST & 0,172 & 0,411 \\
\hline SREP x SEST & 0,882 & $\mathbf{0 , 0 0 0}$ \\
\hline
\end{tabular}

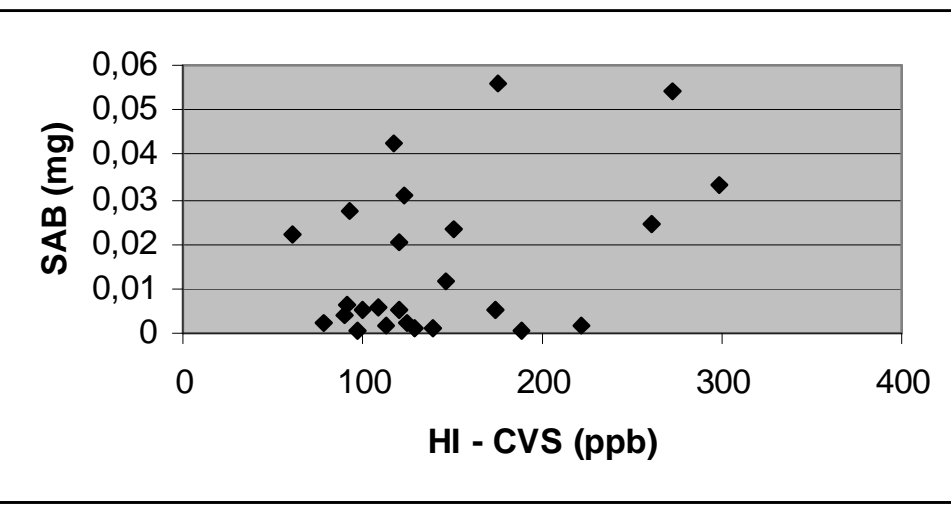

FIGURA 19 - Gráfico de dispersão entre $\mathrm{HI}$ e SAB do grupo radio. 


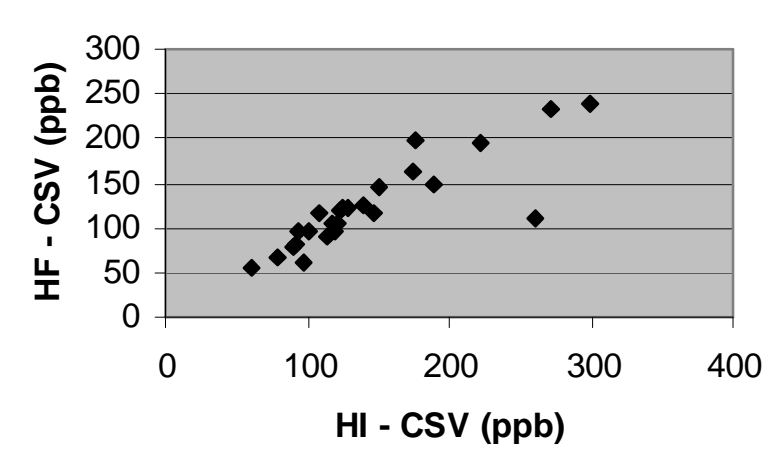

FIGURA 20 - Gráfico da dispersão entre $\mathrm{HI}$ e HF do grupo radio.

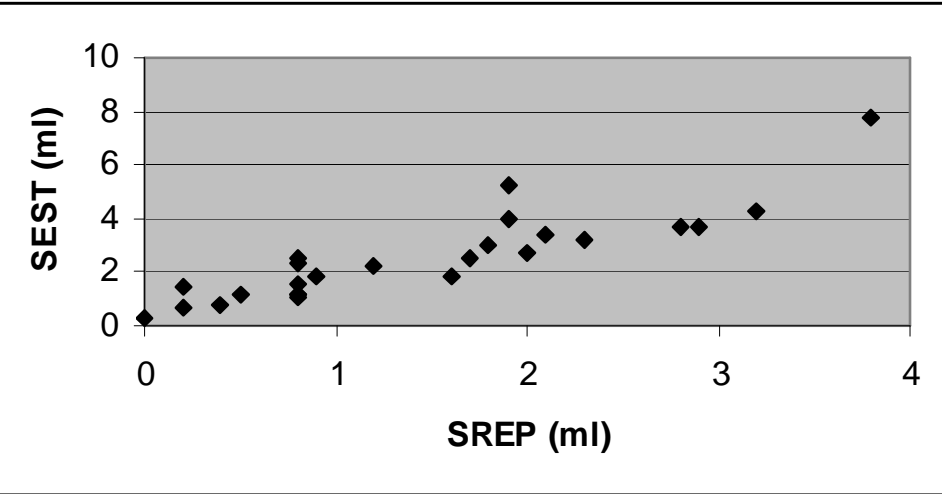

FIGURA 21 - Gráfico da de dispersão entre SREP e SEST do grupo radio.

Tabela 11. Resultados do teste de correlação de Pearson entre as variáveis com possíveis relações causais com a halitose, no grupo Saúde.

\begin{tabular}{c|c|c}
\hline VARIÁVEIS & $\mathbf{r}$ & $\mathbf{P}$ \\
\hline HI x SAB & 0,598 & 0,067 \\
\hline HI $\times$ SREP & 0,457 & 0,183 \\
\hline HI x SEST & 0,317 & 0,371 \\
\hline HI x HF & 0,874 & $\mathbf{0 , 0 0 1}$ \\
\hline SAB X SREP & 0,046 & 0,900 \\
\hline SAB x SEST & 0,026 & 0,943 \\
\hline SREP x SEST & 0,801 & $\mathbf{0 , 0 0 5}$ \\
\hline
\end{tabular}

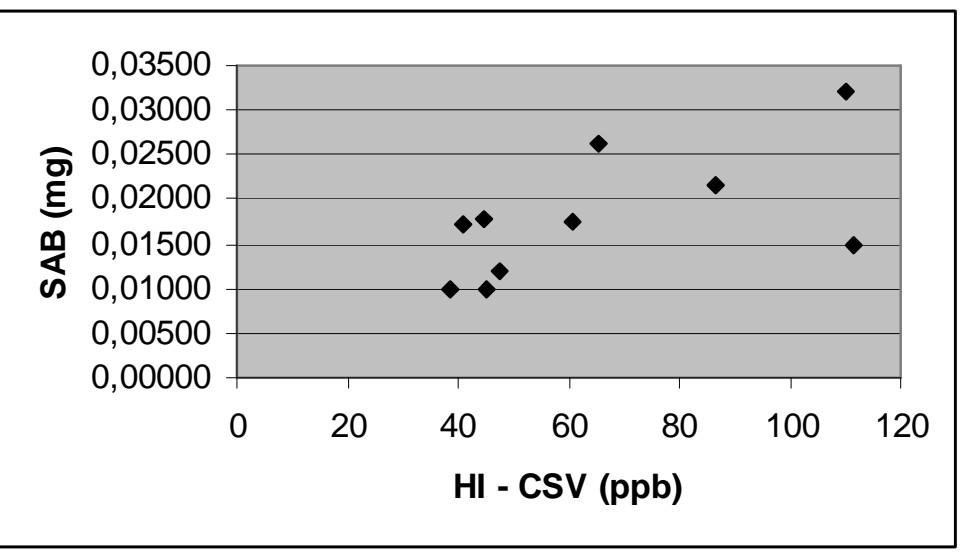

FIGURA 22 - Gráfico da dispersão entre HI e SAB do grupo saúde. 


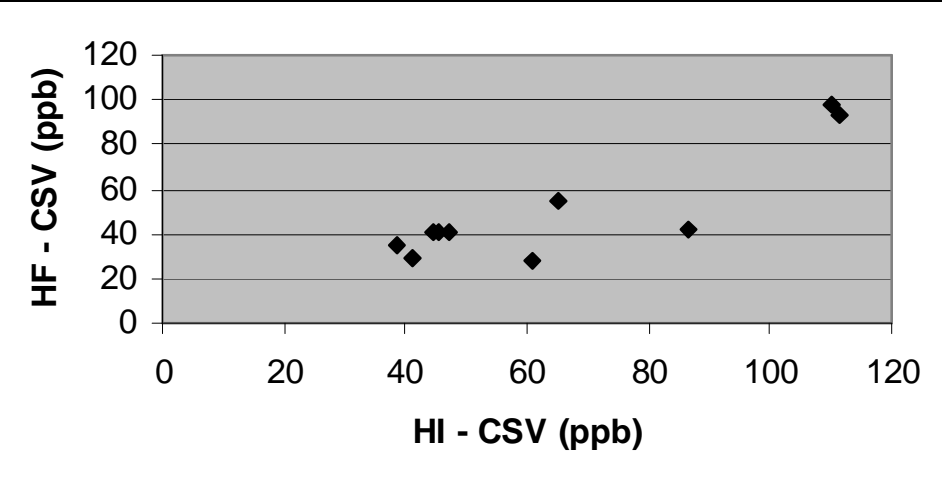

FIGURA 23 - Gráfico de dispersão entre HI e HF do grupo saúde.

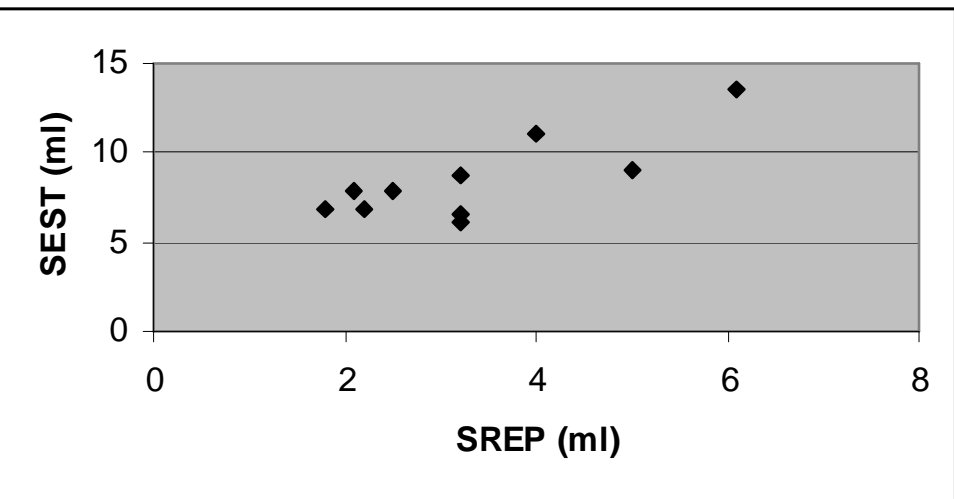

FIGURA 24 - Gráfico de dispersão entre SREP e SEST do grupo saúde.

Tabela 12. Resultados do teste de correlação de Pearson entre as variáveis com possíveis relações causais com a halitose, no grupo N.O.

\begin{tabular}{c|c|c}
\hline VARIÁVEIS & $\mathbf{r}$ & $\mathbf{P}$ \\
\hline HI $\times$ SAB & 0,672 & $\mathbf{0 , 0 1 2}$ \\
\hline HI X SREP & 0,238 & 0,434 \\
\hline HI $\times$ SEST & 0,037 & 0,904 \\
\hline HI X HF & 0,971 & $\mathbf{0 , 0 0 0}$ \\
\hline SAB X SREP & 0,132 & 0,668 \\
\hline SAB X SEST & 0,269 & 0,374 \\
\hline SREP $\times$ SEST & 0,049 & 0,873 \\
\hline
\end{tabular}

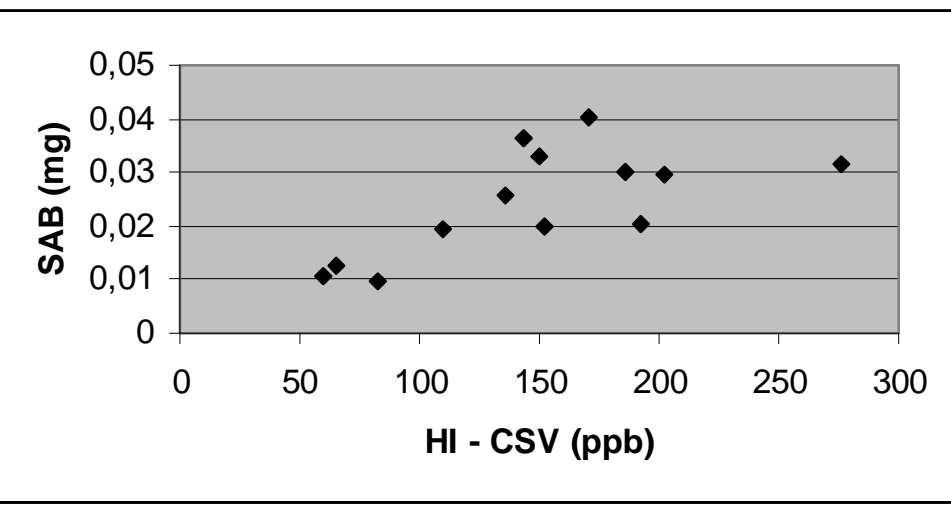

FIGURA 25 - Gráfico de dispersão entre $\mathrm{HI}$ e SAB, do grupo N.O. 


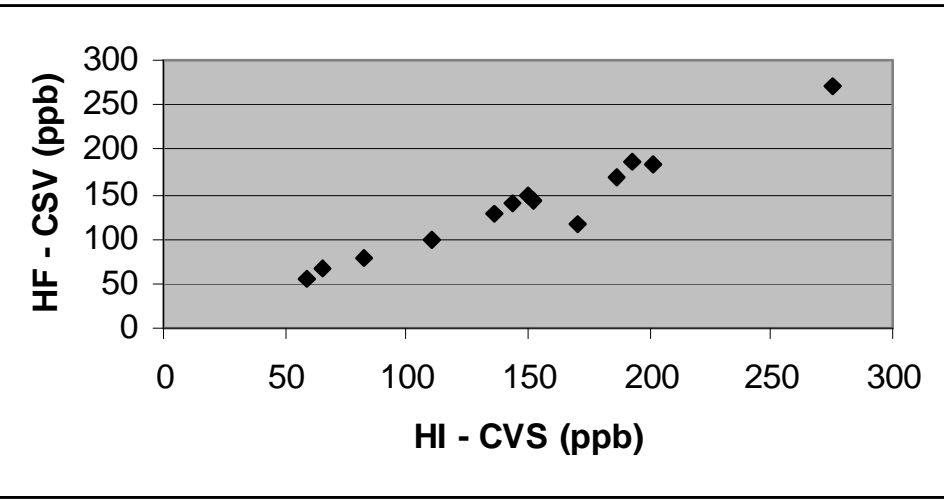

FIGURA 26 - Gráfico da dispersão entre $\mathrm{HI}$ e HF do grupo N.O.

Tabela 13. Resultado do teste de " $\mathrm{t}$ " de Student, aplicado para comparação entre a halimetria e entre os grupos positivos e negativos para 0 teste BANA.

\begin{tabular}{l|c|c|c|c|c|c}
\cline { 2 - 5 } & \multicolumn{2}{c|}{ Negativo } & \multicolumn{2}{c|}{ Positivo } & \multirow{2}{*}{ T } & p \\
\cline { 2 - 5 } & média & D.P. & média & D.P. & T & $\mathbf{0 , 0 0 3}$ \\
\hline Todos & 104,1 & 51,2 & 157,3 & 67,1 & $-3,10$ & $0,1,58$ \\
\hline Radio & 128,1 & 45,6 & 167,1 & 77,6 & $-1,58$ & 0,126 \\
\hline Saúde & 47,0 & 9,4 & 92,2 & 23,9 & $-4,25$ & $\mathbf{0 , 0 0 2}$ \\
\hline N.O. & 100,7 & 44,1 & 177,7 & 50,2 & $-2,80$ & $\mathbf{0 , 0 1 7}$ \\
\hline
\end{tabular}



"Podes dizer-me, por favor, que caminho devo seguir para sair daqui?

- Isso depende muito de para onde queres

$$
\text { ir - respondeu o gato. }
$$

-Preocupa-me pouco aonde ir - disse

\section{Alice.}

-Nesse caso, pouco importa o caminho que sigas - replicou o gato." (Lewis Carroll-Alice no País das Maravilhas)

\section{Discussão}





\section{6 - DISCUSSÃO}

Apesar dos avanços científicos da medicina, campanhas de prevenção e tratamento precoce das neoplasias malignas, as estimativas de novos casos ainda são altas, tanto no Brasil como em outros países. O câncer na região de cabeça e pescoço é responsável por um número acentuado de pacientes submetidas à cirurgia, radioterapia e a quimioterapia.

Ainda nos dias atuais, os principais meios terapêuticos no controle dos tumores malignos de cabeça e pescoço são a cirurgia, a radioterapia e a quimioterapia, quer isoladamente ou associadas entre si. (HERCHENHORN ${ }^{41}$, 2004)

Entretanto, esses tratamentos, na maioria das vezes, interferem na qualidade de vida dos pacientes que a eles são submetidos.

Os efeitos adversos da radioterapia são variados e muitas revisões são encontradas na literatura buscando elucidar a importância do cirurgião-dentista no controle, prevenção e tratamento desses efeitos.

Os efeitos podem ser divididos em agudos ou crônicos (ALMEIDA ${ }^{2}$, 2004). Os agudos são: mucosite (BORAKS, CHILVARQUE, PANELLA ${ }^{11}, 2000$; HANDSCHEL ${ }^{40}$ et al.,2001), disgeusia (VISSINK $\left.{ }^{96}, 2003\right)$, disfagia, (VISSINK ${ }^{96}$, 2003), infecções oportunistas, xerostomia(VISSINK ${ }^{96}$, 2003), Os crônicos ou tardios são: cárie de radiação (VISSINK ${ }^{96}$, 2003), osteorradionecrose (VISSINK ${ }^{96}$, 2003), trismo. A hipossalivação é um efeito que se inicia durante a radioterapia e se estende por um longo tempo, sendo considerado, tanto efeito agudo, quanto tardio.

Não foram encontrados, na literatura pesquisada, relados da halitose como efeito adverso da radioterapia na região de cabeça e pescoço, quer de forma direta ou indireta, o que justificou a origem dessa pesquisa.

Por muitos anos a halitose tem sido estudada pela sua grande influência negativa na qualidade de vida e socialização do paciente. A relação de odores orais com os aspectos sociais sempre foi um fator de preocupação para a sociedade que, procurando mascará-los, se utilizava de diversos artifícios e substâncias. Estima-se que o mau odor seja um obstáculo para a plenitude da vivência conjugal. (TARZIA $\left.{ }^{87}, 2004\right)$. 
Vários estudos (TARZIA ${ }^{87}$, 2004; LOESCHE ${ }^{51}, 2003$; GREIN ${ }^{36}$, 2002; SCULLY $^{77}$, 1997; BOGDASARIAN ${ }^{8}$, 1986; TONZETICH ${ }^{92}$, 1977) concordam que a halitose origina de causas orais e que apenas de 10 a $20 \%$ dos casos são não-orais. Na boca, as bactérias anaeróbicas degradam aminoácidos, liberando os compostos de enxofre voláteis (CSV), como sulfeto de hidrogênio e metil mercaptana, que geram um odor desagradável.

A etiologia multifatorial da halitose torna o estudo nesta área complexo. O mau hálito é comumente resultado da putrefação microbiana de partículas, tais como: alimentos, células, saliva, descamação epitelial e sangue na boca. A lise de proteínas, reduzidas a peptídeos e aminoácidos e, em seguida, a substratos com grupos tióis livres, como cisteína e glutationa reduzida, originam os CSVs. A intensidade do mau hálito está significantemente relacionada com o aumento nos níveis intra-bucais dos CSVs (ROSENBERG; MCCULLOCH ${ }^{71}$, 1992). Os compostos voláteis não sulfurados, incluindo acetona, acetaldeído, etanol, propanol e diacil, podem estar envolvidos na formação do hálito, assim como a cadaverina, uma diamina volátil produto de degradação da saliva que é originada pela descarboxilação da lisina (SCULLY ${ }^{77}$ et al., 1997), e pode ser um importante componente do mau cheiro.

A halitose é um assunto recorrente na literatura; no entanto, ainda há muita desinformação por parte dos médicos, cirurgiões-dentistas e pacientes sobre suas características, etiologia e tratamento. A halitose não deve ser tratada como assunto para cosmético, pois segundo MARCU ${ }^{54}, 1979$, SPRINGFIELD ${ }^{83}$, 2001 e RATCLIFF; JOHNSON ${ }^{67}$, 1999, evidências indicam que muitos membros da família dos CSVs são tóxicos aos tecidos bucais, mesmo em baixas concentrações

\section{1 - Delineamento do estudo}

A halitose pode ser separada em fisiológica e patológica. Existem mudanças normais do hálito durante o dia e múltiplas causas podem ser descritas para estas mudanças. (TARZIA $\left.{ }^{88}, 2003\right)$ A halitose matinal acomete grande parte da população e provavelmente ocorre devido à quase total cessação de fluxo salivar durante o sono e ao acúmulo e putefração de células epiteliais descamadas, alimento e saliva. O comer e ou escovar os dentes são 
o suficiente para remover esse tipo de halitose. (LU $\left.{ }^{52}, 1982\right)$. LU ${ }^{52}$, em 1982, relata que uma outra razão para o hálito desagradável ao acordar é a leve hipoglicemia devida ao longo período sem alimentação.

A halitose patológica tem, em sua maioria, causas bucais. Há inúmeros fatores tanto intra como extra-orais que podem ser identificados como contribuinte da halitose. A halitose originada da cavidade bucal pode estar associada com a má higiene oral (SCULLY \& ROSEMBERG ${ }^{79}$, 2003), placa dental (SCULLY \& ROSEMBERG $\left.{ }^{79}, 2003\right)$, cáries extensas, restaurações mal adaptadas, próteses porosas não higienizadas, impacção alimentar (SANZ, ROLDAN, HERRERA ${ }^{74}, 2001$; SCULLY \& ROSEMBERG ${ }^{79}$, 2003), gengivite (MORITA, WANG ${ }^{62,}$ 2001; MORITA, WANG ${ }^{63}$, 2001; SCULLY \& ROSEMBERG ${ }^{79}$, 2003), periodontite (MORITA, WANG ${ }^{62}$, 2001; MORITA, WANG $^{63}, 2001$; SCULLY \& ROSEMBERG ${ }^{79}, 2003$ ), estomatites (SCULLY \& ROSEMBERG ${ }^{79}$, 2003, DURHAM, MALLOY, HODGES ${ }^{26}$, 1993), saburra lingual (TARZIA ${ }^{88}$, 2003; YAEGAKI; SANADA ${ }^{100}, 1992$; SEEMANN ${ }^{80}$, et al. 2001) e tumores. As causas não orais podem estar associadas a infecções nasais, sinusite crônica, corpos estranhos nas vias aéreas (BENNETT $\left.{ }^{7}, 1988\right)$. $\mathrm{E}$ a halitose pode indicar alterações sistêmicas, tais como diabetes mellitus, cirrose hepática, uremia, falência dos rins, sífilis e outros.

O sulfidreto e outros compostos voláteis de enxofre (metil mercaptanas, dimetilsufeto) são os principais responsáveis pelo hálito forte e desagradável que se forma na boca.

Pesquisas demonstraram uma relação positiva entre as medidas organolépticas do hálito e os valores de CSVs, obtidos através de monitor de sulfetos (MORITA; MUSINSKY; WANG ${ }^{61}$, 2001; OHO ${ }^{65}$ et al., 2001), o que incentivou ao uso do monitor Halimeter $^{\mathrm{TM}}$ para a realização deste estudo.

AYESH, MITCHELL e SMITH ${ }^{5}$, em 1995, afirmaram que problemas de mau cheiro corporal, reais ou não, podem ser clinicamente importantes, e que tal fenômeno não é bem compreendido, e pode gerar angústia no indivíduo afetado.

O sintoma de boca seca foi a mais importante queixa relatada pela maioria dos pacientes do grupo "radio" da pesquisa. A hipossalivação ocorre comumente nos pacientes tratados com radioterapia na região de cabeça e 
pescoço, e é um efeito que acompanha boa parte da vida do paciente, afetando significamente sua qualidade de vida.

Muitos estudos avaliam a qualidade de vida de pacientes pós radioterapia (EPSTEIN ${ }^{29}$, 1999; MATIAS $^{56}$, 2005; SAWADA, DIAS, ZAGO ${ }^{75}$, 2006; MCMILLAN ${ }^{57}$, 2006) e mostram que há uma íntima relação com os efeitos adversos da radioterapia. Combatê-los e preveni-los acometeria em uma grande melhora para a qualidade de vidas desses indivíduos.

\section{2 - Metodologia}

Várias metodologias já foram estudadas para a determinação do hálito, como a utilização de osmoscópio e crioscópio, espectrometria de massa, substâncias redutoras voláteis (TONZETICH $\left.{ }^{93}, 1964\right)$, cromatografia gasosa (LARSSON $^{47}$, 1973; OHO ${ }^{65}$, 2001; SPRINGFIELD ${ }^{83}$, 2001; SUAREZ ${ }^{86}, 2000$ ), monitor portátil de sulfetos (ROSENBERG ${ }^{70}, 1991$; WALER ${ }^{97}, 1997$; WILLIS ${ }^{99}$, 1999).

ROSENBERG ${ }^{70}$ et al. (1991) afirmaram que o monitor de sulfetos pode ser uma ferramenta para a avaliação do hálito, baseado na superior reprodutibilidade e sensibilidade das mensurações de sulfetos, comparado às medidas organolépticas, sendo que o monitor tem ainda as vantagens de não exigir habilidade, não é invasivo, não oferece a possibilidade de infecção cruzada, é portátil, relativamente barato e oferece medidas rápidas.

Pesquisadores em um variado número de campos científicos têm usado a cromatografia gasosa como meio de identificação dos gases encontrados nas amostras estudadas. Igualmente, cromatografia gasosa tem sido utilizada por dentistas e em estudos sobre o mau-hálito, e tem oferecido um meio pelo qual o pesquisador pode definitivamente quantificar os níveis precisos de compostos específicos presentes no hálito de um indivíduo. Enquanto que a cromatografia gasosa é provavelmente o melhor meio para testar os compostos associados com a halitose, ela não tem sido largamente utilizada em estudos por diversas razões. Cromatógrafos gasosos são relativamente caros e precisam de treinamento especial para operá-los. O equipamento não é portátil e um tempo significante é necessário para fazer cada medição do hálito (AMADO³ 2003). 
Entretanto, a quantificação do mau-hálito é um problema que tem limitado as investigações científicas sobre suas causas e tratamentos. As medidas intrabucais com monitor de sulfetos oferecem dados quantitativos rápidos, que são reproduzíveis e sensíveis, fáceis de utilizar e relativamente baratos (KOZLOYSKY ${ }^{45}$ et al., 1994). Esses monitores de sulfetos dão os valores de CSVs em ppb, mas não são capazes de diferenciar os tipos de gases de voláteis.

O Oral Chroma ${ }^{\text {TM }}$ um novo equipamento para mensurar o hálito, que avalia separadamente os gases CSVs, dando valores numéricos ou em gráficos do sulfidritos, metilmercaptana, dimeteilsulfeto em unidade de ppb ou em ng/10ml (nanogramas por 10ml). (ODOMED, 2007). Esse aparelho trás um grande avanço na pesquisa e na área clínica da halitose, pois a identificação dos diferentes gases implica em diferenciar as causas e direcionar o tratamento adequado. Este aparelho foi disponibilizado no mercado brasileiro a partir de 2007.

A tentativa de determinar as possíveis causas da halitose também vem de longa data, com o estudo da influência da doença periodontal, das condições gerais de saúde bucal, da escovação dos dentes e de presença de saburra lingual. Os pacientes do grupo "radio" e do grupo "N.O." tinham a saúde oral deficiente, com presença de placa, cárie e/ou alteração periodontal, visível em exame clínico. Os do grupo saúde, por terem sido atendidos imediatamente após alta de atendimento multidisciplinar da Faculdade de odontologia, apresentavam a saúde oral íntegra.

A anamnese detalhada com a história médica dos pacientes examinados para a halitose é de fundamental importância (BOSY $\left.{ }^{12}, 1997\right)$. Em estudos sobre a halitose, critérios de exclusão são fundamentais para eliminar o maior número de variáveis que possam influenciar no odor bucal. No presente estudo, os pacientes apresentaram vários fatores locais orais, que segundo literatura pesquisada, influenciariam no hálito. No entanto, fatores sistêmicos influentes foram considerados como critérios de exclusão e uso de bochechos, gomas de mascar, fumo, alimentos condimentados e outros fatores modificadores de odores bucais foram eliminados por tempo suficientes que não alterariam os valores da halimetria. 
Embora o hálito desagradável possa ocorrer devido a toda variedade de desordens orgânicas, as variáveis desta pesquisa foram limitadas aos valores de fluxo salivar, teste BANA ${ }^{\mathrm{TM}}$, halimetria bucal e peso seco da saburra, não tendo o intuito de avaliar a influência do estado periodontal do paciente nos valores medidos, visto que os mesmos foram obtidos antes e após a remoção da saburra, objetivando, desta forma, relacionar tão exclusivamente esta variável aos dados obtidos. Essa metodologia foi baseada em AMADO; CHINELLATO; REZENDE ${ }^{60}$, 2005, que usaram as mesmas variáveis em pacientes com e sem fissuras labial e/ou palatal.

Todos os pacientes do grupo experimental ("radio") já tinham sido submetidos à radioterapia na região de cabeça e pescoço, não sendo possível fazer os exames previamente à radiação. Essa metodologia também foi usada por BURCHER ${ }^{15}$ et al. 1988 e DAWES; ODLUM ${ }^{21}$, 2004, em que compararam os pacientes submetidos à radioterapia com um grupo controle de pacientes saudáveis. Entretanto, os autores PONTES; POLIZELLO, SPADARO ${ }^{22}, 2004$; GUEBUR $^{38}$ et al. 2006; MÖLLER ${ }^{59}$ et al., 2004 avaliaram pacientes antes e depois da radioterapia, não fazendo necessário o uso de grupo controle. Esse tipo de modelo de metodologia requer maior tempo de acompanhamento dos pacientes, maior número atendimentos e uma equipe multidisciplinar, o que torna a avaliação mais complexa e fidedigna.

No grupo "radio", os pacientes sofreram a radioterapia imediatamente após diagnóstico de neoplasia e/ou tratamento cirúrgico. Não foi realizado atendimento odontológico prévio. Os efeitos adversos que acometeram a boca e áreas associadas foram controlados pelo radioterapeuta e oncologista, sem presença de um cirurgião-dentista na equipe multidisciplinar.

O cirurgião dentista é o profissional com maior possibilidade de avaliar e tratar essas complicações, assim como aplicar medidas preventivas de acompanhamento da saúde bucal do paciente radiado na área da cabeça e do pescoço. (ALMEIDA ${ }^{2}$ et al., 2004).

Pesquisas mostram que as complicações orais de pacientes irradiados na região cabeça e pescoço são as que têm maior influência negativa na qualidade de vida a longo prazo desses pacientes. 


\section{3 - Discussão dos resultados}

Neste estudo, avaliou-se exclusivamente a relação dos CSV com a halitose, o que representa uma limitação da metodologia, já que em alguns casos o mau-hálito é composto por diferentes compostos orgânicos voláteis e também outros gases (GOLDBERG $\left.{ }^{33}, 1997\right)$.

\subsection{1 - Halimetria oral}

O grupo saúde (grupo 1) foi o que apresentou menor média na halimetria inicial $(65,13 \mathrm{ppb})$. Houve diferença estatisticamente significante ao comparar o grupo saúde e o grupo "N.O.", e o grupo saúde e o grupo "radio". Isso pode ser justificado, principalmente, porque o grupo saúde estava livre de alterações bucais, uma vez que as medidas de halimetria foram realizadas imediatamente após o término de acompanhamento odontológico multidiciplinar. Tais dados concordaram com os de SCULLY, $1997^{77}$, que acreditam haver relações estritas da halitose com a saúde oral.

O grupo "N.O." (2) foi o que apresentou maior valor (148,102 ppb) na halimetria inicial em comparação com grupo "radio" (3), que apresentou média de 143,746 ppb, no entanto, sem diferença estatisticamente significante. Entretanto, apesar de os pacientes irradiados na região de cabeça e pescoço apresentarem uma hipossalivação grave, que será discutido mais adiante, e de haver uma correlação entre o fluxo salivar e halitose (GUEBUR ${ }^{38}$ et al., 2006) não podemos afirmar a exata causa deste achado, visto que a situação oral não foi avaliada metodologicamente. Pode-se afirmar que ao exame físico as características desses dois grupos foram semelhantes, quanto às patologias orais.

\subsection{2 - Peso da saburra}

Em nosso estudo, a quantidade de saburra foi avaliada quantitativamente após a secagem (peso seco), o que vai ao encontro da metodologia utilizada por YAEGAKI; SANADA ${ }^{100}$ e de acordo com a de AMADO, CHINELLATO e REZENDE ${ }^{60}$ (2005).

A diferença do peso de saburra entre os grupos foi estatisticamente significante. O grupo N. O. foi o que apresentou maior quantidade de saburra e foi o que apresentou maior valor na halimetria inicial. YAEGAKI; SANADA ${ }^{100}$, 
em 1992, observaram em suas pesquisas que a remoção de saburra fazia reduzir pela metade a produção de CSVs. DE BOEVER; LOESCHE ${ }^{23}$ (1995) avaliaram a quantidade de saburra visualmente, e notaram que o escore de hálito bucal esteve altamente associado ao odor da língua, presença e extensão da saburra.

Os valores de halimetria inicial foram maiores que o da halimetria final em todos os grupos, havendo diferença estatisticamente significante em cada grupo e, também, após agrupamento de toda a amostra. A halimetria final foi realizada após a limpeza da saburra lingual com um limpador bucal. Esse resultado confirma a hipótese de que a saburra lingual é um importante causador de mau hálito e que a limpeza adequada da língua deva fazer parte da higiene oral diária (ROSENBERG, 1996 ${ }^{68}$ ). WALER ${ }^{97}$ (1997) demonstrou que a maior atividade de produção de CSVs é no dorso lingual.

O peso seco da saburra do grupo "radio" foi o menor. Esse fato chamou a atenção dos pesquisadores, pois esse grupo apresentava características de má higiene oral e, mesmo assim, a quantidade de saburra foi menor que a do grupo saúde que apresenta boa higiene oral e, inclusive, limpeza lingual. Provavelmente esse fato está ligado a diminuição do fluxo salivar do grupo "radio", que muitas vezes era próximo do zero.

SEEMANN $^{80}$ et al., em 2005 constataram, ao final do estudo, que o limpador lingual mostrou uma maior percentagem de redução dos CSVs, em comparação com a escova dental e o raspador lingual. Isso justifica a utilização do limpador lingual na metodologia dessa pesquisa, além do que o limpador de língua ser de fácil manuseio e gerar menor estímulo para os reflexos de ânsia $\left(\mathrm{CHAIM}^{17}, 2001\right)$.

A partir dos dados da pesquisa, acredita-se que a limpeza da língua com a redução da saburra lingual é uma etapa fundamental para a diminuição dos CSVs e, conseqüentemente, no controle da halitose, pois os níveis iniciais de CSVs foram significantemente maiores que os finais. No entanto, SEEMANN ${ }^{80}$ et al. (2005) questionam o efeito clínico da limpeza da língua de forma isolada, para a redução do mau-hálito. 


\subsection{3 - Fluxo salivar}

A saliva é um componente vital para a manutenção da saúde e função bucais, funcionando como protetor dos tecidos bucais, duros e moles (SREEBNY ${ }^{81}$, 1989). Tem função antimicrobiana, mantém a integridade e lubrifica a mucosa bucal, participa da limpeza e da digestão (EPSTEIN ${ }^{28}$, 1992).

A saliva oferece substrato que são oxidados nos processos de geração de odor, e sua acidez ou alcalinidade podem inibir ou favorecer, respectivamente, o desenvolvimento do mau odor (GREIN ${ }^{36}$, 2002).

Os conceitos de hipossalivação e xerostomia são muito comuns na literatura. Têm conceitos diferentes, no entanto são abordados muitas vezes com o mesmo significado. A hipossalivação é uma redução da quantidade de saliva e a xerostomia é a sensação de boca seca. O primeiro é um dado objetivo e o segundo subjetivo. Algumas vezes pode acontecer de o paciente relatar xerostomia e o fluxo salivar estar dentro dos parâmetros da normalidade.

Todos os pacientes do grupo "radio" apresentaram diminuição da quantidade de saliva, tanto na sialometria em repouso quanto na estimulada. O valor de $0,1 \mathrm{ml} / \mathrm{min}$ para o fluxo salivar em repouso foi considerado uma hipofunção glandular acentuada.

Houve uma redução na sialometria em repouso do grupo "radio" de $56,51 \%$ em relação ao grupo saúde, caracterizando uma redução bastante acentuada no fluxo salivar. GUEBUR ${ }^{38}$ et al. (2006), em seus achados encontraram uma diminuição no fluxo salivar de 53,33\% em pacientes irradiados.

A xerostomia causada pela hipofunção das glândulas salivares, em resposta à agressão da radioterapia, causa a perda de importantes funções da saliva na cavidade bucal e no próprio sistema digestivo, (GUEBUR ${ }^{38}$, 2006) levando às alterações na qualidade de vida dos pacientes que se submetem à radioterapia de cabeça e pescoço, uma vez que mudam os seus hábitos alimentares de vida.

Não foi possível observar uma relação entre o fluxo salivar e a halitose nessa pesquisa. O que se observou é que os pacientes do grupo "radio" 
tinham o fluxo salivar extremamente diminuído, mas tinham a quantidade de saburra menor que o grupo "N.O."

\subsection{4 - Teste BANA}

O teste BANA $^{\mathrm{TM}}$ constitui um método enzimático, empregado como indicador da presença de microorganismos responsáveis por doenças periodontais. Enzimas comuns a bactérias periodontopatogênicas podem ser identificadas a partir deste teste (ESTRELA, PIMENTA, ESTRELA ${ }^{31}$, 2001).

Em relação ao teste BANA, em todos os grupos, o número de testes negativos (25) foram maiores que os resultados positivos (23). Houve diferença estatisticamente significante entre os resultados positivos e negativos e a halimetria, quando se agrupava toda a amostra, no grupo saúde e no grupo N. O.

Os pacientes do grupo "radio" não tinham queixa principal de halitose, no entanto, quando era perguntado sobre o mau odor bucal, a maioria respondia que apresentavam. No entanto, os pacientes do grupo de "N.O." não procuraram a faculdade para tratamento de halitose, mas tinham queixa de mau odor bucal e apresentavam indicações de tratamento periodontal.

Os pacientes do grupo saúde não tinham queixa de halitose, nem quando questionados. Pode-se apenas afirmar que comprometimento periodontal não foi evidente nesse grupo, quando considerada a sua avaliação clínica estritamente visual.

Alguns autores não observaram relação ente os níveis de CSVs e os resultados do teste BANA $^{T M}$ lingual (WILLIS $^{99}$, 1999). Em AMADO; CHINELLATO; RESENDE ${ }^{60}, 2005$, não houve relação entre o valor do BANA ${ }^{T M}$ e os valores de halimetria.

\section{4 - Considerações Finais}

Este estudo foi realizado em pacientes que já haviam sido submetidos à radioterapia sem tratamento odontológico prévio, que, somado à falta de informação e condição social baixa, levou a um quadro precário de saúde oral. 
Essa condição oral, sem dúvida, piora a qualidade de vida desses pacientes. A adequação bucal, associada com a saliva artificial e/ou lubrificação bucal, foram um alívio imenso para esses pacientes.

Tanto os pacientes do grupo "radio" quanto os do grupo "N.O." apresentaram halitose, utilizando o Halimeter. Segundo TARZIA, 2007, (comunicação oral), halimetria acima de 100 ppb já pode ser considerada halitose. Nos entanto, não houve diferença significativa entre esses dois grupos, o que confirma que a condição de saúde oral é um importante causador da halitose.

Portanto, nas condições dessa pesquisa, foi constatado que a halitose pode ser considerada um efeito adverso da radioterapia, vinculada à hipossalivação e saúde oral deficiente. 

"A vida é uma peça de teatro que não permite ensaios... Por isso, cante, ria, dance, chore e viva intensamente cada momento de sua vida, antes que a cortina se feche e a peça termine sem aplausos..."

Charles Chaplin 



\section{7 - CONCLUSÕES}

De acordo com os resultados obtidos dentro da metodologia aplicada, pode-se concluir que:

1. Foi detectada halitose nos grupo N. O e "radio". No grupo saúde, os níveis de halitose se mantiveram dentro da normalidade.

2. Houve diferença estatisticamente significante para 0 hálito bucal entre os grupos "radio" e saúde e entre N.O. e saúde.

3. O grupo N.O. apresentou maiores valores de halimetria bucal do que o grupo "radio".

4. Houve relação entre a presença de saburra e os níveis de CSVs;

5. Houve uma diminuição estatisticamente significativa entre a halimetria inicial e a halimetria final, após a remoção da saburra nos três grupos.

6. O fluxo salivar em repouso e estimulado é extremamente menor no grupo "radio" em comparação ao grupo saúde e ao grupo N.O., com diferença estatisticamente significativa.

7. A halitose é um efeito adverso da radioterapia intimamente ligado à condições de higiene oral do paciente irradiado. 

"A diferença entre 0 vencedor e o perdedor não é a força nemo conhecimento, mas, sim, a vontade de vencer." Vincent T. Lombard 



\section{REFERÊNCIAS}

1. Aas JA, Paster BJ, Stokes LN, Olsen I, Dewhirst FE. Defining the normal bacterial flora of the oral cavity. J Clin Microbiol. 2005 Nov;43(11):5721-32.

2. Almeida FCS, Cazal C, Ferraz AR, Silva DPd. Rdioterapia em cabeça e pescoço: efeitos colaterais agudos e crônicos bucais Revista Brasileira de Patologia Oral. 2004;3(2):62 - 9.

3. Amado FM. Avaliação dos parâmetros de halitose bucal e nasal em pacientes com e sem fissura de lábio e/ou palato [dissertação de mestrado]. Bauru: Universidade de São Paulo; 2003.

4. Astor FC, Hanft KL, Ciocon JO. Xerostomia: a prevalent condition in the elderly. Ear Nose Throat J. 1999 Jul;78(7):476-9.

5. Ayesh KMS, Colquhon NK. Body malodour syndromes. . Lancet. 1995 May;345(8960):1308 - 9.

6. Baptista Neto C. Avaliação do uso da pilocarpina em pacientes submetidos à radioterapia na região de cabeça e pescoço para controle da xerostomia [Dissertação de Mestrado]. São Paulo: Universidade de São Paulo; 2003.

7. Bennett JD. An unexpected cause of halitosis. J R Army Med Corps. 1988 Oct;134(3):151-2.

8. Bogdasarian RS. Halitosis. Otolaryngol Clin North Am. 1986 Feb;19(1):111-7.

9. Bohn P. Imagined halitosis: a social phobia symptom? J Calif dent Ass. 1997 feb;25(2):161-4.

10. Bonan PR, Pires FR, Lopes MA, Di Hipolito O, Jr. Evaluation of salivary flow in patients during head and neck radiotherapy. Pesqui Odontol Bras. 2003 Apr-Jun;17(2):156-60.

11. Boraks S, Chilvarquer I, Panella J. Radiomucosite: contribuição ao estudo dos efeitos das radiações ionizantes na mucosa bucal normal de paciente 
portadores de carcinomas espinocelular submetidos à tratamento radioterápico. Rev Odontol UNICID. 2000 jul;12(2):149-61.

12. Bosy A. Oral malodor: philosophical and practical aspects. J Can Dent Assoc. 1997 Mar;63(3):196-201.

13. Bretz WA, Loesche WJ, Chen YM, Schork MA, Dominguez BL, Grossman N. Minor salivary gland secretion in the elderly. Oral Surg Oral Med Oral Pathol Oral Radiol Endod. 2000 Jun;89(6):696-701.

14. Bruins $H H$, Koole R, Jolly DE. Pretherapy dental decisions in patients with head and neck cancer. A proposed model for dental decision support. Oral Surg Oral Med Oral Pathol Oral Radiol Endod. 1998 Sep;86(3):256-67.

15. Bucher JA, Fleming TJ, Fuller LM, Keene HJ. Preliminary observations on the effect of mantle field radiotherapy on salivary flow rates in patients with Hodgkin's disease. J Dent Res. 1988 Feb;67(2):518-21.

16. Caielli C, Martha PM, Dib LL. Sequelas orais da radioterapia: atuação da odontologia na prevençao e tratamento. Rev Bras Cancerol. 1995 Out;41(4):231-41.

17. Chaim LAF. Comparação entre 0 uso de um raspador de língua "simplificado" (RLS) e uma escova dental na higiene da língua. Rev ABO Nac. 2001 ago/set;9(4):242 - 6.

18. Coelho CMP, Sousa YTCS, Daré AMZ. Implicações clinicas da xerostomia: abordagens sobre o diagnóstico e tratamento. Rev Assoc Paul Cir Dent 2002;56(4):295-8.

19. Crispim ASS, Sampaio MCC. Halitose - um desafio para o estomatologista. Rev Fac Odont Univ Fed Bahia. 1999 jan / jun;18(1):53-9.

20. Dawes C. How much saliva is enough for avoidance of xerostomia? Caries Res. 2004 May-Jun;38(3):236-40. 
21. Dawes C, Odlum O. Salivary status in patients treated for head and neck cancer. J Can Dent Assoc. 2004 Jun;70(6):397-400.

22. de Barros Pontes C, Polizello AC, Spadaro AC. Clinical and biochemical evaluation of the saliva of patients with xerostomia induced by radiotherapy. Pesqui Odontol Bras. 2004 Jan-Mar;18(1):69-74.

23. de Boever $\mathrm{EH}$, Loesche WJ. Assessing the contribution of anaerobic microflora of the tongue to oral malodor. . J Amer dent Ass. 1995 Oct;126(10):1384-93.

24. Dirix P, Nuyts S, Vander Poorten V, Delaere P, Van den Bogaert W. Efficacy of the BioXtra dry mouth care system in the treatment of radiotherapy-induced xerostomia. Support Care Cancer. 2007 Jan 18.

25. Dominic P. Halitosis: an etiologic classification, a treatment approach, and prevention. . Oral Surg Oral Med Oral Pathol 1982 Nov;54(5):521-6.

26. Durham TM, Malloy T, Hodges ED. Halitosis: knowing when 'bad breath' signals systemic disease. Geriatrics. 1993 Aug;48(8):55-9.

27. Elias MS, Ferriani MG. Historical and social aspects of halitosis. Rev Lat Am Enfermagem. 2006 Sep-Oct;14(5):821-3.

28. Epstein JB. The role of saliva in oral health and the causes and effects of xerostomia. J Canad dent Ass. 1992;58(3):217 - 21.

29. Epstein JB, Emerton S, Kolbinson DA, Le ND, Phillips N, Stevenson-Moore $P$, et al.. Quality of life and oral function following radiotherapy for head and neck cancer. Head Neck. 1999 Jan;21(1):1-11.

30. Epstein JB, Gorsky M, Guglietta A, Le N, Sonis ST. The correlation between epidermal growth factor levels in saliva and the severity of oral mucositis during oropharyngeal radiation therapy. Cancer. 2000 Dec 1;89(11):225865. 
31. Estrela C, Pimenta FC, Estrela CRA. Testes microbiológicos aplicados à pesquisa odontológica. In: Estrela C, editor. Metodologia científica: ensino e pesquisa em odontologia. São Paulo: Artes Médica; 2001. p. 211.

32. Galhardo MC. Avaliação Clínica e Instrumental dos pacientes com queixa subjetiva de halitose. [mestrado]. Ribeirão Preto: Universidade de São Paulo; 2002.

33. Goldberg S, Cardash H, Browning H, 3rd, Sahly H, Rosenberg M. Isolation of Enterobacteriaceae from the mouth and potential association with malodor. J Dent Res. 1997 Nov;76(11):1770-5.

34. Goldberg S, Kozlovsky A, Gordon D, Gelernter I, Sintov A, Rosenberg M. Cadaverine as a putative component of oral malodor. J Dent Res. 1994 Jun;73(6):1168-72.

35. Gomes FC, Küstner E, López JL, Zubeldia FF, Bejamin GM. Manejo odontológico de las complicaciones de la radioterapia y quimioterapia en al cáncer oral. Med Oral. 2003;8:178-87.

36. Grein NJ. Aspectos clínicos da halitose. In: Tommazi. AF, editor. Diagnóstico em Patologia bucal. São Paulo: Pancast; 2002. p. 34 - 8.

37. Gritz ER, Camarck CL, Coscarelli A. First year after head and neck cancer: Quality of Life,. J of Clin Oncol,. 1999;17(1):352 - 60.

38. Guebur MI, Rapoport A, Sassi LM, Cervantes O, Ramos GHA, Machado RA. Avaliação da perda de fluxo salivar total não estimulado durante a radioterapia em cabeça e pescoço. Revista Internacional de Estomatologia. 2006;3(9):56-61.

39. Hammerlid E, Bjordal K, Ahlner-Elmqvist M, Jannert M, Kaasa S, Sullivan $M$, et al.. Prospective, longitudinal quality-of-life study of patients with head and neck cancer: a feasibility study including the EORTC QLQ-C30. Otolaryngol Head Neck Surg. 1997 Jun;116(6 Pt 1):666-73. 
40. Handschel J, Sunderkotter C, Kruse-Losler B, Prott FJ, Meyer U, Piffko J, et al.. Late effects of radiotherapy on oral mucosa in humans. Eur J Oral Sci. 2001 Apr;109(2):95-102.

41. Herchenhorn D, Dias FL. Advances in radiochemotherapy in the treatment of head and neck cancer. Rev Hosp Clin Fac Med Sao Paulo. 2004 Jan;59(1):39-46.

42. INCA. Instituto Nacional do Câncer [homepage na internet]. Rio de Janeiro: Instituto Nacional do Câncer; c2007. [acesso em 2007 jan 10]. Disponível em http://www.inca.gov.br

43. Iwakura M, Yasuno Y, Shimura M, Sakamoto S. Clinical characteristics of halitosis: differences in two patient groups with primary and secondary complaints of halitosis. J Dent Res. 1994 Sep;73(9):1568-74.

44. Jen YM, Lin YC, Wang YB, Wu DM. Dramatic and prolonged decrease of whole salivary secretion in nasopharyngeal carcinoma patients treated with radiotherapy. Oral Surg Oral Med Oral Pathol Oral Radiol Endod. 2006 Mar;101(3):322-7.

45. Kozlovsky A, Gordon D, Gelernter I, Loeshe WJ, Rosenberg M. Correlation between the BANA test and oral malodor parameters. J dent Res. 1994 may;73(5):1036 - 46.

46. Langland OE, Langlais RP. Biologia das Radiações. In: Langland OE, Langlais RP, editors. Principios de Diagnóstico por Imagem em Odontologia. São Paulo: Santos Livraria Editora; 2002. p. 291- 309.

47. Larsson BT. A gas chromatographic study of the effect of ascorbic acid oxidation on the formation of volatiles in saliva samples. Scand J Dent Res. 1973;81(1):22-6.

48. Lima AAS, Figueredo MAZ, Loureiro MS, Duarte R. Radioterapia de neoplasia de cabeça e pescoço - o que o cirurgião dentista precisa saber. Revista Odonto Ciência 2001 maio;16(33):156-65. 
49. Lima AES. Avaliação sialométrica e sialoquímica de indivíduos submetidos à radioterapia na região de cabeça e pescoço [doutorado]. Porto Alegre: Pontifícia Universidade Católica do Rio Grande do Sul; 1999.

50. Liu TM, Hsieh C, Chang T, Lin J, Huang C, Wang A. Prognostic Factors Affecting the Outcome of Nasopharyngeal Carcinoma. Jpn J Clin Oncol. 2003 August;33(10):501 - 8.

51. Loesche WJ. Microbiology and Treatment of Halitosis. Curr Infect Dis Rep. 2003 Jun;5(3):220-6.

52. Lu DP. Halitosis: an etiologic classification, a treatment approach, and prevention. Oral Surg Oral Med Oral Pathol. 1982 Nov;54(5):521-6.

53. Manfro G, Dias FL, Soares Netto JR. Relação entre idade, sexo, tratamento realizado e estágio da doença com a sobrevida em pacientes terminais com carcinoma epidermóide de laringe. Revista Brasileira de Cancerologia. 2006;52(1):17-24.

54. Marcu A. Let's talk about bad breath. . N Y J Dent. 1979 Aug /Sept;49(7):231 - 3.

55. Martins de Castro RF, Dezotti MSG, Azevedo LR, Xavier CRG. Atenção odontológica aos pacientes oncológicos antes, durante e depois do tratamento antineoplásico. Rev Odontol UNICID. 2002 jan;14(1):63-74.

56. Matias KS. Qualidade de vida de pacientes com câncer bucal e da orofaringe através do questionário UW-QOL [Dissertação de mestrado]. São Paulo: Universidade de São Paulo; 2005.

57. McMillan AS, Pow EH, Kwong DL, Wong MC, Sham JS, Leung LH, et al.. Preservation of quality of life after intensity-modulated radiotherapy for early-stage nasopharyngeal carcinoma: results of a prospective longitudinal study. Head Neck. 2006 Aug;28(8):712-22.

58. Minicucci EM, Dib LL, Curi MM, Shinohara EH, Sêneda LM. Seqüelas Odontológicsas do Tratamento Radio e Quimioterápico em Crianças - 
Relato de três casos clínicos. Rev Paulista de Pediatria. 1994 julho;12(2):258-63.

59. Möller P, Perrier M, Ozsahin M, Monnier P. A prospective study of salivary gland function in patients undergoing radiotherapy for squamous cell carcinoma of the oropharynx. Oral Surg Oral Med Oral Pathol Oral Radiol Endod. 2004 Feb;97(2):173-89.

60. Monteiro-Amado F, Chinellato LE, de Rezende ML. Evaluation of oral and nasal halitosis parameters in patients with repaired cleft lip and/or palate. Oral Surg Oral Med Oral Pathol Oral Radiol Endod. 2005 Dec;100(6):6827.

61. Morita M, Musinski DL, Wang HL. Assessment of newly developed tongue sulfide probe for detecting oral malodor. J Clin Periodontol. 2001 May;28(5):494-6.

62. Morita M, Wang HL. Association between oral malodor and adult periodontitis: a review. J Clin Periodontol. 2001 Sep;28(9):813-9.

63. Morita M, Wang HL. Relationship between sulcular sulfide level and oral malodor in subjects with periodontal disease. J Periodontol. 2001 Jan;72(1):79-84

64. Odomed.. Odomed [homepage na internet]. São Paulo: Odomed 2007 [acesso em 2007 fev 10]. Disponível em http://www.odomed.com.br/:

65. Oho T, Yoshida Y, Shimazaki Y, Yamashita Y, Koga T. Characteristics of patients complaining of halitosis and the usefulness of gas chromatography for diagnosing halitosis. Oral Surg Oral Med Oral Pathol Oral Radiol Endod. 2001 May;91(5):531-4.

66. Parsons JT, Mendenhall WM, Stringer SP, Cassisi NJ, Million RR. An analysis of factors influencing the outcome of postoperative irradiation for squamous cell carcinoma of the oral cavity. Int J Radiat Oncol Biol Phys. 1997 Aug 1;39(1):137-48. 
67. Ratcliff PA, Johnson PW. The relationship between oral malodor, gingivitis, and periodontitis. A review. J Periodont. 1999 May;70(5):485 -9.

68. Rosenberg M. Clinical assessment of bad breath: current concepts. J Am Dent Assoc. 1996 Apr;127(4):475-82.

69. Rosenberg M, Kozlovsky A, Wind Y, Mindel E. Self-assessment of oral malodor 1 year following initial consultation. Quintessence Int. 1999 May;30(5):324-7.

70. Rosenberg M, Kulkarni GV, Bosy A, McCulloch CA. Reproducibility and sensitivity of oral malodor measurements with a portable sulphide monitor. J Dent Res. 1991 Nov;70(11):1436-40.

71. Rosenberg M, McCulloch CA. Measurement of oral malodor: current methods and future prospects. J Periodontol. 1992 Sep;63(9):776-82.

72. Salvador SL, Figueiredo L. Halitose. In: Oppermann RV, Sösing CK, editors. Periodontia: Ciência e clínica. São Paulo: Artes Médicas; 2001. p. 267674.

73. Samarawickrama DY. Saliva substitutes: how effective and safe are they? Oral Dis. 2002 Jul;8(4):177-9.

74. Sanz M, Roldan S, Herrera D. Fundamentals of breath malodour. J Contemp Dent Pract. 2001 Nov 15;2(4):1-17.

75. Sawada ON, Dias AM, Zago MMF. O efeito da radioterapia sobre a qualidade de vida dos pacientes com câncer de cabeça e pescoço. Revista Brasileira de Cancerologia. 2006;52(4):323-9.

76. Schimidt NF, Tarbet WJ. The effect of oral rinses on organoleptic mouth odor ratings and levels of volatile sulfur compounds. Oral Surg 1978;45:876-83 
77. Scully C, el-Maaytah M, Porter SR, Greenman J. Breath odor: etiopathogenesis, assessment and management. Eur J Oral Sci. 1997 Aug;105(4):287-93.

78. Scully C, Porter S. Orofacial disease: update for the dental clinical team: 10. Halitosis and disturbances of taste, orofacial movement or sensation. Dent Update. 1999 Dec;26(10):464-8.

79. Scully C, Rosenberg M. Halitosis. Dent Update. 2003 May;30(4):205-10.

80. Seemann R, Kison A, Bizhang M, Zimmer S. Effectiveness of mechanical tongue cleaning on oral levels of volatile sulfur compounds. J Am Dent Assoc. 2001 Sep;132(9):1263-7; quiz 318.

81. Sereebny LM. Recognition and treatment of salivary induced conditions. Int dent J. 1989 sept;39(3):197 - 204.

82. Sohn WY, Chun YH, Hong JP. A study of relationship between halitosis and salivary gland function. . J dent Res. 1999 May;78(5):1148.

83. Springfield J, Suarez FL, Majerus GJ, Lenton PA, Furne JK, Levitt MD. Spontaneous fluctuations in the concentrations of oral sulfur-containing gases. J Dent Res. 2001 May;80(5):1441-4.

84. Store G, Smith HJ, Larheim TA. Dynamic MR imaging of mandibular osteoradionecrosis. Acta Radiol. 2000 Jan;41(1):31-7.

85. Sturdart-Soares EC, Paz LS, Lopes RA, Pezzi LPG, Carreiro Filho FP. Osteorraddionecrose - Relato de caso clínico. R Fac Odontol, Porto Alegre,. $2002 \mathrm{dez} ; 43(2): 7$-10.

86. Suarez FL, Furne JK, Springfield J, Levitt MD. Morning breath odor: influence of treatments on sulfur gases. J Dent Res. 2000 Oct;79(10):1773-7.

87. Tarzia O. Halitose: Etiologia Diagnóstico e Tratamento. Biodonto. 2004 maio/junho;1(2):8 - 108. 
88. Tarzia O. Halitose: Um desafio que tem cura. Rio de Janeiro: EPUB; 2003.

89. Taylor SE, Miller EG. Preemptive pharmacologic intervention in radiationinduced salivary dysfunction. Proc Soc Exp Biol Med. 1999 May;221(1):1426.

90. Terrell JE. Quality of life assessment in head and neck cancer patients. Hematol Oncol Clin North Am. 1999 Aug;13(4):849-65.

91. Testa MA, Simonson DC. Assesment of quality-of-life outcomes. N Engl J Med. 1996 Mar 28;334(13):835-40.

92. Tonzetich J. Production and origin of oral malodor: a review of mechanisms and methods of analysis. J Periodontol. 1977 Jan;48(1):13-20.

93. Tonzetich J, Richter VJ. Evaluation of Volatile Odoriferous Components of Saliva. Arch Oral Biol. 1964 Jan-Feb;16:39-46.

94. Torres R, Vianna R. Comparative study between two different groups regarding halitosis. J dent Res. 1999 may;78(5):985.

95. Vissink A, Burlage FR, Spijkervet FK, Jansma J, Coppes RP. Prevention and treatment of the consequences of head and neck radiotherapy. Crit Rev Oral Biol Med. 2003;14(3):213-25.

96. Vissink A, Jansma J, Spijkervet FK, Burlage FR, Coppes RP. Oral sequelae of head and neck radiotherapy. Crit Rev Oral Biol Med. 2003;14(3):199212.

97. Waler SM. On the transformation of sulfur-containing amino acids and peptides to volatile sulfur compounds (VSC) in the human mouth. . Europ J Oral Sci. 1997 oct;105(5):534-7.

98. Whitmyer CC, Waskowski JC, Iffland HA. Radiotherapy and oral sequelae: preventive and management protocols. J Dent Hyg. 1997 JanFeb;71(1):23-9. 
99. Willis CL, Gibson GR, Holt J, Allison C. Negative correlation between oral malodour and numbers and activities of sulphate-reducing bacteria in the human mouth. Arch Oral Biol. 1999 Aug;44(8):665-70.

100. Yaegaki K, Sanada K. Volatile sulfur compounds in mouth air from clinically healthy subjects and patients with periodontal disease. $J$ Periodontal Res. 1992 Jul;27(4 Pt 1):233-8. 

"O futuro não pode ser previsto, mas pode ser inventado. É a nossa habilidade de inventar o futuro que nos dá esperança para fazer de nós o que somos."

Dennis Gabor 



\section{Apêndice A}

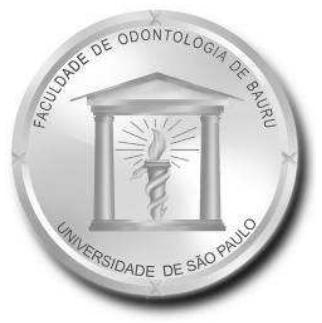

UNIVERSIDADE DE SÃO PAULO

FACULDADE DE ODONTOLOGIA DE BAURU

Al. Dr. Octávio Pinheiro Brisolla, 9-75 - Bauru-SP - CEP 17012-901 - C.P. : PABX (0XX14)235-8000 - FAX (0XX14)223-4679

\section{DEPARTAMENTO DE ESTOMATOLOGIA}

\section{CARTA DE INFORMAÇÃO AO PACIENTE}

Por este instrumento que atende às exigências do COMITÊ DE ÉTICA EM PESQUISA da Faculdade de Odontologia de Bauru (FOB) - USP, venho informar a portador(a) da cédula de identidade no sobre os procedimentos aos quais será submetido durante 0 transcorrer desta pesquisa.

A pesquisa da qual você foi solicitado(a) a participar não envolve a requisição de documentação realizada por centros especializados, não implicando assim em quaisquer gastos pessoais de sua parte. Você responderá a um questionário e será submetido a um exame bucal, que terá a finalidade de descobrir a presença de algum fator que possa provocar alteração no hálito. Na detecção de algum dos fatores causadores da halitose você será tratado ou encaminhado(a) para tal.

Sua contribuição será colaborar comparecendo ao exame odontológico solicitado pelo seu dentista e cumprindo suas recomendações, evitando assim qualquer problema que possa comprometer os resultados da pesquisa à qual você estará participando. Em caso de duvida sobre a pesquisa pode entrar em contato com a pesquisadora ou orientador pelo numero de telefone (14) 32344532 . Deve-se esclarecer que todas as fotografias, históricos de antecedentes familiares, resultados de exames clínicos e de laboratório e quaisquer outras informações concernentes ao seu atendimento poderão ser utilizados por esta Faculdade (FOB), para fins de pesquisa, ensino e divulgação em jornais e/ou revistas nacionais e internacionais. Estando ciente e tendo sido informado de todos os procedimentos a serem realizados, o senhor (paciente) autoriza a prosseguimento das etapas do tratamento, segundo o protocolo mencionado e descrito anteriormente.

Caso o sujeito da pesquisa queira apresentar reclamações em relação a sua participação na pesquisa, poderá entrar em contato com o Comitê de Ética em Pesquisa em Seres Humanos, da FOB-USP, pelo endereço da Al. Dr. Octávio Pinheiro Brisolla, 9-75 (sala no prédio da Biblioteca, FOB/USP) ou pelo telefone (14)3235-8356 


\section{Apêndice B}

\section{TERMO DE CONSENTIMENTO LIVRE E ESCLARECIDO}

Pelo presente instrumento que atende às exigências legais, o Sr. (a) portador da cédula de identidade após leitura minuciosa da CARTA DE INFORMAÇÃO AO PACIENTE, devidamente explicada pelos profissionais em seus mínimos detalhes, ciente dos serviços e procedimentos aos quais será submetido, não restando quaisquer dúvidas a respeito do lido e explicado, firma seu CONSENTIMENTO LIVRE E ESCLARECIDO concordando em participar da pesquisa proposta.

Fica claro que o paciente ou seu representante legal, pode a qualquer momento retirar seu CONSENTIMENTO LIVRE E ESCLARECIDO e deixar de participar desta pesquisa e ciente de que todas as informações prestadas tornaram-se confidenciais e guardadas por força de sigilo profissional (Art. 9 do Código de Ética Odontológica).

Por estarem de acordo assinam o presente termo.

Bauru-SP, de de

Assinatura do paciente ou responsável

Danielle Frota de Albuquerque Mestranda em Estomatologia pela FOB-USP 


\section{Apêndice C}

\section{UNIVERSIDADE DE SÃO PAULO}

FACULDADE DE ODONTOLOGIA DE BAURU

Al. Dr. Octávio Pinheiro Brisolla, 9-75 - Bauru-SP - CEP 17012-901 - C.P. :

PABX (0XX14)235-8000 - FAX (0XX14)223-4679

\section{DEPARTAMENTO DE ESTOMATOLOGIA}

\section{Protocolo de coleta de dados e avaliacãa dos parâmetros de halitose}

FICHA:

Nome:

Data e local do nascimento:

Profissão:

idade: sexo: cor:

Endereço: Estado civil:

Cidade: Estado: Bairro: Telefone:

\section{EXAME GERAL}

Fez radioterapia?

Fez cirurgia? Data

Qual foi a extensão da cirurgia?

Qual foi o tumor inicial?

Local:

Sobre a radioterapia:

Região:

Dose: Tempo:

Durante o tratamento radioterápico teve alguma intercorrência significante?

Histórico familiar?

\section{HÁBITOS \\ Fumo/Bebidas/Drogas}

Fuma? Quantidade:

Bebe: Quantidade: Tipo:

Uso de drogas?

Alguma alteração sistêmica?

Faz uso de medicamentos? Qual?

\section{OTORRINOLARINGOLOGIA}

Sinusite/Rinite/Amigdalite/Adenóides

SAÚDE GERAL (há algum problema?)

Digestivo/Intestinal/Hepático/Pulmonar/Renal/Diabetes/Hipertensão/Reumatismo Problema ginecológico/Alergia/Doença auto-imune.

Algum problema que não foi perguntado? 


\section{EXAME CLÍNICO}

Higiene: BOA REGULAR RUM

Escovação:_Uso de fio dental:

Há sangramento com o uso do fio dental?

Usa bochechos ou "spray"? Qual?

Cáries:

Quantas?

Impacção alimentar:

Uso de prótese:

Cálculo: Sangramento gengival:

Gengivite: Feridas cirúrgicas:

Comunicação buco-sinusal ou buco-nasal:

\section{AVALIAÇÃO DAS MUCOSAS \\ (Cor, textura, alterações)}

Lábios:

Sup.:

Inf.:

Mucosa julgal:

Papila do ducto da parótida

Região retromolar

Língua:

Dorso:

Ventre:

Lateral:

Assoalho da boca:

Palato

\section{Duro}

Mole

Região amigdaliana

Rebordo alveolares:

Gengivas:

Uso de aparelho ortodôntico:

Uso de prótese:

Respirador Bucal:

$\begin{array}{ll}\text { SIM } & \text { NÃO } \\ \text { SIM } & \text { NÃO } \\ \text { SIM } & \text { NÃO }\end{array}$

Observações: 


\section{UNIVERSIDADE DE SÃO PAULO}

FACULDADE DE ODONTOLOGIA DE BAURU

Al. Dr. Octávio Pinheiro Brisolla, 9-75 - Bauru-SP - CEP 17012-901 - C.P. :

PABX (0XX14)235-8000 - FAX (0XX14)223-4679

\section{DEPARTAMENTO DE ESTOMATOLOGIA}

FICHA:

\section{XEROSTOMIA}

Boca seca: SIM

Olhos secos: SIM

NÃO Ardência na boca: SIM

NÃO

Listar medicamentos

NÃO Uso de algum medicamento: SIM NÃO

Ingestão de água:

AUTO-PERCEPÇÃO DO HÁLITO

HOJE

$\begin{array}{lllllllllll}0 & 1 & 2 & 3 & 4 & 5 & 6 & 7 & 8 & 9 & 10\end{array}$

EM UM DIA COMUM

$\begin{array}{lllllllllll}\mathbf{0} & 1 & 2 & 3 & 4 & 5 & 6 & 7 & 8 & 9 & 10\end{array}$




\title{
UNIVERSIDADE DE SÃO PAULO
}

FACULDADE DE ODONTOLOGIA DE BAURU

Al. Dr. Octávio Pinheiro Brisolla, 9-75 - Bauru-SP - CEP 17012-901 - C.P. $~$

PABX (0XX14)235-8000 - FAX (0XX14)223-4679

\section{DEPARTAMENTO DE ESTOMATOLOGIA}

FICHA:

\author{
EXAMES OBJETIVOS PARA O HÁLITO
}

\section{HALIMETRIA}

boca: $\frac{\text { boca }(\text { soltando o ar): }}{\text { narina direita: }}=$ narina esquerda:
RESULTADO DO TESTE DE BANA-

\section{PESO DA SABURRA}

\section{HALIMETRIA}

boca:

boca:

boca:

\section{SIALOMETRIA}

Não estimulada:

Estimulada: 


\section{Apêndice D}

\section{UNIVERSIDADE DE SÃO PAULO}

FACULDADE DE ODONTOLOGIA DE BAURU

Al. Dr. Octávio Pinheiro Brisolla, 9-75 - Bauru-SP - CEP 17012-901 - C.P. :

PABX (0XX14)235-8000 - FAX (0XX14)223-4679

\section{DEPARTAMENTO DE ESTOMATOLOGIA}

\section{INSTRUÇÕES PRÉVIAS À CONSULTA}

1. Evitar, 24 horas antes da consulta, comida muito condimentada.

2. Evitar, 3 horas antes da consulta:
a. Escovar os dentes;
b. Usar fio dental;
c. Usar enxaguatório bucal;
d. Usar pastilha, chiclete;
e. Bebidas alcoólicas;
f. Fumar.

3. No momento da consulta, não estar usando perfume, colônia, loção pós-barba. 


\section{Apêndice $E$}

Resumo do tratamento dos pacientes submetidos à radioterapia.

\begin{tabular}{c|c|c|c|c|c}
\hline Paciente & Lesão & Local & Dose total & Dose diária & Dias \\
\hline 1 & CEC & Laringe & 6480 & 180 cGy & 38 \\
\hline 2 & CEC & Língua & 5040 & 180 & 28 \\
\hline 3 & CEC & Fossa amigdalina & 6300 & 180 & 35 \\
\hline 4 & CEC & Laringe & 5040 & 180 & 28 \\
\hline 5 & C. adenoma & Parótida & 5040 & 180 & 28 \\
\hline 6 & CEC & Laringe & 5040 & 180 & 28 \\
\hline 7 & C. adenoide & Parótida & 5580 & 180 & 31 \\
\hline 8 & CEC & Laringe & 5940 & 180 & 33 \\
\hline 9 & CEC & Laringe & 5040 & 180 & 28 \\
\hline 10 & CEC & Língua & 5040 & 180 & 28 \\
\hline 11 & CEC & Laringe & 5040 & 180 & 28 \\
\hline 12 & CEC & Faringe & 6300 & 180 & 35 \\
\hline 13 & CEC & Faringe & 5940 & 180 & 35 \\
\hline 14 & CEC & Língua & 5040 & 180 & 28 \\
\hline 15 & CEC & Faringe & 5900 & 180 & 35 \\
\hline 16 & CEC & Língua & 5040 & 180 & 28 \\
\hline 17 & CEC & Laringe & 6300 & 180 & 35 \\
\hline 18 & CEC & jugal & 5040 & 180 & 28 \\
\hline 19 & CEC & Prega Vocal & 6300 & 180 & 35 \\
\hline 20 & CEC & jugal & 5040 & 180 & 28 \\
\hline 21 & C. adenoide & parótida & 5940 & 180 & 33 \\
\hline 22 & CEC & soalho de boca & 5040 & 180 & 28 \\
\hline 23 & CEC & Laringe & 5040 & 180 & 28 \\
\hline 24 & CEC & Fossa amigdalina & 5040 & 180 & 28 \\
\hline 25 & CEC & Fossa amigdalina & 5040 & 180 & 28 \\
\hline & & & & & \\
\hline
\end{tabular}


Apêndice F

\begin{tabular}{|c|c|c|c|c|c|c|c|c|c|c|}
\hline \multirow{2}{*}{$\begin{array}{c}\text { Pacientes } \\
\text { (Radio) }\end{array}$} & \multicolumn{3}{|c|}{ Halimetria Inicial } & \multirow{2}{*}{$\begin{array}{c}\text { Peso } \\
\text { saburra }\end{array}$} & \multicolumn{3}{|c|}{ Halimetria Final } & \multicolumn{2}{|c|}{ Sialometria } & \multirow{2}{*}{$\begin{array}{l}\text { Teste } \\
\text { BANA }\end{array}$} \\
\hline & 10 & 20 & 30 & & 10 & 20 & 30 & não & estimulada & \\
\hline 1 & 59 & 60 & 63 & 0,02193 & 52 & 61 & 54 & 3,2 & 4,3 & negativo \\
\hline 2 & 100 & 100 & 90 & 0,00048 & 70 & 60 & 50 & 1,7 & 2,5 & negativo \\
\hline 3 & 150 & 100 & 90 & 0,00187 & 110 & 90 & 70 & 0,8 & 1,1 & positivo \\
\hline 4 & 229 & 199 & 239 & 0,00198 & 203 & 194 & 190 & 2,9 & 3,7 & positivo \\
\hline 5 & 125 & 126 & 118 & 0,03107 & 122 & 119 & 119 & 0,8 & 1,6 & positivo \\
\hline 6 & 157 & 139 & 142 & 0,01184 & 110 & 118 & 121 & 2,3 & 3,2 & negativo \\
\hline 7 & 107 & 137 & 118 & 0,00528 & 98 & 101 & 115 & 2,8 & 3,7 & negativo \\
\hline 8 & 90 & 87 & 94 & 0,00383 & 75 & 80 & 77 & 1,9 & 5,2 & negativo \\
\hline 9 & 142 & 111 & 106 & 0,0203 & 100 & 97 & 92 & 0,9 & 1,8 & negativo \\
\hline 10 & 126 & 120 & 108 & 0,04268 & 111 & 101 & 99 & 1,2 & 2,2 & negativo \\
\hline 11 & 136 & 160 & 156 & 0,02339 & 143 & 146 & 150 & 0,8 & 2,3 & negativo \\
\hline 12 & 221 & 195 & 110 & 0,05597 & 200 & 192 & 198 & 0,8 & 1,2 & positivo \\
\hline 13 & 313 & 276 & 306 & 0,033074 & 256 & 229 & 234 & 1,6 & 1,8 & positivo \\
\hline 14 & 275 & 254 & 287 & 0,05430 & 227 & 233 & 241 & 2 & 2,7 & positivo \\
\hline 15 & 282 & 246 & 254 & 0,02426 & 110 & 109 & 115 & 0,4 & 0,8 & negativo \\
\hline 16 & 112 & 106 & 108 & 0,00578 & 116 & 119 & 112 & 0,2 & 1,5 & negativo \\
\hline 17 & 211 & 165 & 189 & 0,00064 & 155 & 142 & 151 & 0,5 & 1,2 & positivo \\
\hline 18 & 72 & 64 & 99 & 0,00255 & 60 & 62 & 76 & 0 & 0,3 & positivo \\
\hline 19 & 130 & 129 & 127 & 0,00121 & 120 & 117 & 132 & 3,8 & 7,8 & positivo \\
\hline 20 & 102 & 98 & 100 & 0,00503 & 95 & 100 & 97 & 0,2 & 0,7 & negativo \\
\hline 21 & 100 & 87 & 92 & 0,02730 & 100 & 98 & 88 & 1,9 & 4 & positivo \\
\hline 22 & 88 & 92 & 96 & 0,00653 & 79 & 83 & 80 & 1,8 & 3 & positivo \\
\hline 23 & 160 & 185 & 176 & 0,00525 & 156 & 171 & 162 & 0,8 & 1,2 & negativo \\
\hline 24 & 137 & 142 & 138 & 0,00098 & 123 & 128 & 125 & 2,1 & 3,4 & negativo \\
\hline 25 & 126 & 119 & 128 & 0,00216 & 121 & 122 & 127 & 0,8 & 2,5 & negativo \\
\hline
\end{tabular}




\section{Apêndice G}

\begin{tabular}{|c|c|c|c|c|c|c|c|c|c|c|}
\hline \multirow{2}{*}{$\begin{array}{l}\text { Pacientes } \\
\text { (Saúde) }\end{array}$} & \multicolumn{3}{|c|}{ Halitose } & \multirow{2}{*}{$\begin{array}{c}\text { Peso } \\
\text { saburra }\end{array}$} & \multicolumn{3}{|c|}{ halitose } & \multicolumn{2}{|c|}{ Sialometria } & \multirow{2}{*}{$\begin{array}{l}\text { Teste } \\
\text { BANA }\end{array}$} \\
\hline & 10 & 20 & 30 & & 10 & 20 & 30 & não & estimulada & \\
\hline 1 & 44 & 48 & 50 & 0,01200 & 39 & 42 & 41 & 4 & 11 & negativo \\
\hline 2 & 60 & 70 & 66 & 0,02632 & 52 & 54 & 60 & 3,2 & 8,8 & negativo \\
\hline 3 & 58 & 58 & 66 & 0,017384 & 33 & 26 & 25 & 5 & 9 & positivo \\
\hline 4 & 44 & 47 & 43 & 0,01770 & 46 & 41 & 37 & 6,1 & 13,6 & negativo \\
\hline 5 & 40 & 42 & 41 & 0,01718 & 42 & 27 & 20 & 3,2 & 6,1 & negativo \\
\hline 6 & 100 & 90 & 70 & 0,02147 & 41 & 39 & 47 & 3,2 & 6,6 & positivo \\
\hline 7 & 99 & 111 & 121 & 0,03211 & 98 & 95 & 100 & 2,1 & 7,9 & positivo \\
\hline 8 & 135 & 100 & 99 & 0,01485 & 99 & 100 & 81 & 1,8 & 6,9 & positivo \\
\hline 9 & 58 & 30 & 28 & 0,01002 & 42 & 37 & 27 & 2,5 & 7,8 & negativo \\
\hline 10 & 45 & 48 & 43 & 0,00987 & 40 & 42 & 39 & 2,2 & 6,9 & negativo \\
\hline
\end{tabular}




\section{Apêndice $\mathrm{H}$}

\begin{tabular}{|c|c|c|c|c|c|c|c|c|c|c|}
\hline \multirow{2}{*}{$\begin{array}{c}\text { Pacientes } \\
\text { (N.O.) }\end{array}$} & \multicolumn{3}{|c|}{ Halitose } & \multirow{2}{*}{$\begin{array}{c}\text { Peso } \\
\text { saburra }\end{array}$} & \multicolumn{3}{|c|}{ halitose } & \multicolumn{2}{|c|}{ Sialometria } & \multirow{2}{*}{$\begin{array}{l}\text { Teste } \\
\text { BANA }\end{array}$} \\
\hline & 10 & 20 & 30 & & 10 & 20 & 30 & não & estimulada & \\
\hline 1 & 65 & 67 & 64 & 0,01286 & 64 & 69 & 72 & 4 & 11 & negativo \\
\hline 2 & 135 & 140 & 132 & 0,02556 & 131 & 129 & 127 & 3,2 & 10,1 & positivo \\
\hline 3 & 60 & 59 & 59 & 0,01068 & 57 & 57 & 56 & 3,8 & 9,8 & negativo \\
\hline 4 & 152 & 147 & 150 & 0,03325 & 150 & 153 & 145 & 2,9 & 9,7 & positivo \\
\hline 5 & 172 & 170 & 169 & 0,04023 & 120 & 112 & 118 & 6,7 & 9 & positivo \\
\hline 6 & 78 & 89 & 82 & 0,00958 & 87 & 77 & 75 & 5,5 & 7,3 & negativo \\
\hline 7 & 275 & 277 & 275 & 0,03132 & 269 & 270 & 275 & 7 & 10,8 & positivo \\
\hline 8 & 135 & 146 & 151 & 0,03620 & 139 & 139 & 140 & 4,1 & 10 & negativo \\
\hline 9 & 190 & 179 & 189 & 0,03001 & 161 & 173 & 172 & 3,8 & 10,2 & positivo \\
\hline 10 & 148 & 155 & 153 & 0,01972 & 145 & 140 & 144 & 4 & 7 & negativo \\
\hline 11 & 195 & 190 & 193 & 0,02058 & 185 & 190 & 188 & 3,8 & 5,2 & positivo \\
\hline 12 & 110 & 108 & 112 & 0,01952 & 100 & 98 & 101 & 4,5 & 9 & positivo \\
\hline 13 & 225 & 185 & 195 & 0,02968 & 180 & 181 & 187 & 2,2 & 9 & positivo \\
\hline
\end{tabular}

